Western Kentucky University

TopSCHOLAR®

$10-2020$

\title{
Trends in Water Quality of Cave Pools at Timpanogos Cave National Monument, July 2008-September 2018
}

\author{
Rebecca Weissinger \\ Northern Colorado Plateau Network, National Park Service \\ Andy Armstrong \\ Timpanogos Cave National Monument \\ Kirsten Bahr \\ Timpanogos Cave National Monument \\ Chris Groves \\ Mammoth Cave Area Biosphere Reserve, Department of Earth, Environmental, and Atmospheric Sciences \\ Western Kentucky University
}

Follow this and additional works at: https://digitalcommons.wku.edu/geog_chl

Part of the Environmental Monitoring Commons, Geochemistry Commons, Geology Commons, and the Natural Resources Management and Policy Commons

\section{Recommended Citation}

Weissinger, R., A. Armstrong, K. Bahr, and C. Groves. 2020. Trends in water quality of cave pools at Timpanogos Cave National Monument, July 2008-September 2018. Natural Resource Report NPS/ NCPN/NRR-2020/2181. National Park Service, Fort Collins, Colorado. https://doi.org/10.36967/ nrr-2279316.

This Report is brought to you for free and open access by TopSCHOLARß. It has been accepted for inclusion in Crawford Hydrology Laboratory by an authorized administrator of TopSCHOLARß. For more information, please contact topscholar@wku.edu. 


\section{Trends in Water Quality of Cave Pools at Timpanogos Cave National Monument, July 2008-September 2018}

Natural Resource Report NPS/NCPN/NRR—2020/2181

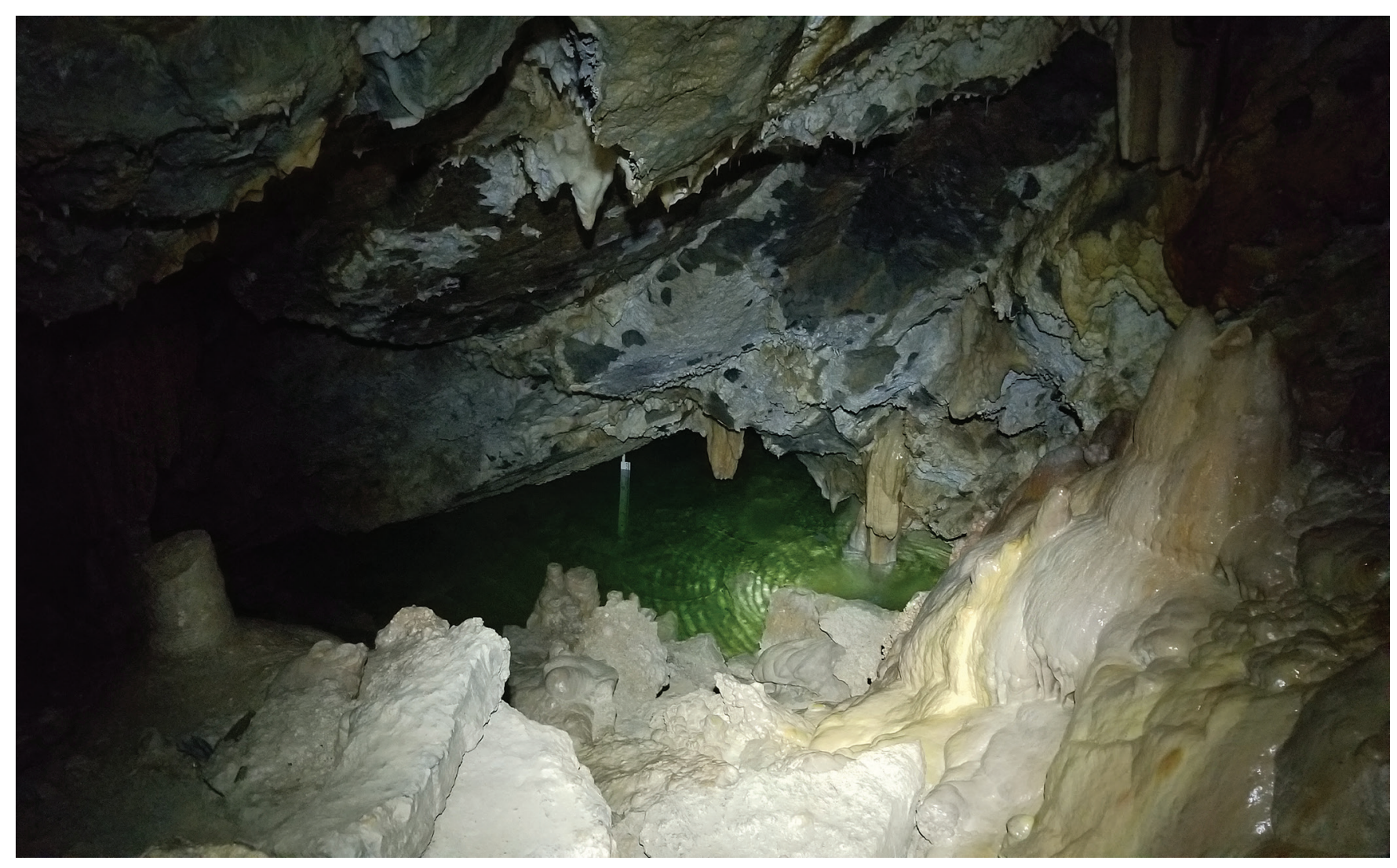


The production of this document cost $\$ 12,542$, including costs associated with data collection, processing, analysis, and subsequent authoring, editing, and publication.

\section{ON THE COVER}

Hansen Lake at Timpanogos Cave National Monument, April 2019. NPS photo. 


\section{Trends in Water Quality of Cave Pools at Timpanogos Cave National Monument, July 2008-September 2018}

Natural Resource Report NPS/NCPN/NRR—2020/2181

Prepared by

Rebecca Weissinger

Northern Colorado Plateau Network

National Park Service

P.O. Box 848

Moab, UT 84532

Andy Armstrong

Kirsten Bahr

Timpanogos Cave National Monument

2038 W. Alpine Loop Road

American Fork, UT 84003

Chris Groves

Mammoth Cave Area Biosphere Reserve

Department of Earth, Environmental, and Atmospheric Sciences

Western Kentucky University

1906 College Heights Blvd. \#31066

Bowling Green, KY 42101

Editing and Design

Alice Wondrak Biel

Northern Colorado Plateau Network

National Park Service

P.O. Box 848

Moab, UT 84532

October 2020

U.S. Department of the Interior

National Park Service

Natural Resource Stewardship and Science

Fort Collins, Colorado 
The National Park Service, Natural Resource Stewardship and Science office in Fort Collins, Colorado, publishes a range of reports that address natural resource topics. These reports are of interest and applicability to a broad audience in the National Park Service and others in natural resource management, including scientists, conservation and environmental constituencies, and the public.

The Natural Resource Report Series is used to disseminate comprehensive information and analysis about natural resources and related topics concerning lands managed by the National Park Service. The series supports the advancement of science, informed decisionmaking, and the achievement of the National Park Service mission. The series also provides a forum for presenting more lengthy results that may not be accepted by publications with page limitations.

All manuscripts in the series receive the appropriate level of peer review to ensure that the information is scientifically credible, technically accurate, appropriately written for the intended audience, and designed and published in a professional manner. This report received informal peer review by subject-matter experts who were not directly involved in the collection, analysis, or reporting of the data.

Views, statements, findings, conclusions, recommendations, and data in this report do not necessarily reflect views and policies of the National Park Service, U.S. Department of the Interior. Mention of trade names or commercial products does not constitute endorsement or recommendation for use by the U.S. Government.

This report is available from the Northern Colorado Plateau Network website, as well as at the Natural Resource Publications Management website. If you have difficulty accessing information in this publication, particularly if using assistive technology, please email irma@ nps.gov.

Please cite this publication as:

Weissinger, R., A. Armstrong, K. Bahr, and C. Groves. 2020. Trends in water quality of cave pools at Timpanogos Cave National Monument, July 2008-September 2018. Natural Resource Report NPS/NCPN/NRR-2020/2181. National Park Service, Fort Collins, Colorado. https://doi.org/10.36967/nrr-2279316.

NPS 153/173792, October 2020 


\section{Contents}

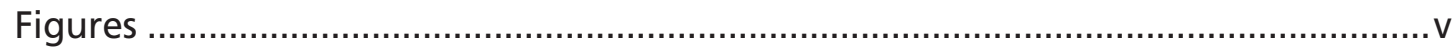

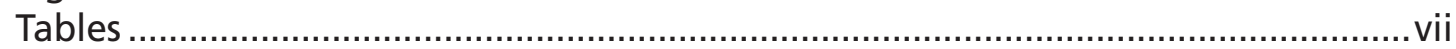

Glossary of Cave Terms .............................................................................................

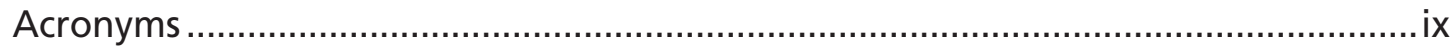

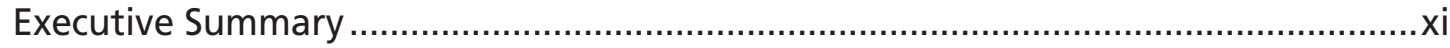

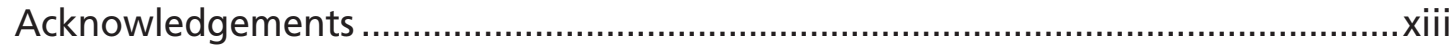

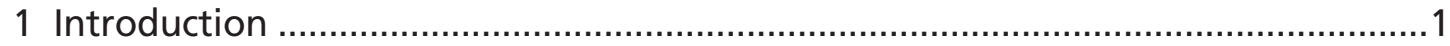

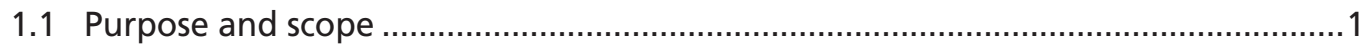

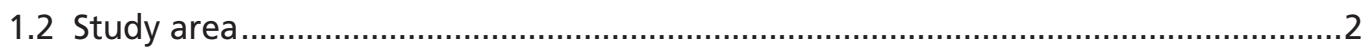

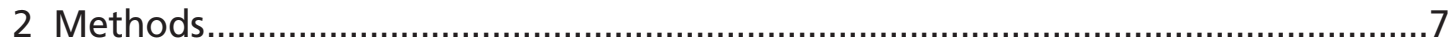

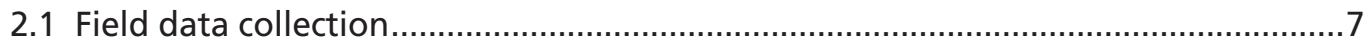

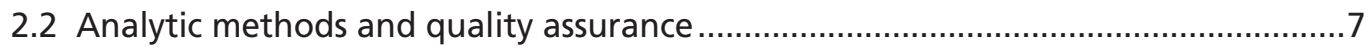

2.3 Carbonate-chemistry calculations .....................................................................

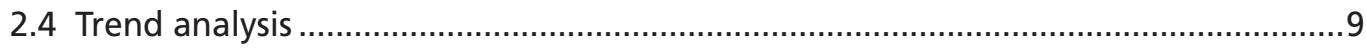

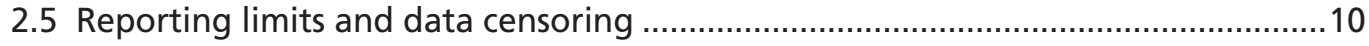

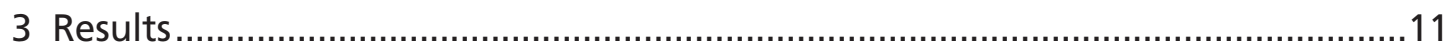

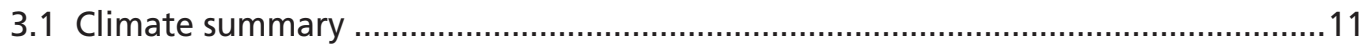

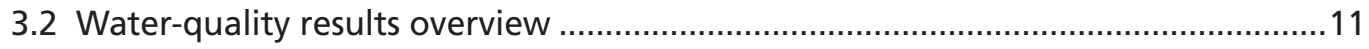

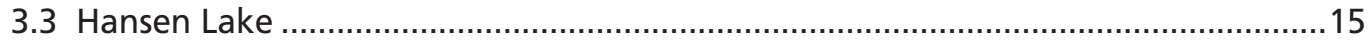

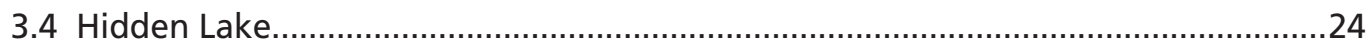

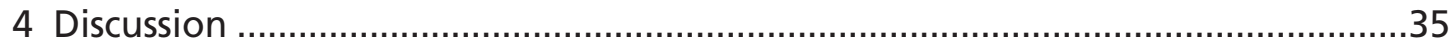

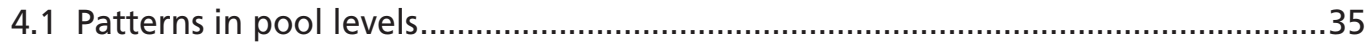

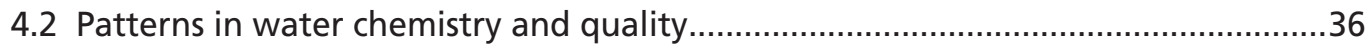

4.3 Conclusions and management recommendations.................................................. 38

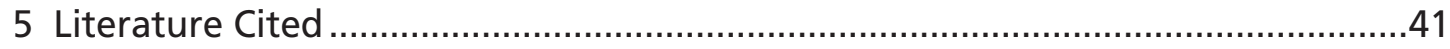

Appendix A: Analytical Methods and Reporting Limits .........................................45

Appendix B. Time Series Graphs of All Parameters ............................................... 47 



\section{Figures}

Figure 1-1. Location of Timpanogos Cave National Monument........................................................ 3

Figure 1-2. Plan view of the Timpanogos Cave system ........................................................................ 4

Figure 1-3. Speleothems ("cave decorations") at Timpanogos Cave National Monument....................... 4

Figure 3-1. Departures from 30-year climate normals for the CO-OP weather station at

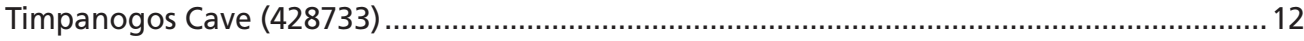

Figure 3-2. Average maximum temperature was close to the 30-year climate normal at Timpanogos Cave from 2008 to 2018, with a slight increase over time... 12

Figure 3-3. Average minimum temperature was above the 30-year climate normal from 2008 to 2018 and tended to increase over time

Figure 3-4. April 1 snow water equivalent was variable but mostly below the 30-year climate normal from 2008 to 2018, with 2008, 2009, 2011, and 2015 all higher than average ........... 13

Figure 3-5. Photos of Hansen Lake in April (above) and November (below) 2019, showing fluctuations in water levels and the locations of two staff gages............................................ 16

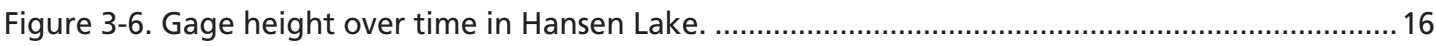

Figure 3-7. Saturation indices (SI) for calcite and dolomite at Hansen Lake over time .......................... 17

Figure 3-8. Dissolved $\mathrm{CO}_{2}\left(\mathrm{PCO}_{2}\right)$ in Hansen Lake as a multiple of the daily mean global atmospheric $\mathrm{CO}_{2}$ concentration, as recorded at the Mauna Loa observatory.......................... 17

Figure 3-9. Decrease in dissolved oxygen at Hansen Lake, with a quantile regression at the median (slope $=-0.02 \mathrm{mg} / \mathrm{L}$ per year)

Figure 3-10. Increase in specific conductance over time in Hansen Lake, with a quantile regression at the median (slope $=14 \mu \mathrm{S} / \mathrm{cm}$ per year).

Figure 3-11. Increase in water temperature over time in Hansen Lake, with a quantile regression at the median (slope $=0.05^{\circ} \mathrm{C}$ per year).

Figure 3-12. Increase in calcium over time in Hansen Lake, with a quantile regression at the median (slope $=1.9 \mathrm{mg} / \mathrm{L}$ per year).

Figure 3-13. Increase in chloride over time in Hansen Lake, with a quantile regression at the median (slope $=0.2 \mathrm{mg} / \mathrm{L}$ per year).

Figure 3-14. Increase in magnesium over time in Hansen Lake, with a quantile regression at the median (slope $=0.5 \mathrm{mg} / \mathrm{L}$ per year).

Figure 3-15. Increase in sodium over time in Hansen Lake, with a quantile regression at the median (slope $=0.07 \mathrm{mg} / \mathrm{L}$ per year)

Figure 3-16. Increase in sulfate over time in Hansen Lake, with a quantile regression at the median (slope $=6.5 \mathrm{mg} / \mathrm{L}$ per year).

Figure 3-17. Increase in total dissolved solids over time in Hansen Lake, with a quantile regression

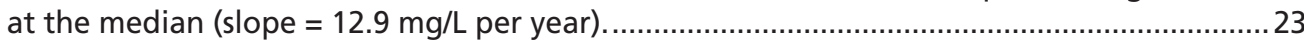

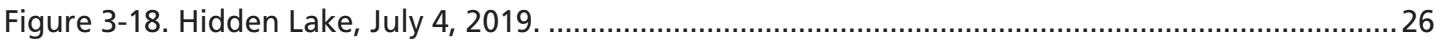

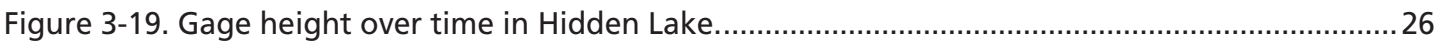

Figure 3-20. Saturation indices (SI) for calcite and dolomite at Hidden Lake over time.........................27

Figure 3-21. Dissolved $\mathrm{CO}_{2}\left(\mathrm{PCO}_{2}\right)$ in Hidden Lake as a multiple of the daily mean global atmospheric $\mathrm{CO}_{2}$ concentration, as recorded at the Mauna Loa observatory...........................28

Figure 3-22. Increase in pH over time at Hidden Lake, with a quantile regression at the median (slope $=0.03 \mathrm{pH}$ units per year)

Figure 3-23. Decrease in specific conductance over time at Hidden Lake, with a quantile regression at the median (slope $=-6.6 \mu \mathrm{S} / \mathrm{cm}$ per year).

Figure 3-24. Increase in water temperature over time at Hidden Lake, with seasonality (dashed line) and a quantile regression at the median (slope $=0.03^{\circ} \mathrm{C}$ per year). 
Figure 3-25. Decrease in alkalinity over time at Hidden Lake, with seasonality (dashed line) and a quantile regression at the median (slope $=-3.2 \mathrm{mg} / \mathrm{L} \mathrm{CaCO}_{3}$ per year).

Figure 3-26. Decrease in dissolved inorganic carbon (DIC) over time at Hidden Lake, with a quantile regression at the median (slope $=-0.00007 \mathrm{~mol} / \mathrm{L}$ per year).

Figure 3-27. Decrease in calcium over time at Hidden Lake, with seasonality (dashed line) and a quantile regression at the median (slope $=-0.9 \mathrm{mg} / \mathrm{L}$ per year).

Figure 3-28. Decrease in total dissolved solids over time at Hidden Lake, with a quantile regression at the median (slope $=-2.2 \mathrm{mg} / \mathrm{L}$ per year).

Figure 3-29. Decrease in nickel over time at Hidden Lake, with a quantile regression at the median (slope $=-0.56 \mu \mathrm{g} / \mathrm{L}$ per year).

Figure 3-30. Increase in selenium over time at Hidden Lake, with a quantile regression at the median (slope $=0.05 \mu \mathrm{g} / \mathrm{L}$ per year).

Figure 4-1. Annual mean water temperatures in two cave pools compared to the 10-year mean annual surface temperature calculated from Daymet data. 36

Figure 4-2. Dissolved $\mathrm{CO}_{2}$ (ppm) in Hansen and Hidden lakes over time. ......................................3

Figure B-1. Timeseries graphs of parameters for Hansen Lake............................................................47

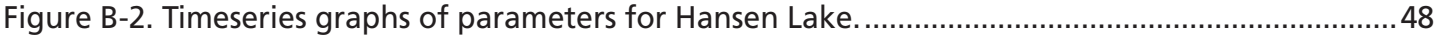

Figure B-3. Timeseries graphs of parameters for Hansen Lake.........................................................49

Figure B-4. Timeseries graphs of parameters for Hansen Lake.....................................................5

Figure B-5. Timeseries graphs of parameters for Hidden Lake. ......................................................5 51

Figure B-6. Timeseries graphs of parameters for Hidden Lake. ..................................................... 52

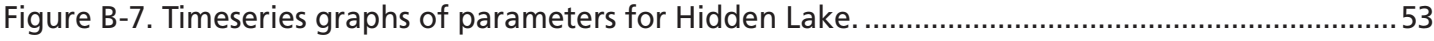

Figure B-8. Timeseries graphs of parameters for Hidden Lake. ........................................................ 54 


\section{Tables}

Table 1-1. Water-quality parameters evaluated at Timapnogos Cave National Monument, 2008-2018. 2

Table 1-2. Characteristics of Hansen and Hidden lakes, Timpanogos Cave National Monument. 6

Table 3-1. Trends in water quality in two cave pools at Timpanogos Cave National Monument, 2008-2018.

Table 3-2. Summary statistics for saturation indices $(\mathrm{SI})$ and dissolved $\mathrm{CO}_{2}\left(\mathrm{PCO}_{2}\right)$ as a multiple of atmospheric $\mathrm{CO}_{2}$ in Hansen Lake, including values at the 10th, 50th, and 90th percentiles. 18

Table 3-3. Summary statistics for core parameters in Hansen Lake, including the number of samples that were censored; concentrations at the 10th, 50th, and 90th percentiles; and trend results.

Table 3-4. Summary statistics for major ions in Hansen Lake, including the number of samples that were censored; concentrations at the 10th, 50th, and 90th percentiles; and trend results ...20

Table 3-5. Summary statistics for nutrients in Hansen Lake, including the number of samples that were censored; concentrations at the 10th, 50th, and 90th percentiles; and trend results. .23

Table 3-6. Summary statistics for trace elements in Hansen Lake, including the number of samples that were censored; concentrations at the 10th, 50th, and 90th percentiles; and trend results.

Table 3-7. Summary statistics for saturation indices $(\mathrm{SI})$ and dissolved $\mathrm{CO}_{2}\left(\mathrm{PCO}_{2}\right)$ as a multiple of atmospheric $\mathrm{CO}_{2}$ in Hidden Lake, including values at the 10th, 50th, and 90th percentiles. . 27

Table 3-8. Summary statistics for core parameters in Hidden Lake, including the number of samples that were censored; concentrations at the $10^{\text {th }}, 50^{\text {th }}$, and $90^{\text {th }}$ percentiles; and trend results.

Table 3-9. Summary statistics for major ions in Hidden Lake, including the number of samples that were censored; concentrations at the 10th, 50th, and 90th percentiles; and trend results. ...30

Table 3-10. Summary statistics for nutrients in Hidden Lake, including the number of samples that were censored; concentrations at the 10th, 50th, and 90th percentiles; and trend results. ...33

Table 3-11. Summary statistics for trace elements in Hidden Lake, including the number of samples that were censored; concentrations at the 10th, 50th, and 90th percentiles; and trend results.

Table A-1. Analytical methods and reporting limits for water-quality parameters analyzed at the Utah Public Health Laboratory for Hansen Lake.

Table A-2. Analytical methods and reporting limits for water-quality parameters analyzed at the American West Analytical Laboratory for Hidden Lake. 



\section{Glossary of Cave Terms}

aragonite-A crystallized form of calcium carbonate $\left(\mathrm{CaCO}_{3}\right)$ with orthrhombic crystals.

calcite-The most common form of crystallized calcium carbonate, with trigonal crystals.

dissolution-The process by which caves are formed as carbonic acid, formed by rain and snowmelt, combines with carbon dioxide in the air and soil and seeps downward, dissolving limestone it encounters.

dolomite - Calcium magnesium carbonate, $\mathrm{CaMg}\left(\mathrm{CO}_{3}\right)_{2}$, a rock-forming mineral.

hydraulic head-A measure of the energy associated with pressure and elevation at a point in an incompressible liquid. It can also be described as the stored energy due to the weight of the water column above an outflow point plus the energy associated with the elevation of the outflow point above a reference datum.

meteoric water-Water derived from precipitation.

speleothem-Mineral deposit formed from groundwater within underground caverns; "cave decoration."

\section{Acronyms}

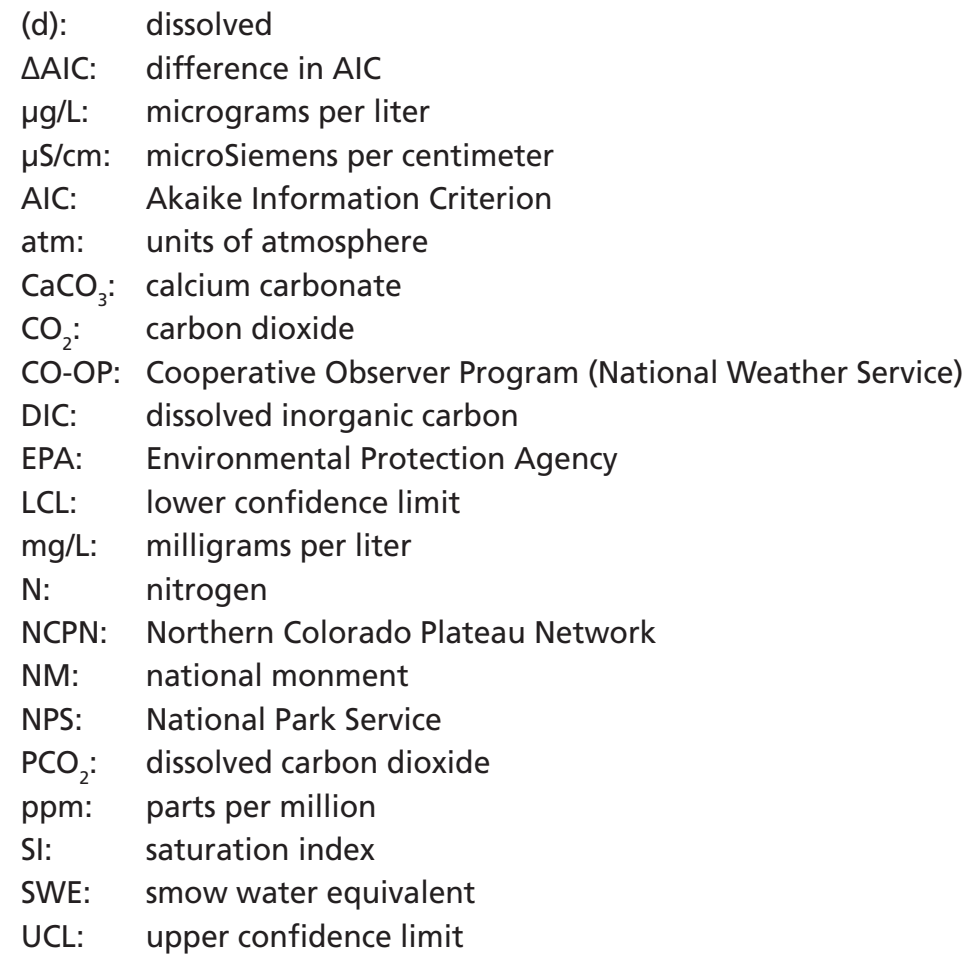





\section{Executive Summary}

This report summarizes results from water-quality samples collected in two cave pools at Timpanogos Cave National Monument (NM) from July 2008 to September 2018. Samples were collected monthly during April-November; during winter and early spring, samples could not be collected due to avalanche risk on the trail leading up to the cave. The period of record began at a time that was wetter than average in the region, and spanned both wet and dry years. Mean annual minimum temperatures were higher than the 30-year climate normal throughout the period, while mean annual maximum temperatures were near the 30 -year normal.

The two pools selected can serve as sensitive "instruments" that respond to and record various physical and chemical environmental conditions affecting the park. They represent different patterns of both recharge and visitation in two different sections of the cave system. Hansen Lake is fed by near-immediate recharge from surface flows during precipitation events and is located well off the main cave tour route, in the Hansen Cave section of the system. Hidden Lake responds to precipitation events with a lag of up to six months, and is directly adjacent to the main cave tour route, in the Timpanogos Cave section of the system. Carbonate chemistry calculations indicate that in 2018, both pools were consistently oversaturated with calcite and dolomite, leading to conditions that favored the formation of speleothems.

Water quality and pool levels were analyzed for trends over time using quantile regression at the median. Although there were many seasonal and overall changes in quality and quantity of cave water, the two pools did not change in similar ways. Pool levels fluctuated seasonally at Hansen Lake but remained stable over time, while pool levels dropped precipitously in Hidden Lake before rebounding and then dropping again. Hansen Lake had increases in most major ions, specific conductance, and total dissolved solids, while Hidden Lake had decreases in calcium, specific conductance, and total dissolved solids. The only common trend in both pools was an increase in water temperature.

In Hansen Lake, trends in water chemistry mimicked trends noted in surface-water chemistry that can be caused by air pollution, and particularly by dust deposition. Up-canyon transport of dust from the Wasatch Front urban area and beyond may have contributed to increases in sulfate, magnesium, calcium, sodium, and chloride, as has been noted regionally. Timpanogos Cave NM recently installed an air-quality monitoring station that will help managers track local contaminant flows of atmospheric $\mathrm{PM}_{2.5}$. Additional research could help managers better understand how atmospheric conditions, surface deposition, and the timing and amount of precipitation affect the chemistry of recharge into Hansen Lake.

At Hidden Lake, the timing of a reduction in dissolved $\mathrm{CO}_{2}$ in 2013 corresponded to the implementation of a new cave management plan that decreased the number of visitors on each tour from 20 to 16 and changed the starting interval for tours from 10 minutes to 15 minutes. A reduction in the total number of visitors allowed into the cave seems to have triggered a decrease in dissolved $\mathrm{CO}_{2}$, with cascading effects on water chemistry. Calcite and dolomite saturation indices increased, leading to precipitating conditions. Decreases in calcium, alkalinity, dissolved inorganic carbon, and total dissolved solids, and an increase in $\mathrm{pH}$, also followed the same timing. Due to the COVID-19 pandemic, the caves were closed to visitation in 2020. This closure will facilitate further investigation of the relationship between visitor management, carbon dioxide, and water chemistry - as an indicator of the cave's environmental conditions-in the lakes.

Another factor likely to play an important role in future cave recharge is climate changeparticularly, changes in the amount and timing of precipitation in the cave watershed. In May 2020, instrumentation at the Timpanogos Cave weather station was updated with new 
sensors and an internet connection for real-time reporting. The data are now reported as MesoWest Lone Peak-Timpanogos Cave. These improvements should help minimize future gaps in weather data to better track the influence of climate change on the cave system.

Long-term cavewater monitoring is not well-represented in the body of scientific literature on caves. The ten-year record at Timpanogos Cave NM shows the value of such monitoring by revealing unanticipated trends in water quality. These trends hint at important changes in the cave watershed and cave system, suggesting that cave-water quality is an important indicator of the health of cave resources at the park. 


\section{Acknowledgements}

H. Thomas and D. Tucker provided data management for the project. T. Philippi assisted with developing R code for statistical analysis. Joe Meiman, Dusty Perkins, and Ben Tobin improved this report with their thoughtful reviews. 



\section{Introduction}

The overall mission of the National Park Service (NPS) is to preserve, unimpaired, the natural and cultural resources of the National Park System for the enjoyment of this and future generations. Timpanogos Cave National Monument (NM) protects 101 hectares surrounding a cave system in the steep-sided American Fork Canyon, Utah. The park contains three caves: Hansen, Middle, and Timpanogos. Cave pools and active drips contribute to the unusual and abundant speleothems within the cave system (Tranel et al. 1992). Maintaining unimpaired water quality within the cave systems is a high priority for park managers as a means of protecting active cave processes (Thornberry-Ehrlich 2006).

The Timpanogos Cave system contains many seasonally active and perennial pools of dripwater. The largest of these are locally known as cave lakes. Park staff began collecting routine water-quality data in two cave lakes in July 2008, in partnership with the Northern Colorado Plateau Network (NCPN) and the Utah Division of Water Quality. Hansen Lake (in Hansen Cave) and Hidden Lake (in Timpanogos Cave) were chosen for long-term monitoring due to their perennial nature, relatively large size, location along faults that provide meteoric recharge, and perceived ability to represent overall cave hydrology cycles. The purpose of NCPN water-quality monitoring can be framed in a series of general questions that can be answered quantitatively via measurable objectives:

- What are the ranges in water-quality parameters for selected waters of NCPN parks?

- What are the current status and longterm trends in selected water-quality parameters at sites monitored in NCPN parks?

Previous evaluations of routine water-quality data from Timpanogos Cave NM have documented few exceedances of standards developed for flowing surface waters by the State of Utah (Van Grinsven et al. 2010; Hackbarth and Weissinger 2013; Hack- barth and Weissinger 2016; Hackbarth and Weissinger 2020). A screening program for contaminants of emerging concern indicated that park visitation may introduce novel contaminants, such as caffeine and the insect repellent, DEET, into cave waters (Weissinger et al. 2018). Although the park's caves are located high within the expected watershed, changes in land use and management, urban growth to the west and northwest, recent large wildfires, and climate processes also carry the potential to affect water quality within the cave systems. Analysis of waterquality trends can indicate whether conditions are changing in the cave pools, providing valuable information to park managers for use in management decisions. Long-term datasets can also document variability in the aquatic system.

\subsection{Purpose and scope}

The purpose of this report is to evaluate water-quality data collected at long-term monitoring sites in Timpanogos Cave National Monument from 2008 to 2018 for temporal trends in constituent concentrations. This period was selected to provide an assessment of data since the beginning of the monitoring program. The 10 -year period of record analyzed in this study is recognized as a relatively short period for trend analysis. It is, however, useful as a status check of the program and as a means of documenting any significant problem areas for park managers. The authors hope to learn more about trends in the chemistry and quantity of cave water in order to identify any current or future areas of concern for the protection of cave resources. In addition, this report will help managers interpret what has been learned so far from these data and highlight areas where future research is needed in order to better understand the complex hydrology of the Timpanogos Cave system.

Two cave lakes were evaluated for as many as 35 constituents each. Constituents included core parameters, such as pool water level (gage height), water temperature, dissolved oxygen, $\mathrm{pH}$, and specific conductance, as well as laboratory analyses, including major ions, nutrients, and trace elements (Table 1-1). Constituents were also used to calculate indices of calcite and dolomite 
Table 1-1. Water-quality parameters evaluated at Timapnogos Cave National Monument, 2008-2018.

\begin{tabular}{ll}
\hline Sample type & Parameters \\
\hline Core parameters & Dissolved oxygen, gage height, pH, specific conductance, turbidity, water temperature \\
Major ions & $\begin{array}{l}\text { Alkalinity, calcium, chloride, magnesium, potassium, sodium, sulfate, total dissolved solids, total } \\
\text { suspended solids }\end{array}$ \\
Nutrients & $\begin{array}{l}\text { Ammonia, nitrite plus nitrate, total dissolved nitrogen, dissolved phosphate or phosphorus, total } \\
\text { phosphate or phosphorus } \\
\text { Trace elements }\end{array}$ \\
$\begin{array}{l}\text { Aluminum, arsenic, barium, boron, cadmium, chromium, copper, iron, lead, manganese, mercury, } \\
\text { nickel, selenium, silver, zinc }\end{array}$ \\
\hline
\end{tabular}

saturation, dissolved inorganic carbon, and dissolved carbon dioxide $\left(\mathrm{CO}_{2}\right)$.

\subsection{Study area}

Timpanogos Cave National Monument is located in American Fork Canyon, which cuts through the geologically complex Wasatch Mountain Range approximately 30 kilometers south-southeast of Salt Lake City, Utah (Figure 1-1). Although small in area, the park ranges in elevation from 1,670 to 2,455 meters. Timpanogos Cave NM is located primarily on the northern slope of 3,851-meter Mount Timpanogos, and is surrounded by the Uinta-Wasatch-Cache National Forest. Along the park's southern border, a rolling plateau known as Sagebrush Flats intersects the steep-sided canyon at an elevation of 2,450 meters (White and Van Gundy 1974).

The caves are located approximately $45-120$ meters below the local surface, at an elevation of about 2,040 meters (330 meters above the bottom of American Fork Canyon). Hansen and Middle caves appear to have formed as one cave that is now separated by breakdown collapse, flowstone, and a small sump. Timpanogos Cave likely formed independently but at the same time (White and Van Gundy 1974). The three caves have been connected by artificial tunnels since the 1930s. There is a total of 1,705 meters of passage in the cave system, with a vertical relief of 55 meters (Figure 1-2).

Dissolution of the Timpanogos Cave system is believed to be the result of rising thermal waters contacting the water table at the intersection of faults and geologic bedding planes in the Mississippian-age Deseret Limestone (Herron 1997). Downcutting by the American Fork River and regional uplift of the Wasatch Mountains resulted in the caves' current elevation of about 2,040 meters. As the caves rose above the water table, water-filled passages drained. After cave-forming waters receded, meteoric water began infiltrating from the surface, dripping from cave ceilings. Precipitation of calcium carbonate and other trace minerals continues to create the speleothems that make the cave famous (Figure 1-3) (Thornberry-Ehrlich 2006). The Deseret Limestone is high in magnesium:calcium ratio and is more accurately described as a dolomite. Magnesium-rich waters in the precipitational environment appear to have contributed to the high proportion of aragonite speleothems found in the cave system, as has been noted in other caves (Palmer 2007). Yellow and green speleothems owe their coloration to trace concentrations of nickel (White and Van Gundy 1974).

Despite attempts at dye-trace studies, the hydrogeology of the cave system is still poorly understood. The watershed for the caves likely includes an area of the Uinta National Forest adjacent to and above the park (Tranel et al. 1992). Stable-isotope studies support the hypothesis that rapid recharge in cave pools occurs from talus slopes near the canyon rim, particularly in the Sagebrush Flats region (Florea et al. 2013). This presumed watershed is largely inaccessible, and the land is primarily natural with limited recreational use. Potentially longer and more complex groundwater paths are unknown.

Each cave contains one or more perched pools, the largest of which are Hansen Lake in Hansen Cave, Middle Cave Lake in 


\section{Timpanogos Cave National Monument Utah}

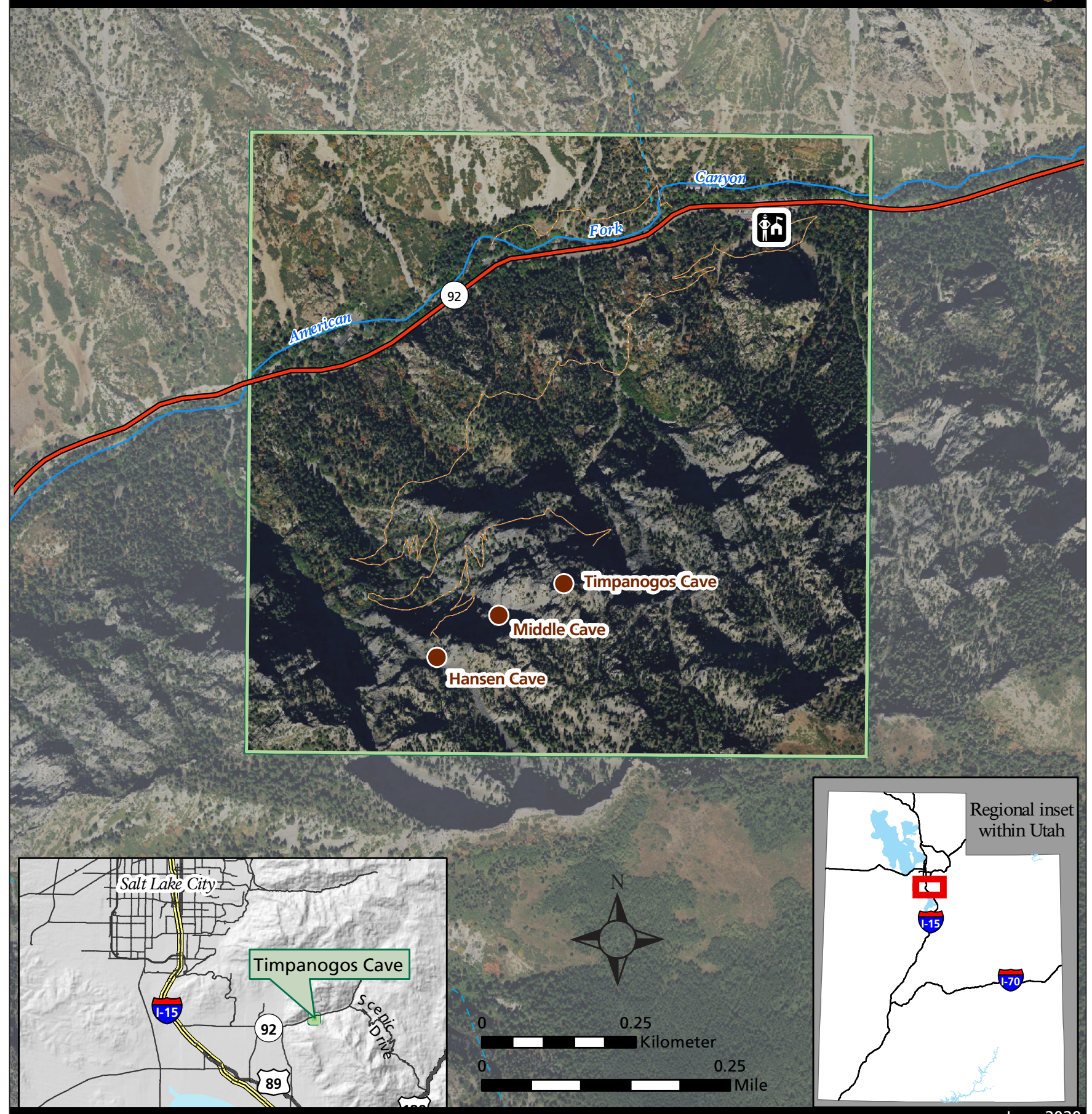

Figure 1-1. Location of Timpanogos Cave National Monument. 


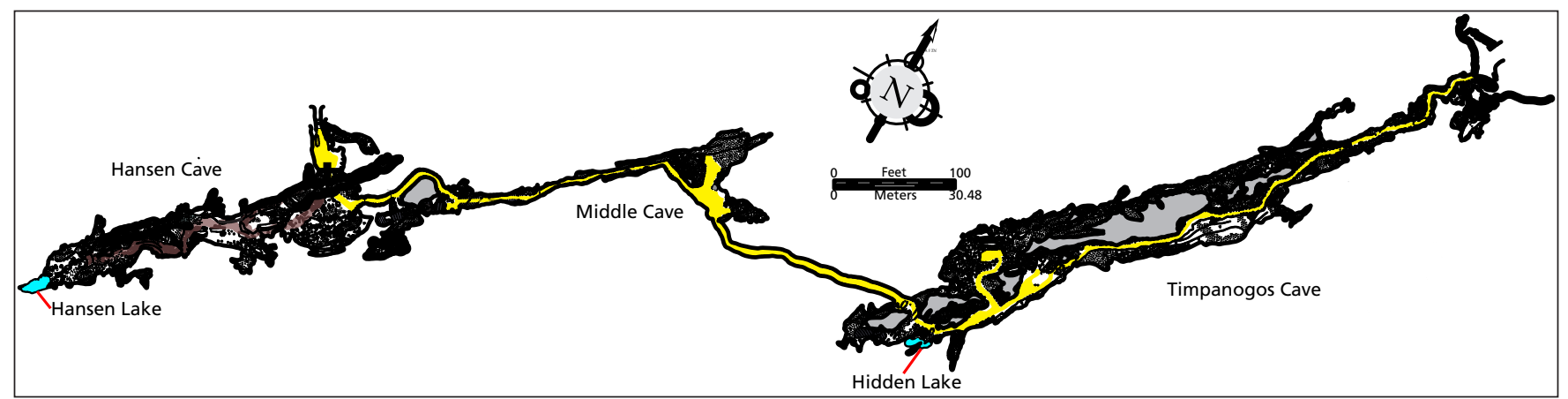

Figure 1-2. Plan view of the Timpanogos Cave system. Areas in blue are water-quality sampling locations. The tour route is shown in yellow.
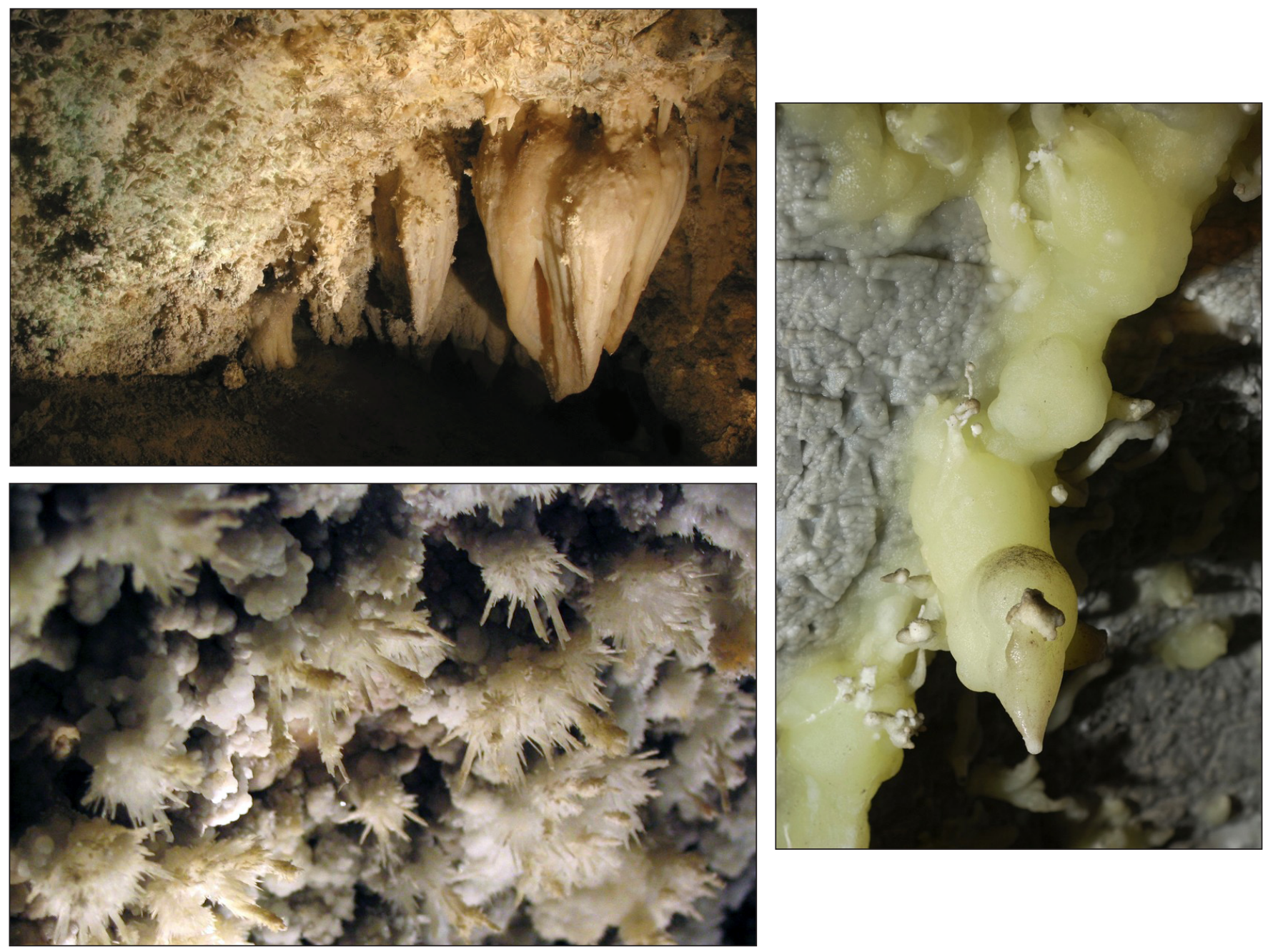

Figure 1-3. Speleothems ("cave decorations") at Timpanogos Cave National Monument. Clockwise, from top left: The Great Heart of Timpanogos, the park's largest hanging formation; calcite formation, in which nickel causes a lemon yellow color; frostwork, a form of aragonite. 
Middle Cave, and Hidden Lake in Timpanogos Cave (Herron 1997). A study by Tranel and others (1992) found that drip rates in Hansen and Middle caves responded almost immediately to local precipitation due to pipe-like conduit flow along fractures, while Timpanogos Cave had slower drip rates and delays of up to six months between surface recharge events and a change in drip rates. They concluded that Timpanogos Cave hydrogeology has a larger component of flow along thin discontinuities called bedding planes that separate adjacent rock layerswhich both slows the flow of water and increases its contact with the surrounding rock-than either Hansen or Middle caves. Hidden Lake itself showed little response to precipitation or snowmelt events (Tranel et al. 1992).

The groundwater reaching the caves is rich in bicarbonate, calcium, and magnesium ions, which come from the dissolution of limestone and dolomite. Also common are sulfate, chloride, potassium, and sodium ions, which may come from aerosols in the atmosphere or the oxidation of reduced sulfur in the bedrock surrounding the cave (Florea et al. 2013). Relatively high concentrations of sulfate and fluorine in Hidden Lake suggest that either the local bedrock is enriched with those minerals or that water reaching the pool has had longer interaction with the bedrock than in other pools (Florea et al. 2013). Total dissolved solids and $\mathrm{pH}$ vary considerably throughout the year in the caves, likely in response to surface-water recharge, suggesting that the potential for mineral precipitation also varies seasonally (Tranel et al. 1992).

In July 2008, long-term water-quality monitoring stations were established in Hansen and Hidden lakes to represent the two types of cave pools found at the park: a pool with rapid surface-water recharge and a pool minimally affected by rapid recharge. The two pools also have markedly different visitation patterns. An additional station was established on the cave tour route in Middle Cave Lake in 2015, so one pool from each cave in the system would be sampled. (Data for that site are not presented in this report due to the short period of record.)
Hansen Lake is at the end of Hansen Cave, in the easternmost part of the cave system (see Figure 1-2). Located off the main cave tour route, it is visited by only a handful of people each day during the Introduction to Caving tour, which stops at an overlook about 20 meters from the lake. As such, it remains in darkness much of the time and is considered more representative of natural cave conditions than Hidden Lake. Relatively lower $\mathrm{CO}_{2}$ measurements and evaporative speleothems at Hansen Lake suggest an unproven airflow connection to the surface.

Recharge is primarily through a ceilingfissure expression of the near-vertical Hansen Cave Fault. During snowmelt and rain events, this main water source rapidly delivers water into the lake through approximately 100 meters of overburden. Throughout the remainder of the year, water drips slowly, with very little recharge in the winter months, when most surface moisture is frozen. There is a flowstone speleothem formed at the input with rills on its surface, suggesting an oscillation between aggressive and saturated inflow. Hansen Lake has a large seasonal fluctuation in pool level, often between approximately 1.5 meters in winter and 4 meters at the peak of local snowmelt (usually in late April). The lakebed is a mixture of sediments and speleothems, both subaerial and subaqueous, owing to the gage-height fluctuations.

Hidden Lake is located directly adjacent to the main tour route in Timpanogos Cave, which can have more than 500 visitors in a day. It is located near the end of Timpanogos Cave, close to one of the cave tunnel doors (see Figure 1-2), and is subject to artificial light for most of the day during the tour season (generally May-October, depending on snowpack). The entire recharge system for Hidden Lake is not completely understood, but likely represents water that has traveled as much as 395 meters down the narrow, inclined Timpanogos Cave Fault to Timpanogos Cave. Upon reaching the cave, the water builds up hydraulic head behind a cave wall with a carbonate crust-andcoating system that only allows water to leak through where there are pores or fractures. At these locations, speleothems have formed 
that continue to feed water into Hidden Lake: both high-energy speleothems, such as stalactites and draperies, where openings are large enough to emit drops of water, and low-energy speleothems, like shields and helictites, where openings are much smaller and water must move by hydrostatic pressure and capillary action. In contrast to Hansen Lake, flow in Hidden Lake is much more metered by the confined nature of the flow paths. A seasonal rise is often noted many weeks after the peak of Hansen Lake. At Hidden Lake, some amount of recharge continues throughout the year.

Table 1-2. Characteristics of Hansen and Hidden lakes, Timpanogos Cave National Monument.

\begin{tabular}{lcc}
\hline Parameter & Hansen Lake & Hidden Lake \\
\hline Cave location & Hansen Cave & Timpanogos Cave \\
On main tour route? & No & Yes \\
Response to surface recharge & Rapid & Lag of up to six months \\
\hline
\end{tabular}




\section{Methods}

\subsection{Field data collection}

Water-quality visits occurred monthly from July 2008 to September 2018, with some exceptions. Winter and early spring samples were not regularly collected due to accessibility and safety issues on the avalancheprone trail to the caves and, starting in 2013, the sampling season was limited to AprilDecember. For the purposes of our analysis for the period of record, sufficient data were available for April-November. Our analysis is limited to samples collected during those months.

Field-data collection methods followed standards outlined in the Northern Colorado Plateau Network's water-quality monitoring protocol (Thoma et al. 2017). During each sampling event, water temperature, $\mathrm{pH}$, specific conductance, and dissolved oxygen were measured in the field using a calibrated In-Situ TROLL 9000 or 9500 multiparameter water-quality sonde.

Water samples were collected as surface grab samples. Each sample was processed into four aliquots: an unfiltered aliquot for major anions and alkalinity (unpreserved), an unfiltered and acidified (sulfuric acid) aliquot for total nutrients, a $0.45-\mu \mathrm{m}$ filtered and acidified aliquot (sulfuric acid) for dissolved nutrients, and a $0.45-\mu \mathrm{m}$ filtered and acidified aliquot (nitric acid) for major cations and trace elements. Samples were kept on ice and delivered to the Utah Public Health Laboratory or American West Analytical Laboratory within one day of collection.

\subsection{Analytic methods and quality assurance}

Water-quality samples from Hansen Lake were analyzed monthly for major ions and nutrients, and in April, July, and October for trace elements as part of a partnership with the Utah Division of Water Quality. Samples from Hansen Lake were processed at the EPA-certified Utah State Public Health Laboratory, using EPA-approved methods. Due to logistical constraints at the Utah state lab, samples from Hidden Lake were analyzed at the American West Analytical Laboratory, using EPA-approved methods, and chemistry samples were only submitted in April, July, and October. Analytical methods and reporting limits for both laboratories are detailed in Appendix A. Data were reviewed visually for anomalous results and quantitatively by identifying outliers, calculating a charge balance for the sample, and comparing results of dissolved fractions to total samples (see methods detailed in Weissinger 2016). Samples with a major ion charge balance of $<15 \%$ were included in the analysis. Anomalous results were reviewed for errors based on field datasheets, visit comments, and lab sheets. If no errors were found, the data were retained in the dataset.

\subsection{Carbonate-chemistry calculations}

We used temperature, $\mathrm{pH}$, bicarbonate $\left(\mathrm{HCO}_{3}^{-}\right)$, calcium $\left(\mathrm{Ca}^{2+}\right)$, and magnesium $\left(\mathrm{Mg}^{2+}\right)$ values to calculate several useful parameters that describe carbonate system behavior and trends, including dissolved $\mathrm{CO}_{2}$ concentrations $\left(\mathrm{PCO}_{2}\right)$, total dissolved inorganic carbon (DIC) concentrations, and saturation indices for calcite $\left(\mathrm{SI}_{\text {cal }}\right)$ and dolomite $\left(\mathrm{SI}_{\mathrm{dol}}\right)$.

Concentrations of dissolved $\mathrm{CO}_{2}$ are an important control on the behavior of water/ rock interactions in carbonate rock karst aquifers, such as that surrounding Timpanogos Cave, where limestone and dolomite are present. This is described by $\mathrm{PCO}_{2}$ values that quantify the amount of $\mathrm{CO}_{2}$ that has dissolved into the water sample of interest. A complication of the carbonate system is that once this $\mathrm{CO}_{2}$ has dissolved into water, it is converted to other forms of inorganic carbon and can no longer be called dissolved $\mathrm{CO}_{2}$. To resolve this problem, the dissolved $\mathrm{PCO}_{2}$ is defined as the $\mathrm{CO}_{2}$ concentration of a hypothetical gas atmosphere in which the water is in equilibrium, typically expressed in units of atmosphere (atm), or the proportion of that gas to the total gas present in a sample. In the unpolluted atmosphere, $\mathrm{PCO}_{2}$ values are currently about 0.000415 atm (SIO 2020), which we can also express as 415 parts per million (ppm). The $\mathrm{PCO}_{2}$ for water is calculated according to 


$$
\mathrm{PCO}_{2}=\frac{\left[\mathrm{H}^{+}\right]\left[\mathrm{HCO}_{3}^{-}\right]}{K_{H} K_{1}}
$$

(Equation 1), in which square brackets denote chemical species activities, $\left[H^{+}\right]=10^{-p H}$, $K_{H}$ is the Henry's Law constant for $\mathrm{CO}_{2}$, and $K_{1}$ is the first dissociation constant for carbonic acid (Harned and Owen 1958; Stumm and Morgan 1970). The $K$ value calculations account for temperature, and the effects of ion pairs and complexes are assumed to be negligible.

Although both air and dissolved $\mathrm{CO}_{2}$ concentrations are commonly expressed in units of ppm, one can divide these values by the current values of the atmospheric background (currently about $415 \mathrm{ppm}$ ) to obtain easily interpreted values of "multiples of atmospheric background." In this case, because the atmospheric background increased substantially over the 10 years of the study, we used data from the wellknown "Keeling Curve" of atmospheric background $\mathrm{CO}_{2}$ collected at the summit of Hawaii's Mauna Loa since 1958 (Keeling et al. 2001; SIO 2020). We divided the calculated $\mathrm{PCO}_{2}$ at Hidden and Hansen lakes by the average atmospheric $\mathrm{CO}_{2}$ concentration on the day of sampling. For the few sampling days in the Mauna Loa dataset that were missing values, we either used the following day or, if several following days were missing, the previous day. Atmospheric $\mathrm{CO}_{2}$ data for Timpanogos Cave NM are not available, and the potential for impacts from the urban areas of nearby Salt Lake City and its southern suburbs (Nehrkorn et al. 2013), as well as upwind wildfires (Mallia et al. 2015), are not known.

The relationships used to calculate equilibrium conditions, such as Equation 1, express water composition in terms of activities rather than concentrations. Their values are similar to molar concentrations but are corrected to account for charge-related interactions among the ionic species in the solution. The activity of a given species $i$ is given by $a_{i}=m_{i} \gamma_{i}$

(Equation 2), in which $a_{i}$ is activity and $m_{\mathrm{i}}$ is concentration (both in $\mathrm{mol} / \mathrm{L}$ ), and $\gamma_{i}$ is a unitless activity coefficient. Activities are often denoted using brackets, and concentrations in parentheses, and this convention is used here, as in Equation 1. For relatively dilute solutions, such as those generally found within karst flow systems, $\gamma_{\mathrm{i}}$ for individual ions can be obtained with the extended Debye-Hückel limiting law (Stumm and Morgan 1981):

$$
-\log \gamma=\frac{A z^{2} \sqrt{I}}{1+B \dot{a} \sqrt{I}}
$$

(Equation 3), in which $A$ and $B$ are temperature-dependent parameters and å is an ion size parameter $(\AA)$. The ionic strength $I$, which measures the effect of electrical interactions between the various ions in the solution, is given by

$$
I=1 / 2 \sum_{i=1}^{n}\left(m_{i} z_{i}^{2}\right)
$$

(Equation 4), in which $z_{i}$ is the charge on a given ion. In this calculation, the major ions (see Table 1-1) were considered. For computational purposes, calculations for nondetected concentrations substituted zero for the reporting limit, with negligible impact on the final calculated values.

The total dissolved inorganic carbon (DIC) is the sum of the dominant inorganic carbon species, including carbonic acid $\left(\mathrm{H}_{2} \mathrm{CO}_{3}{ }^{*}\right.$, where $\mathrm{H}_{2} \mathrm{CO}_{3}{ }^{*}$ is the sum of $\mathrm{H}_{2} \mathrm{CO}_{3}{ }^{\circ}$ and aqueous $\left.\mathrm{CO}_{2}\right)$, bicarbonate $\left(\mathrm{HCO}_{3}^{-}\right)$, and carbonate $\left(\mathrm{CO}_{3}^{-}\right)$. In this work, bicarbonate was measured directly in the lab and the others were calculated using appropriate equilibria, where

$$
\left[\mathrm{H}_{2} \mathrm{CO}_{3}^{*}\right]=\frac{\left[\mathrm{H}^{+}\right]\left[\mathrm{HCO}_{3}^{-}\right]}{K_{1}}
$$

(Equation 5) and

$$
\left[\mathrm{CO}_{3}^{2-}\right]=\frac{k_{2}\left[\mathrm{HCO}_{3}^{-}\right]}{\left[\mathrm{H}^{+}\right]}
$$

(Equation 6). DIC is then 


$$
\mathrm{DIC}=\left[\mathrm{H}_{2} \mathrm{CO}_{3}^{*}\right]+\left[\mathrm{HCO}_{3}^{-}\right]+\left[\mathrm{CO}_{3}^{2-}\right]
$$

(Equation 7).

To quantify water/rock interactions, we can consider the dissociation reactions for calcite and dolomite, where

$$
\mathrm{CaCO}_{3} \leftrightarrow \mathrm{Ca}^{2+}+\mathrm{CO}_{3}^{2-}
$$

(Equation 8), and

$$
(\mathrm{Ca}, \mathrm{Mg})\left(\mathrm{CO}_{3}\right)_{2} \leftrightarrow \mathrm{Ca}^{2+}+\mathrm{Mg}^{2+}+\left(\mathrm{CO}_{3}^{2-}\right)_{2}
$$

(Equation 9).

We then calculated associated saturation indices with respect to calcite $\left(\mathrm{SI}_{\text {cal }}\right)$ and dolomite $\left(\mathrm{SI}_{\mathrm{dol}}\right)$, describing equilibrium conditions, where

$$
S I_{c a l}=L O G_{10} \frac{\left[\mathrm{Ca}^{2+}\right]\left[\mathrm{CO}_{3}^{2-}\right]}{K_{c}}
$$

(Equation 10), and

$$
S I_{d o l}=L O G_{10} \frac{\left[\mathrm{Ca}^{2+}\right]\left[\mathrm{Mg}^{2+}\right]\left[\mathrm{CO}_{3}^{2-}\right]^{2}}{K_{d}}
$$

(Equation 11), where $K_{c}$ and $K_{d}$ are the equilibrium constants for calcite and dolomite dissociation, respectively (Busenberg and Plummer 1982; Langmuir 1971; White 1988). For each case, SI values of zero predict equilibrium. Negative values predict undersaturated solutions and mineral dissolution (the reactions in equations 8 and 9 , moving from left to right), while positive values predict oversaturation and thus mineral precipitation (the reactions in equations 8 and 9, moving right to left). In some cases, however, details of the kinetics of precipitation can inhibit mineral precipitation in the region of positive values - but not far from equilibrium (Herman and Lorah 1988; Dreybrodt et al. 1997).

\subsection{Trend analysis}

Data were summarized and evaluated to de- termine the number of samples available for each parameter and site combination (e.g., dissolved oxygen at Hansen Lake). Site and parameter combinations with fewer than 5 years or 12 observations were excluded from analysis due to the limited ability to detect trends in very short or small datasets (Schertz et al. 1991). Data summary and analysis were completed using the freeware R v.3.5.1 (R Core Team 2018).

Data were evaluated for linear trends using quantile regression at the median using the quantreg package for R (Koenker 2018). Quantile regression is a form of linear regression that estimates the conditional quantile, for example, the median or the $90^{\text {th }}$ percentile, rather than the mean of the dataset (Koenker and Bassett 1978). It is especially useful when variability in the dataset changes over time, as in many ecological datasets, and it is robust to outliers, missing data, and censored data (Cade and Noon 2003; Cade 2017). Confidence intervals were estimated by bootstrapping with 10,000 iterations (Rogers 1992). When the 95\% confidence interval - that is, the interval between the lower confidence limit (LCL) and upper confidence limit (UCL) - for the slope estimate for trend included zero, we concluded that there was no trend in the data. When the $95 \%$ confidence interval for the slope estimate did not include zero, a trend over time is very likely to exist, and we concluded there was a trend over time.

Water-quality data from surface waters are often affected by seasonality and discharge rates. Cave-pool water levels are a balance of recharge from drips and flows and loss due to leakage, evaporation, and overflow. Evaporation can change water chemistry by increasing ion concentrations; as such, pool water levels may be strongly related to water quality. Because it was unclear whether seasonality and pool level would affect water quality in cave pools at Timpanogos Cave NM, the models were compared using the following forms:

- Result centered date (time trend-only model)

- Result $\sim$ centered date + season (time trend plus seasonality model) 
- $\quad$ Result $\sim$ centered date + centered gage height (time trend plus pool level model)

- $\quad$ Result $\sim$ centered date + season + centered gage height (time trend plus seasonality plus pool-level model)

Where "centered date" is the sampling date in decimal years centered around the median sampling date, "season" is the day of the year/length of year in days and "centered gage height" is the gage height in tenths of feet centered around the median gage height for each pool in the period of record.

Models were compared using the Akaike Information Criterion (AIC) to determine whether adjusting for seasonality and/or pool level substantially improved model fit. We considered models with a difference in AIC ( $\triangle \mathrm{AIC})$ of $>4$ as improved models (Burnham and Anderson 2002). When $\triangle$ AIC was $<4$ between models, we used the simplest model for trend analysis.

\subsection{Reporting limits and data censoring}

Some water-quality parameters, especially nutrients and trace elements, typically have very low concentrations that are close to the detection limitations of common analytical methods. Water samples without detectable levels of an analyte were reported as below the reporting limit (e.g., $<10 \mathrm{mg} / \mathrm{L}$ for chloride) and referred to as "censored data" because a cut-off, rather than a true value, was known. As analytical methods or laboratory practices change, the reporting limits can also change, so it is common for multiple reporting limits to apply to a single waterquality parameter over time. For example, for chloride, the reporting limit from the Utah Public Health Laboratory decreased from $10 \mathrm{mg} / \mathrm{L}$ in 2008 to $1 \mathrm{mg} / \mathrm{L}$ in 2011.

Censored data can affect quantile regression results, particularly as the amount of censoring approaches the quantile of interest, in this case $50 \%$ of the data for estimating trends in the median values. For this study, we investigated each parameter with more than one reporting limit. For most such parameters, a majority of the dataset was censored, and the dataset was re-censored to the highest reporting limit for summary statistics but was not used for trend analysis. For chloride, dissolved phosphorus, and total phosphorus, the higher reporting limit corresponded to the beginning of the site's record, and all or most data were censored until the reporting limit was lowered. For these parameters, the earlier portion of the record was removed prior to data analysis. For datasets with $>5 \%$ censored data, data were analyzed using censored quantile regression with the random censoring method of Portnoy (2003). Site and parameter combinations with $>50 \%$ censored data are summarized in this report but were excluded from trend analysis due to the limited ability to detect trends in highly censored datasets. 


\section{Results}

\subsection{Climate summary}

\subsubsection{Climate overview and data availability}

Weather data were collected from Timpanogos Cave (428733), the National Weather Service Cooperative Observer Program (CO-OP) weather station located within the park at 1,750 meters' elevation. For that station, the Western Regional Climate Center reported average precipitation of 629 millimeters per year and average snowfall of 2,162 millimeters per year from 1946 to 2016. The average maximum temperature was $16.1^{\circ} \mathrm{C}$, and the average minimum temperature was $3.1^{\circ} \mathrm{C}$ (wrcc.dri.edu climate summary, accessed 10/2/2019). However, metadata for the site show gaps in data from 2010 to 2014. Some months did not have sufficient data to calculate average temperatures or cumulative precipitation at the monthly level from 2008 to 2018 (Figure 3-1, climateanalyzer.us, accessed 10/2/2019).

In an attempt to fill in missing climate information, we downloaded Daymet data for the latitude and longitude of the CO-OP weather station (latitude 40.444/ longitude -111.716) (Thornton et al. 2018) and compared Daymet data to observed data. Daymet data related to observed daily minimum temperatures at a nearly $1: 1$ slope, but with a consistent negative bias $\left(y=0.99 x-1.6 ; \mathrm{r}^{2}=0.94\right)$. Daily maximum temperatures were also described well with a linear model, but with a slope that showed increasing underestimates as temperatures increased $\left(y=0.82 x-0.2 ; r^{2}=0.95\right)$. Precipitation data had a poor relationship, with lower precipitation events overestimated by Daymet, and higher precipitation events underestimated $\left(\mathrm{r}^{2}=0.54\right)$. We use modelled Daymet data to represent annual minimum and maximum temperatures over time, recognizing that higher temperatures are likely underestimated in our summaries. We do not present an estimated precipitation record for 2008-2018.

\subsubsection{Climate from 2008 to 2018}

Annual average maximum temperatures were close to the 30-year climate normal as calculated from Daymet data for 2008-2018 (Figure 3-2), while annual average minimum temperatures were well above normal and increased over time (Figure 3-3). A similar increase in minimum temperatures has been noted throughout Utah (Frankson et al. 2017).

The April 1 snow water equivalent (SWE) at the nearest SNOTEL station (Timpanogos Divide, Station 820) was highly variable over time (Figure 3-4). SWE is an estimate of the total water that could instantaneously melt from a snowpack and is used to predict potential runoff and groundwater recharge. The years 2008, 2009, 2011, and 2017 were wetter than average, with 2011 having almost twice the 30-year climate-normal SWE. The remaining years were all below average, with 2013, 2015, and 2018 recording less than half the 30-year climate-normal SWE.

\subsection{Water-quality results overview}

There were many trends in quality and quantity of cave water, but the two pools often did not change in similar ways (Table 3-1). Timeseries graphs of all parameters are available in Appendix B. 


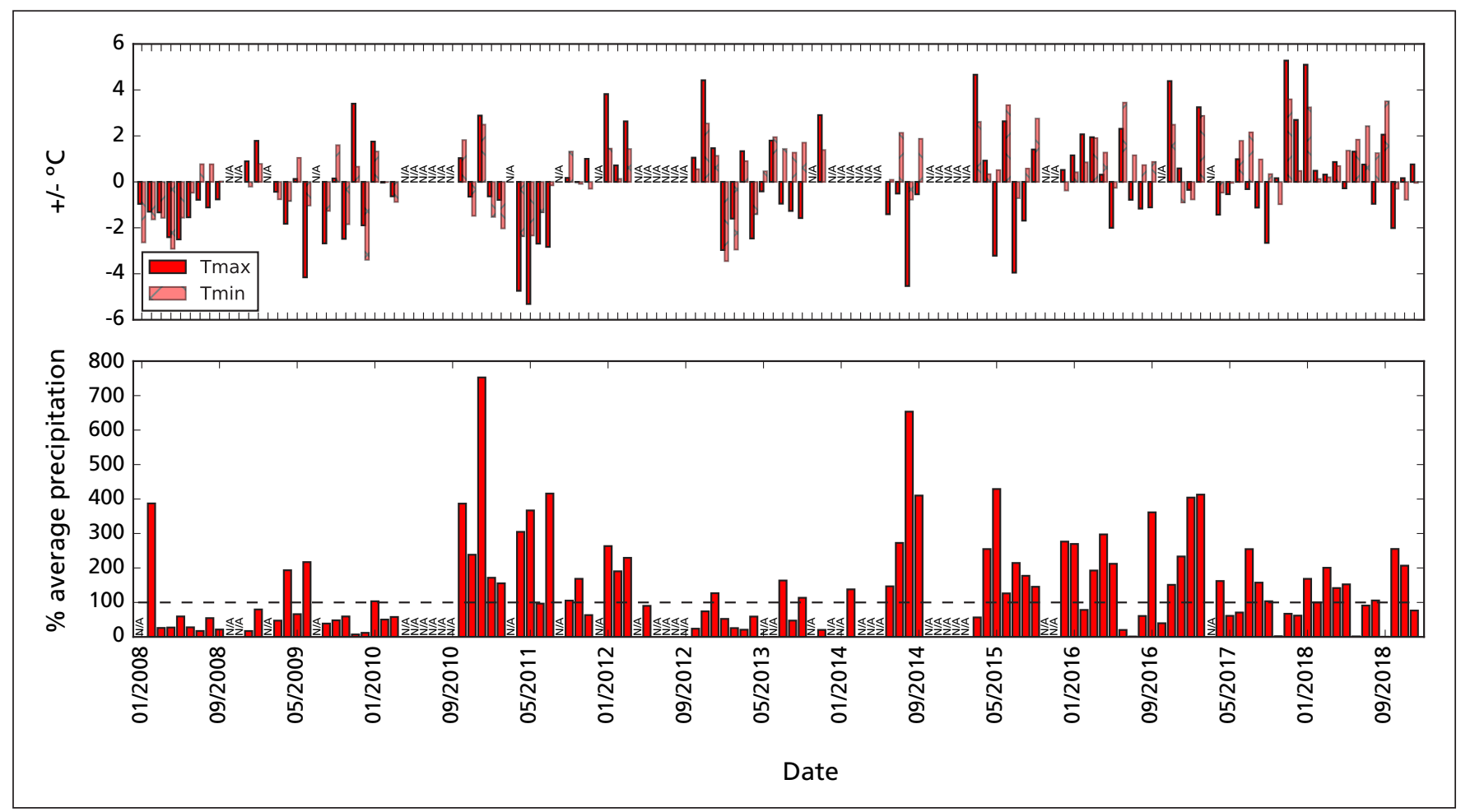

Figure 3-1. Departures from 30-year climate normals for the CO-OP weather station at Timpanogos Cave (428733). Months with insufficient data for calculations are represented with NA. Figure from Climate Analyzer (accessed 10/2/2019).

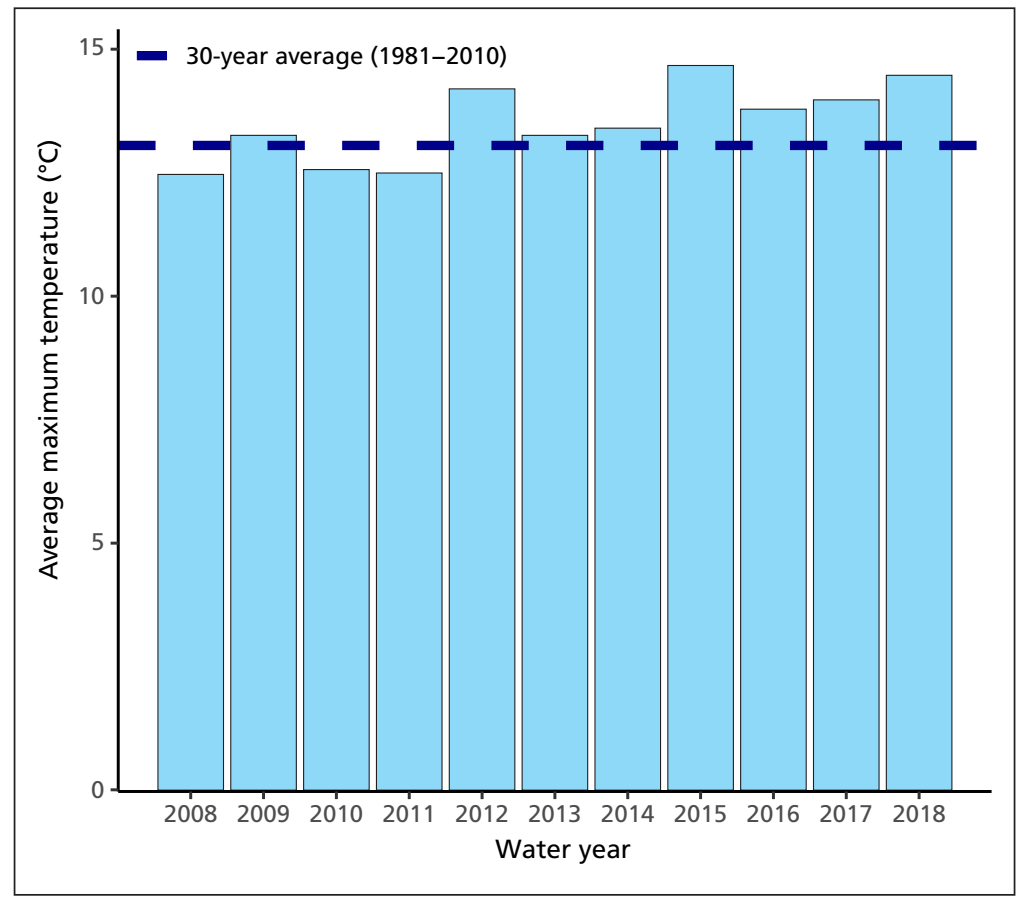

Figure 3-2. Average maximum temperature was close to the 30-year climate normal at Timpanogos Cave from 2008 to 2018, with a slight increase over time. Data are from Daymet (Thornton et al. 2018). 


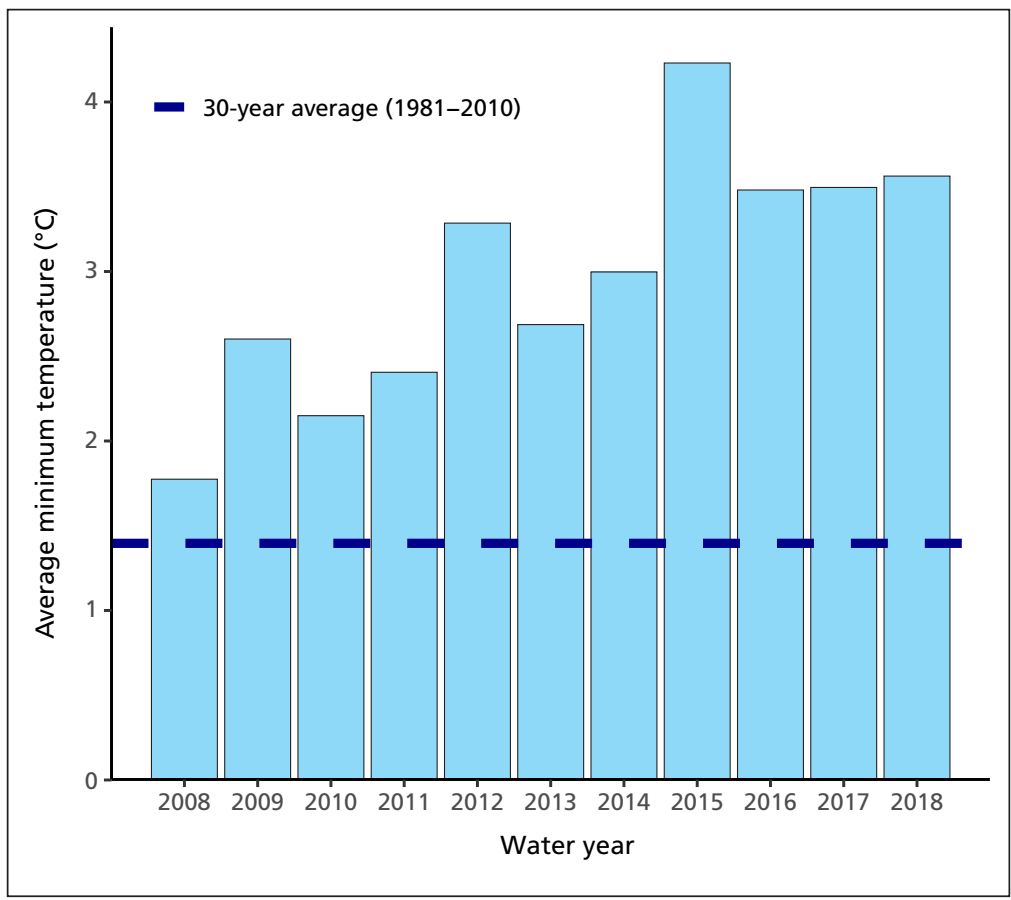

Figure 3-3. Average minimum temperature was above the 30 -year climate normal from 2008 to 2018 and tended to increase over time. Data are from Daymet (Thornton et al. 2018).

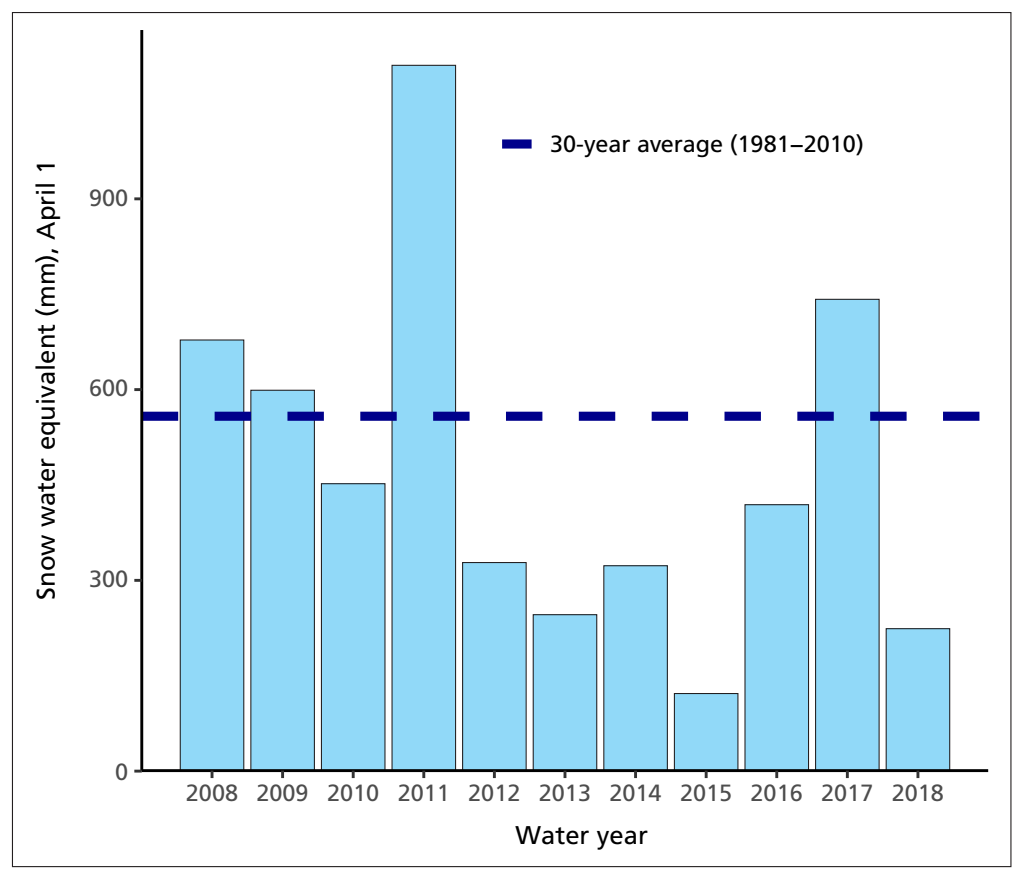

Figure 3-4. April 1 snow water equivalent was variable but mostly below the 30-year climate normal from 2008 to 2018, with 2008, 2009, 2011, and 2017 all higher than average. Data are from SNOTEL station Timpanogos Divide (820). 
Table 3-1. Trends in water quality in two cave pools at Timpanogos Cave National Monument, 2008-2018. ${ }^{\mathrm{A}}$

\begin{tabular}{|c|c|c|c|c|c|c|c|c|}
\hline \multirow[b]{2}{*}{ Parameter } & \multicolumn{4}{|c|}{ Hansen Lake } & \multicolumn{4}{|c|}{ Hidden Lake } \\
\hline & Trend & $\begin{array}{c}\text { Median } \\
\text { annual } \\
\text { change }\end{array}$ & LCL/UCL & $\begin{array}{l}\text { Total } \\
\text { percent } \\
\text { change }\end{array}$ & Trend & $\begin{array}{c}\text { Median } \\
\text { annual } \\
\text { change }\end{array}$ & LCL/UCL & $\begin{array}{l}\text { Total } \\
\text { percent } \\
\text { change }\end{array}$ \\
\hline Dissolved oxygen (mg/L) & $\downarrow$ & -0.02 & $-0.04 /-0.01$ & -2 & $\Leftrightarrow$ & NT & $-0.1 / 0.03$ & NA \\
\hline Gage height (ft) & $\Leftrightarrow$ & NT & $-0.06 / 0.26$ & NA & $\mathrm{NL}$ & NA & NA/NA & NA \\
\hline $\mathrm{pH}$ & $\Leftrightarrow$ & NT & $0 / 0.02$ & NA & - & 0.03 & $0.02 / 0.05$ & NA \\
\hline Specific conductance $(\mu \mathrm{S} / \mathrm{cm})$ & $\boldsymbol{1}$ & 14 & $11 / 19$ & 25 & $\downarrow$ & -6.6 & $-8 /-4$ & -13 \\
\hline Turbidity (NTU) & - & - & - & - & $\Leftrightarrow$ & NT & $-0.01 / 0.12$ & NA \\
\hline Water temperature $\left({ }^{\circ} \mathrm{C}\right)$ & $\boldsymbol{1}$ & 0.05 & $0.04 / 0.05$ & 7 & $\boldsymbol{1}$ & 0.03 & $0.02 / 0.04$ & 4 \\
\hline Alkalinity $\left(\mathrm{mg} / \mathrm{L} \mathrm{CaCO}_{3}\right)$ & $\Leftrightarrow$ & NT & $-0.89 / 1.85$ & NA & 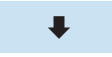 & -3.2 & $-5.3 /-1.5$ & -16 \\
\hline Dissolved inorganic carbon (mol/L) & $\Leftrightarrow$ & NT & $-5 e^{-6} / 4 e^{-5}$ & NA & $\downarrow$ & $-7 e^{-5}$ & $-11 e^{-5 /-3 e^{-5}}$ & -18 \\
\hline Calcium (d) (mg/L) & $\boldsymbol{1}$ & 1.9 & $1.5 / 2.9$ & 24 & 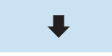 & -0.9 & $-1.4 /-0.2$ & -19 \\
\hline Chloride (mg/L) & - & 0.2 & $0.1 / 0.3$ & 34 & $\Leftrightarrow$ & NT & $-0.09 / 0.02$ & NA \\
\hline Magnesium (d) (mg/L) & $\boldsymbol{1}$ & 0.5 & $0.3 / 0.6$ & 22 & $\Leftrightarrow$ & NT & $-0.4 / 0.1$ & NA \\
\hline Potassium (d) (mg/L) & C & NA & NA/NA & NA & $\mathrm{C}$ & NA & NA/NA & NA \\
\hline Sodium (d) (mg/L) & 1 & 0.07 & $0.04 / 0.09$ & 25 & $\Leftrightarrow$ & NT & $-0.05 / 0.02$ & NA \\
\hline Sulfate (mg/L) & - & 6.5 & $5.4 / 7.5$ & 103 & $\Leftrightarrow$ & NT & $-0.2 / 0.5$ & NA \\
\hline Total dissolved solids (mg/L) & - & 12.9 & $9.9 / 16.6$ & 40 & $\downarrow$ & -2.2 & $-5.4 /-0.3$ & -8 \\
\hline Total suspended solids (mg/L) & - & - & - & - & C & NA & NA/NA & NA \\
\hline Ammonia as $\mathrm{N}$ (mg/L) & C & NA & NA/NA & NA & $\mathrm{C}$ & NA & NA/NA & NA \\
\hline Nitrite + Nitrate as N (d) (mg/L) & $\Leftrightarrow$ & NT & $-0.03 / 0.03$ & NA & $\Leftrightarrow$ & NT & $0 / 0.03$ & NA \\
\hline Nitrogen $(\mathrm{d})(\mathrm{mg} / \mathrm{L})$ & $\Leftrightarrow$ & NT & & NA & $\Leftrightarrow$ & NT & & NA \\
\hline Phosphorus as P (d) (mg/L) & $\Leftrightarrow$ & NT & $0 / 0$ & NA & $\mathrm{C}$ & NA & NA/NA & NA \\
\hline Total Phosphorus as P (mg/L) & $\Leftrightarrow$ & NT & $0 / 0$ & NA & C & NA & NA/NA & NA \\
\hline Aluminum $(d)(\mu g / L)$ & C & NA & NA/NA & NA & C & NA & NA/NA & NA \\
\hline Arsenic $(d)(\mu g / L)$ & C & NA & NA/NA & NA & C & NA & NA/NA & NA \\
\hline Barium (d) $(\mu \mathrm{g} / \mathrm{L})$ & $\mathrm{C}$ & NA & NA/NA & NA & $\Leftrightarrow$ & NT & $-0.58 / 0.14$ & NA \\
\hline Boron $(d)(\mu g / L)$ & C & NA & NA/NA & NA & $C$ & NA & NA/NA & NA \\
\hline Cadmium (d) $(\mu \mathrm{g} / \mathrm{L})$ & C & NA & NA/NA & NA & C & NA & NA/NA & NA \\
\hline Chromium (d) ( $\mu \mathrm{g} / \mathrm{L})$ & $C$ & NA & NA/NA & NA & C & NA & NA/NA & NA \\
\hline Copper (d) ( $\mu \mathrm{g} / \mathrm{L})$ & $\Leftrightarrow$ & NT & $-0.01 / 0.61$ & NA & $\Leftrightarrow$ & NT & $-0.12 / 0.17$ & NA \\
\hline Iron $(d)(\mu \mathrm{g} / \mathrm{L})$ & C & NA & NA/NA & NA & $C$ & NA & NA/NA & NA \\
\hline Lead $(d)(\mu g / L)$ & C & NA & NA/NA & NA & C & NA & NA/NA & NA \\
\hline Manganese $(d)(\mu g / L)$ & C & NA & NA/NA & NA & C & NA & NA/NA & NA \\
\hline Mercury $(d)(\mu \mathrm{g} / \mathrm{L})$ & $\mathrm{C}$ & NA & NA/NA & NA & C & NA & NA/NA & NA \\
\hline Nickel (d) ( $\mu \mathrm{g} / \mathrm{L})$ & C & NA & NA/NA & NA & 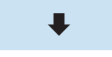 & -0.56 & $-0.78 /-0.34$ & -95 \\
\hline Selenium $(d)(\mu g / L)$ & - & - & - & - & 1 & 0.05 & $0.02 / 0.12$ & 14 \\
\hline Silver $(d)(\mu g / L)$ & C & NA & NA/NA & NA & $\mathrm{C}$ & NA & NA/NA & NA \\
\hline Zinc $(d)(\mu g / L)$ & C & NA & NA/NA & NA & $\Leftrightarrow$ & NT & $-1.7 / 0.5$ & NA \\
\hline
\end{tabular}

${ }^{\mathrm{A} C}=>50 \%$ censored data; not analyzed. $=$ increasing over time; $\boldsymbol{N}=$ decreasing over time; $\boldsymbol{\omega}=$ no trend over time. Cells with no values indicate a parameter is not included in the report. NA $=$ no analysis, NT = no trend, NL = non-linear, LCL $=95 \%$ lower confidence limit, $U C L=95 \%$ upper confidence limit. 


\subsection{Hansen Lake}

Hansen Lake (see Figure 1-2) is located about 15 meters off the cave tour route. No overflow point is known, and the bathymetry, or topography, of the pool's floor has not been mapped. There are two staff gages to record changes in water levels as the pool fluctuates (Figure 3-5).

Pool levels in Hansen Lake fluctuated seasonally from 2010 to 2018 (Figure 3-6) but did not change over time. There was poor correlation between April 1 SWE and median gage height for the water year $\left(\mathrm{r}^{2}=\right.$ 0.13). A lack of accurate local precipitation data precluded additional analysis of how precipitation timing and amounts affected pool levels, but median pool levels remained stable across wet and dry years in the record.

From July 2008 to September 2018, there were increasing trends over time in specific conductance, water temperature, calcium, chloride, magnesium, sodium, sulfate, and total dissolved solids (see Table 3-1). There was a decreasing trend over time in dissolved oxygen.

Dissolved oxygen increased as pool levels increased, and magnesium concentrations decreased as pool levels increased. However, after adjusting for pool levels, trends remained for dissolved oxygen and magnesium. This suggests that changes in pool levels were not the dominant driver of trends in water-quality parameters observed in Hansen Lake.

\subsubsection{Carbonate chemistry summary}

Saturation indices for calcite and dolomite were consistently greater than zero, indicating that conditions in Hansen Lake were potentially favorable for the precipitation of calcite and dolomite and continued speleothem formation (Figure 3-7, Table 3-2). Dissolved $\mathrm{CO}_{2}$ was generally 4-8 times the daily mean global atmospheric $\mathrm{CO}_{2}$ (Figure 3-8, Table 3-2).

\subsubsection{Core parameters}

There were no trends over time in gage height or $\mathrm{pH}$ (Tables 3-1, 3-3). Dissolved oxygen decreased by $2.1 \%$, with a median annual change of $-0.02 \mathrm{mg} / \mathrm{L}$ ( $\mathrm{LCL}=-0.04$, $\mathrm{UCL}=-0.01$; Figure 3-9). Specific conductance increased by $24.7 \%$ over the period of record, with a median annual change of 14 $\mu \mathrm{S} / \mathrm{cm}(\mathrm{LCL}=11, \mathrm{UCL}=19$; Figure 3-10). Water temperature increased by $6.6 \%$ over the period of record, with a median annual change of $0.05^{\circ} \mathrm{C}(\mathrm{LCL}=0.04, \mathrm{UCL}=0.05$; Figure 3-11). After adjusting for pool levels, a decrease in dissolved oxygen remained (slope $=-0.03 \mathrm{mg} / \mathrm{L}$ ). Models for $\mathrm{pH}$, specific conductance, turbidity, and watertemperature were not improved by including pool levels.

\subsubsection{Major ions}

Increasing trends were apparent in almost all major ions, as well as total dissolved solids (Tables 3-1, 3-4). Potassium had $>50 \%$ censored data and was not analyzed for trends, while alkalinity and DIC remained stable over time. Calcium increased by $23.8 \%$ over the period of record, with a median annual change of $1.9 \mathrm{mg} / \mathrm{L}$ (LCL = 1.5, UCL = 2.9; Figure 3-12). Chloride increased by $34.1 \%$, with a median annual change of $0.2 \mathrm{mg} / \mathrm{L}$ $(\mathrm{LCL}=0.1, \mathrm{UCL}=0.3$; Figure 3-13). Magnesium increased by $21.6 \%$, with a median annual change of $0.5 \mathrm{mg} / \mathrm{L}$ (LCL $=0.3$, UCL $=0.6$; Figure 3-14). Including pool level improved the model for magnesium, but an increasing trend remained (slope $=0.6 \mathrm{mg} / \mathrm{L}$ per year). Sodium increased by $24.5 \%$, with a median annual change of $0.07 \mathrm{mg} / \mathrm{L}$ (LCL $=0.04, \mathrm{UCL}=0.09$; Figure 3-15). Sulfate increased by $103 \%$, with a median annual change of $6.5 \mathrm{mg} / \mathrm{L}$ (LCL = 5.4, $\mathrm{UCL}=7.5$; Figure 3-16). Altogether, total dissolved solids increased by $40 \%$, with a median annual change of $12.9 \mathrm{mg} / \mathrm{L}(\mathrm{LCL}=9.9, \mathrm{UCL}=$ 16.6; Figure 3-17).

\subsubsection{Nutrients}

There were no trends in nutrients over time (Tables 3-1, 3-5). Ammonia had $>50 \%$ censored data and was not tested for trends.

\subsubsection{Trace elements}

Most trace elements had $>50 \%$ censored data and were not analyzed for trends over time (Tables 3-1, 3-6). Copper remained stable over time. 
Figure 3-5. Photos of Hansen Lake in April (above) and November (below) 2019, showing fluctuations in water levels and the locations of two staff gages. The gage in the April photo is the taller, closer one in the November photo.
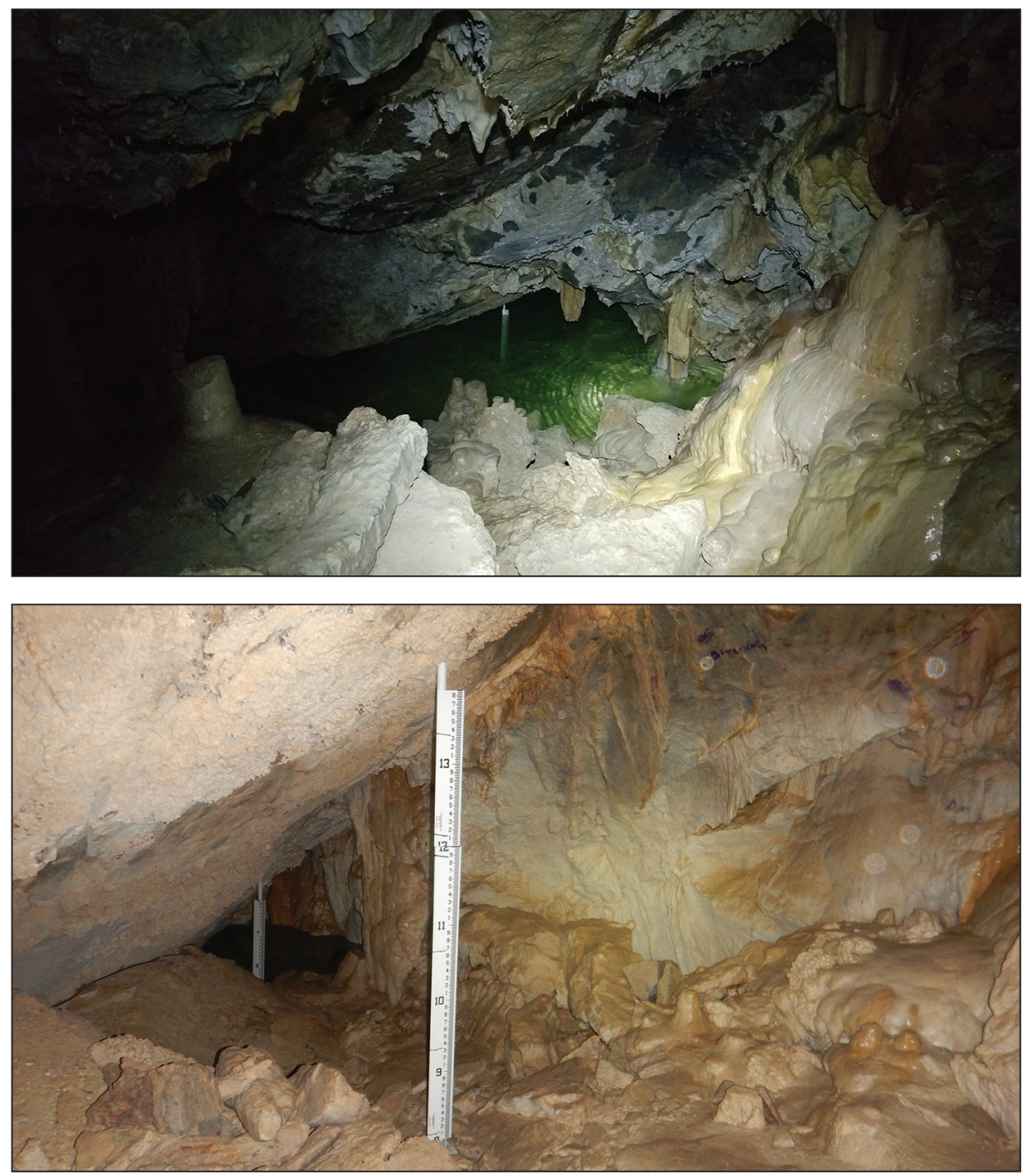

Figure 3-6. Gage height over time in Hansen Lake.

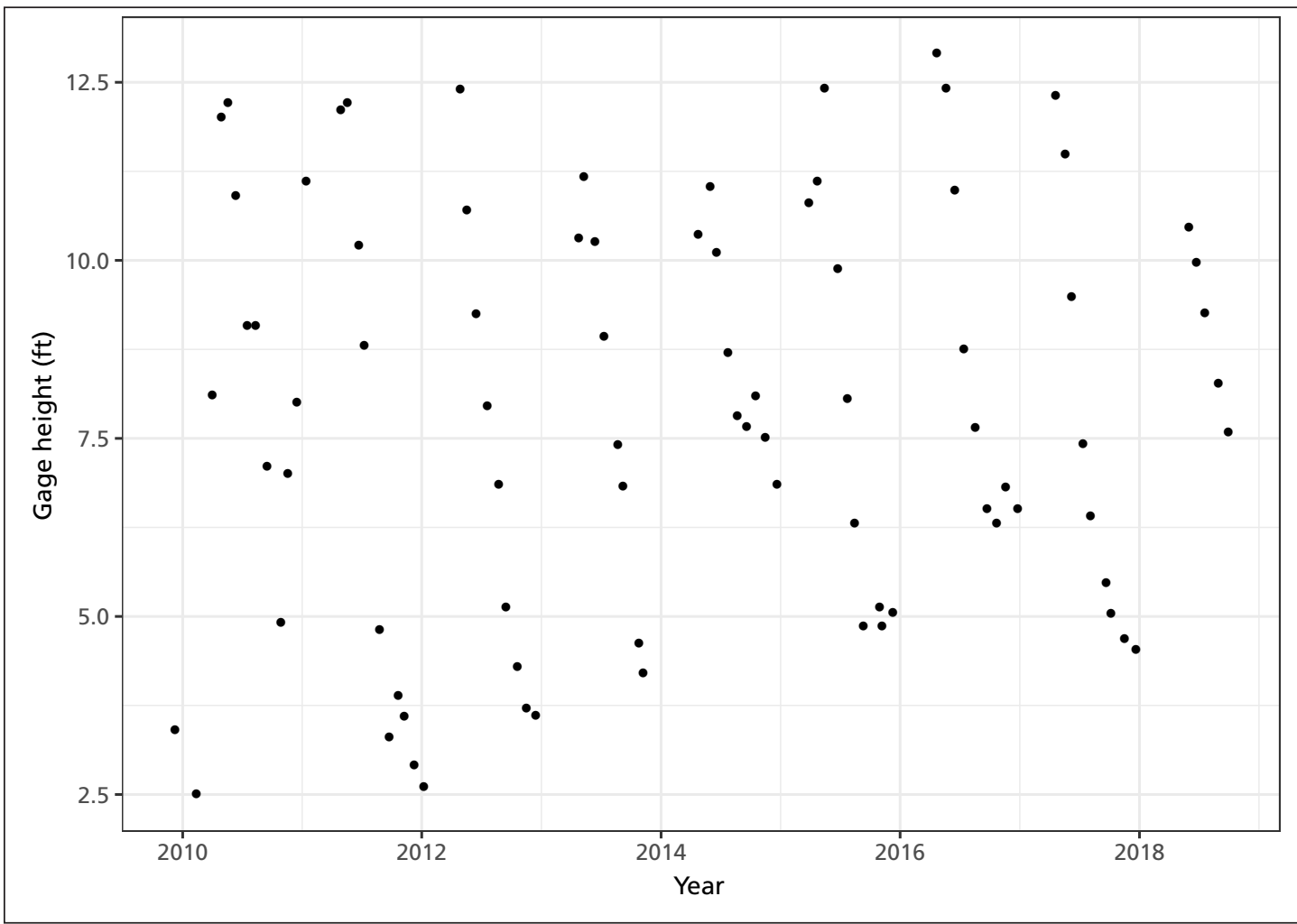

16 Trends in Water Quality of Cave Pools at Timpanogos Cave National Monument, July 2008-September 2018 


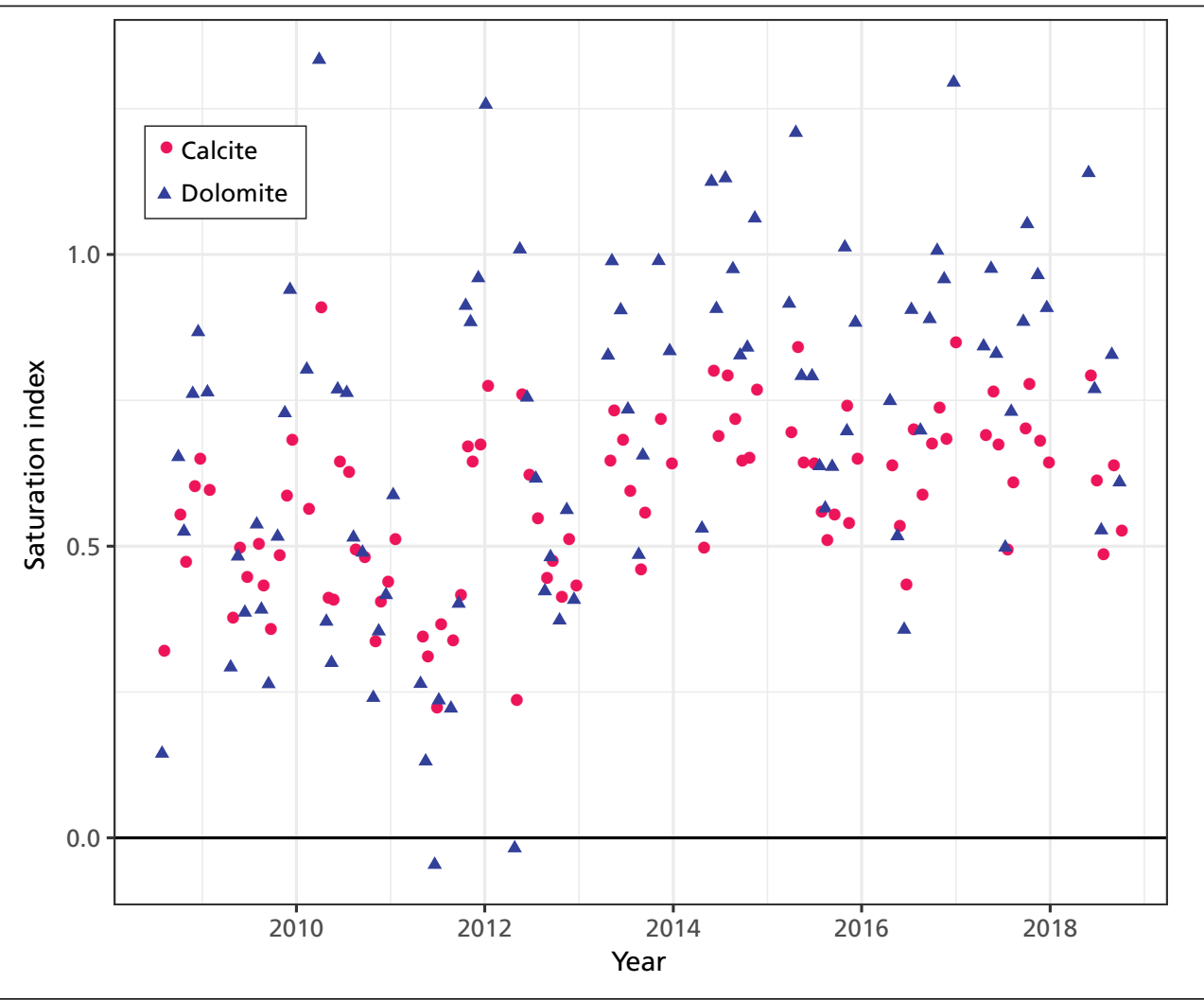

Figure 3-7. Saturation indices (SI) for calcite and dolomite at Hansen Lake over time. The index is logarithmic. Precipitating conditions are noted by positive values, while dissolving conditions are noted by negative values. Equilibrium is marked by a black line.

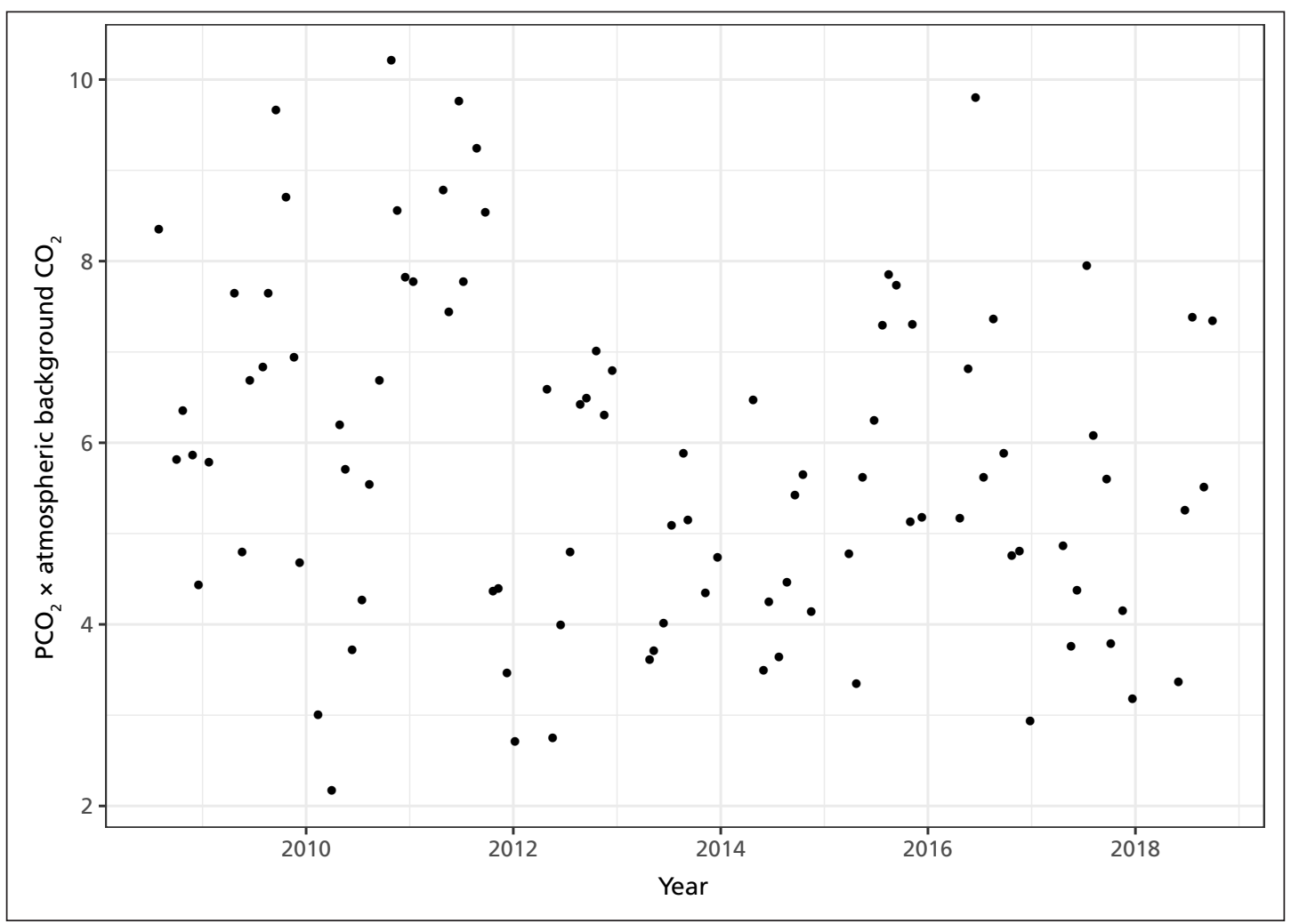

Figure 3-8. Dissolved $\mathrm{CO}_{2}\left(\mathrm{PCO}_{2}\right)$ in Hansen Lake as a multiple of the daily mean global atmospheric $\mathrm{CO}_{2}$ concentration, as recorded at the Mauna Loa observatory. 
Table 3-2. Summary statistics for saturation indices $(\mathrm{SI})$ and dissolved $\mathrm{CO}_{2}\left(\mathrm{PCO}_{2}\right)$ as a multiple of atmospheric $\mathrm{CO}_{2}$ in Hansen Lake, including values at the 10th, 50th, and 90th percentiles.

\begin{tabular}{lcccccc}
\hline Parameter & Start & End & Samples & 10th & Median & 90th \\
\hline $\mathrm{PCO}_{2}$ multiple & $7 / 29 / 2008$ & $9 / 27 / 2018$ & 95 & 3.5 & 5.6 & 8.2 \\
SI calcite & $7 / 29 / 2008$ & $9 / 27 / 2018$ & 95 & 0.38 & 0.59 & 0.76 \\
SI dolomite & $7 / 29 / 2008$ & $9 / 27 / 2018$ & 95 & 0.30 & 0.75 & 1.01 \\
\hline
\end{tabular}

Table 3-3. Summary statistics for core parameters in Hansen Lake, including the number of samples that were censored; concentrations at the 10th, 50th, and 90th percentiles; and trend results.

\begin{tabular}{lcccccccc}
\hline Parameter & Start & End & Test $^{\mathrm{A}}$ & $\begin{array}{c}\text { Samples } \\
\text { (censored) }\end{array}$ & 10th & Median & 90th & Trend \\
\hline Dissolved oxygen $(\mathrm{mg} / \mathrm{L})$ & $9 / 30 / 2008$ & $9 / 27 / 2018$ & $\mathrm{~T}$ & $87(0)$ & 9.0 & 9.3 & 9.6 & down \\
\hline Gage height $(\mathrm{ft})$ & $12 / 7 / 2009$ & $9 / 27 / 2018$ & $\mathrm{~S}$ & $82(0)$ & 3.9 & 7.9 & 11.9 & none \\
$\mathrm{pH}$ & $7 / 29 / 2008$ & $9 / 27 / 2018$ & $\mathrm{~T}$ & $97(0)$ & 7.81 & 7.97 & 8.16 & none \\
Specific conductance $(\mu \mathrm{S} / \mathrm{cm})$ & $7 / 29 / 2008$ & $9 / 27 / 2018$ & $\mathrm{~T}$ & $75(0)$ & 482 & 551 & 610 & up \\
Water temperature $\left({ }^{\circ} \mathrm{C}\right)$ & $9 / 30 / 2008$ & $9 / 27 / 2018$ & $\mathrm{~T}$ & $91(0)$ & 7.39 & 7.59 & 7.75 & up \\
\hline
\end{tabular}

AS = time plus seasonality quantile regression, $\mathrm{T}=$ time-only quantile regression.

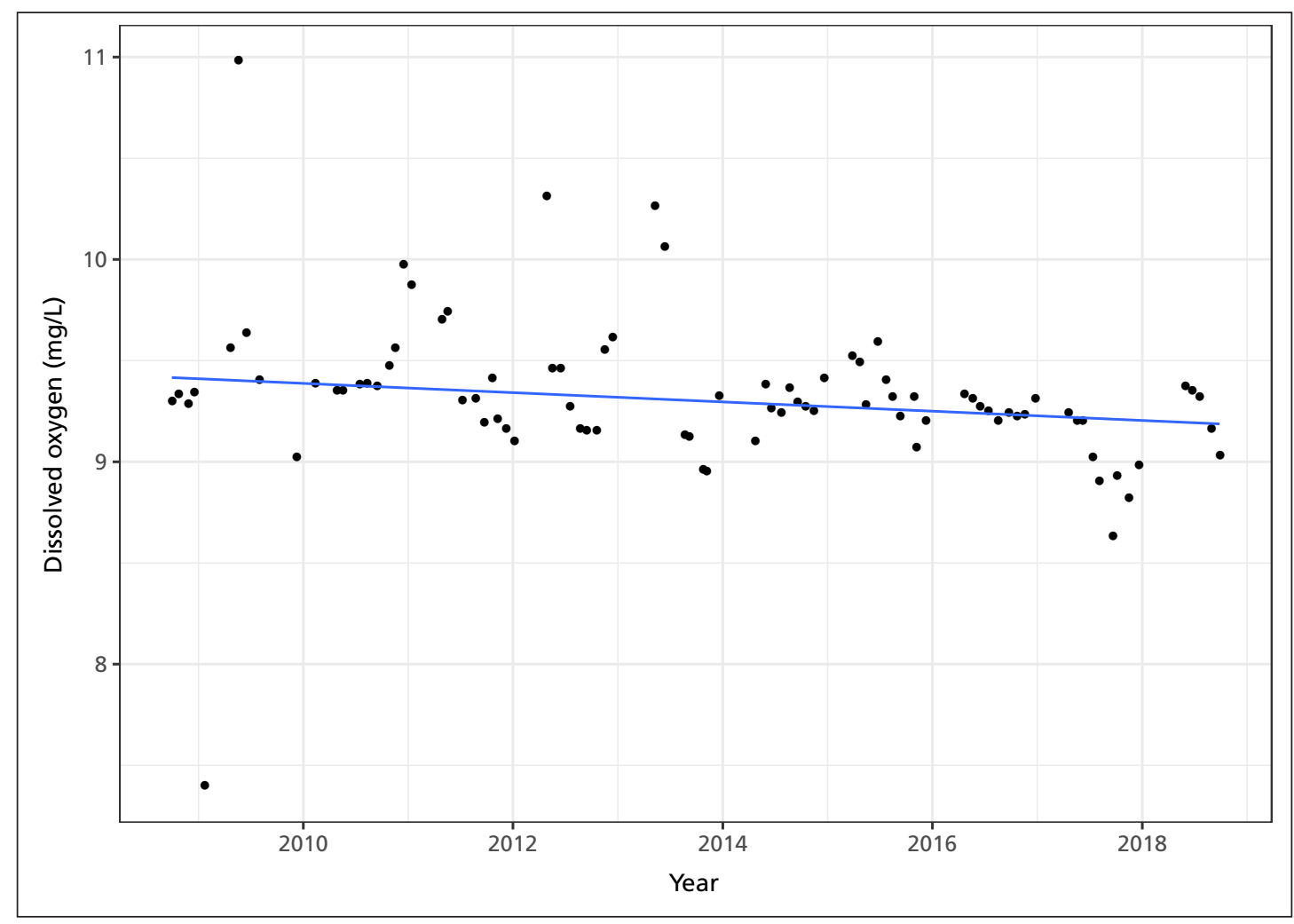

Figure 3-9. Decrease in dissolved oxygen at Hansen Lake, with a quantile regression at the median (slope $=-0.02$ $\mathrm{mg} / \mathrm{L}$ per year). 


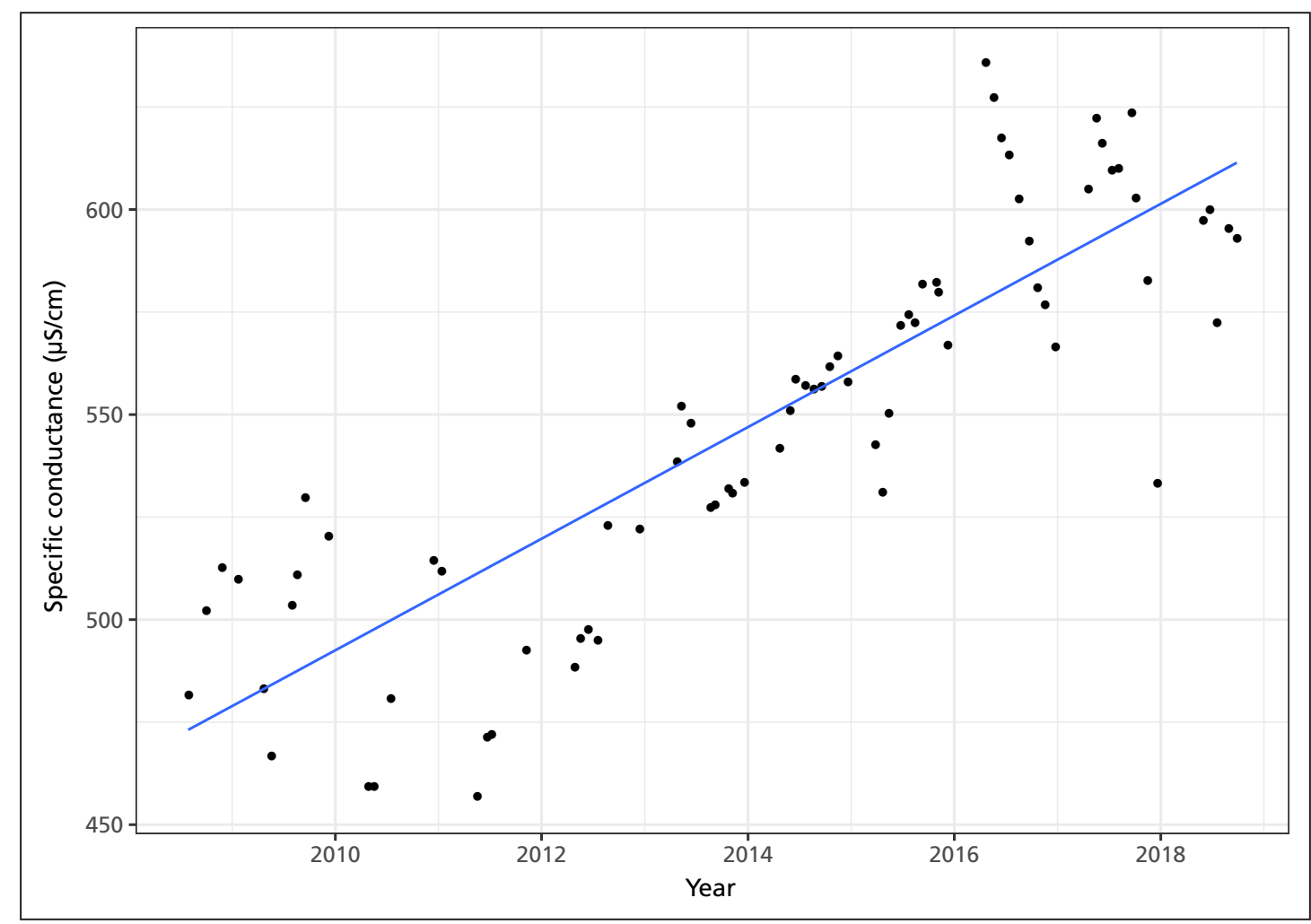

Figure 3-10. Increase in specific conductance over time in Hansen Lake, with a quantile regression at the median (slope $=14 \mu \mathrm{S} / \mathrm{cm}$ per year).

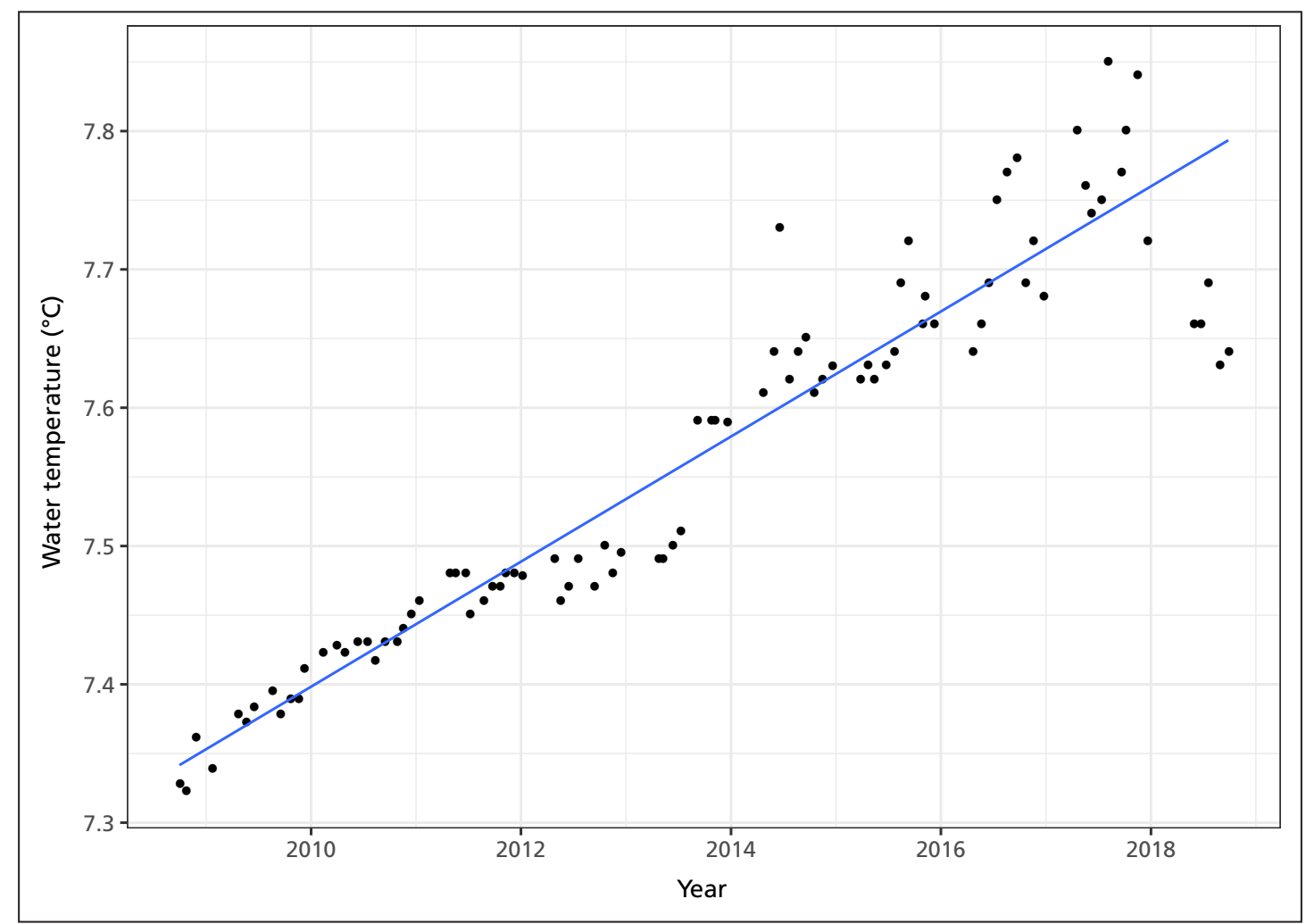

Figure 3-11. Increase in water temperature over time in Hansen Lake, with a quantile regression at the median (slope $=0.05^{\circ} \mathrm{C}$ per year). 
Table 3-4. Summary statistics for major ions in Hansen Lake, including the number of samples that were censored; concentrations at the 10th, 50th, and 90th percentiles; and trend results.

\begin{tabular}{lcccccccc}
\hline Parameter & Start & End & Test ${ }^{\mathrm{A}}$ & $\begin{array}{c}\text { Samples } \\
\text { (censored) }\end{array}$ & 10th & Median & 90th & Trend \\
\hline Alkalinity (mg/L CaCO $)$ & $7 / 29 / 2008$ & $8 / 28 / 2018$ & $\mathrm{~T}$ & $95(0)$ & 197 & 218 & 237 & none \\
\hline $\begin{array}{l}\text { Dissolved inorganic carbon } \\
\text { (mol/L) }\end{array}$ & $7 / 29 / 2008$ & $9 / 27 / 2018$ & $\mathrm{~T}$ & $95(0)$ & 0.0036 & 0.0040 & 0.0044 & none \\
\hline Calcium (d) (mg/L) & $7 / 29 / 2008$ & $8 / 28 / 2018$ & $\mathrm{~T}$ & $96(0)$ & 67.8 & 80.0 & 92.8 & up \\
\hline Chloride (mg/L) & $8 / 23 / 2011$ & $8 / 28 / 2018$ & $\mathrm{~T}$ & $63(0)$ & $<3.5$ & 4.1 & 5.0 & up \\
\hline Magnesium (d) (mg/L) & $7 / 29 / 2008$ & $8 / 28 / 2018$ & $\mathrm{~T}$ & $95(0)$ & 19.2 & 23.1 & 25.4 & up \\
\hline Potassium (d) (mg/L) & $7 / 29 / 2008$ & $8 / 28 / 2018$ & $\mathrm{~N}$ & $95(92)$ & $<1$ & $<1$ & $<1$ & - \\
\hline Sodium (d) (mg/L) & $7 / 29 / 2008$ & $8 / 28 / 2018$ & $\mathrm{~T}$ & $95(0)$ & 2.33 & 2.85 & 3.21 & up \\
\hline Sulfate (mg/L) & $7 / 29 / 2008$ & $8 / 28 / 2018$ & $\mathrm{~T}$ & $96(1)$ & 39.1 & 63.1 & 98.3 & up \\
\hline Total dissolved solids (mg/L) & $7 / 29 / 2008$ & $8 / 28 / 2018$ & $\mathrm{~T}$ & $95(0)$ & 268 & 322 & 409 & up \\
\hline
\end{tabular}

${ }^{A} \mathrm{NA}=$ no analysis (>50\% censored data), $\mathrm{T}=$ time-only quantile regression.

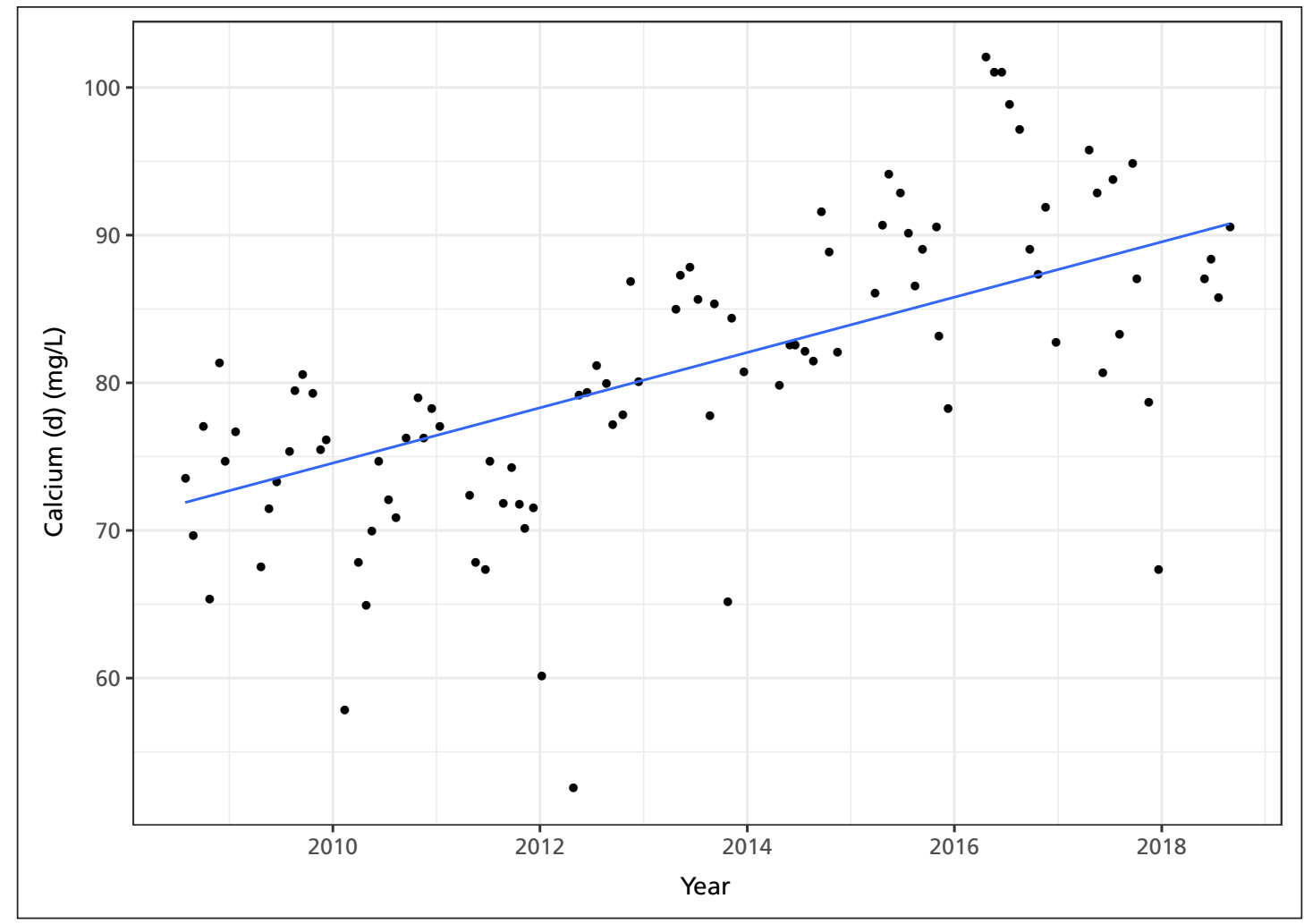

Figure 3-12. Increase in calcium over time in Hansen Lake, with a quantile regression at the median (slope $=1.9$ $\mathrm{mg} / \mathrm{L}$ per year). 


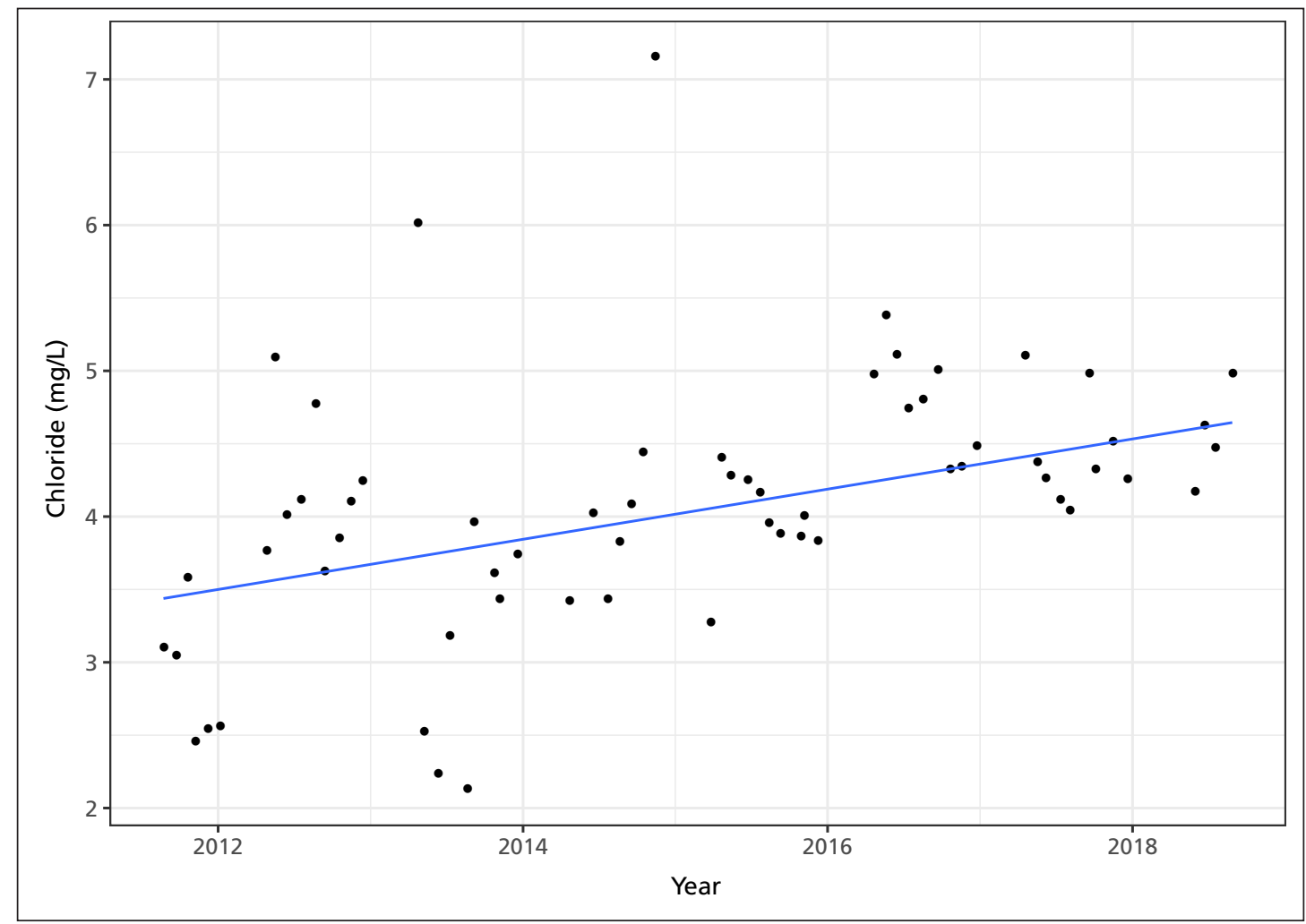

Figure 3-13. Increase in chloride over time in Hansen Lake, with a quantile regression at the median (slope $=0.2$ $\mathrm{mg} / \mathrm{L}$ per year).

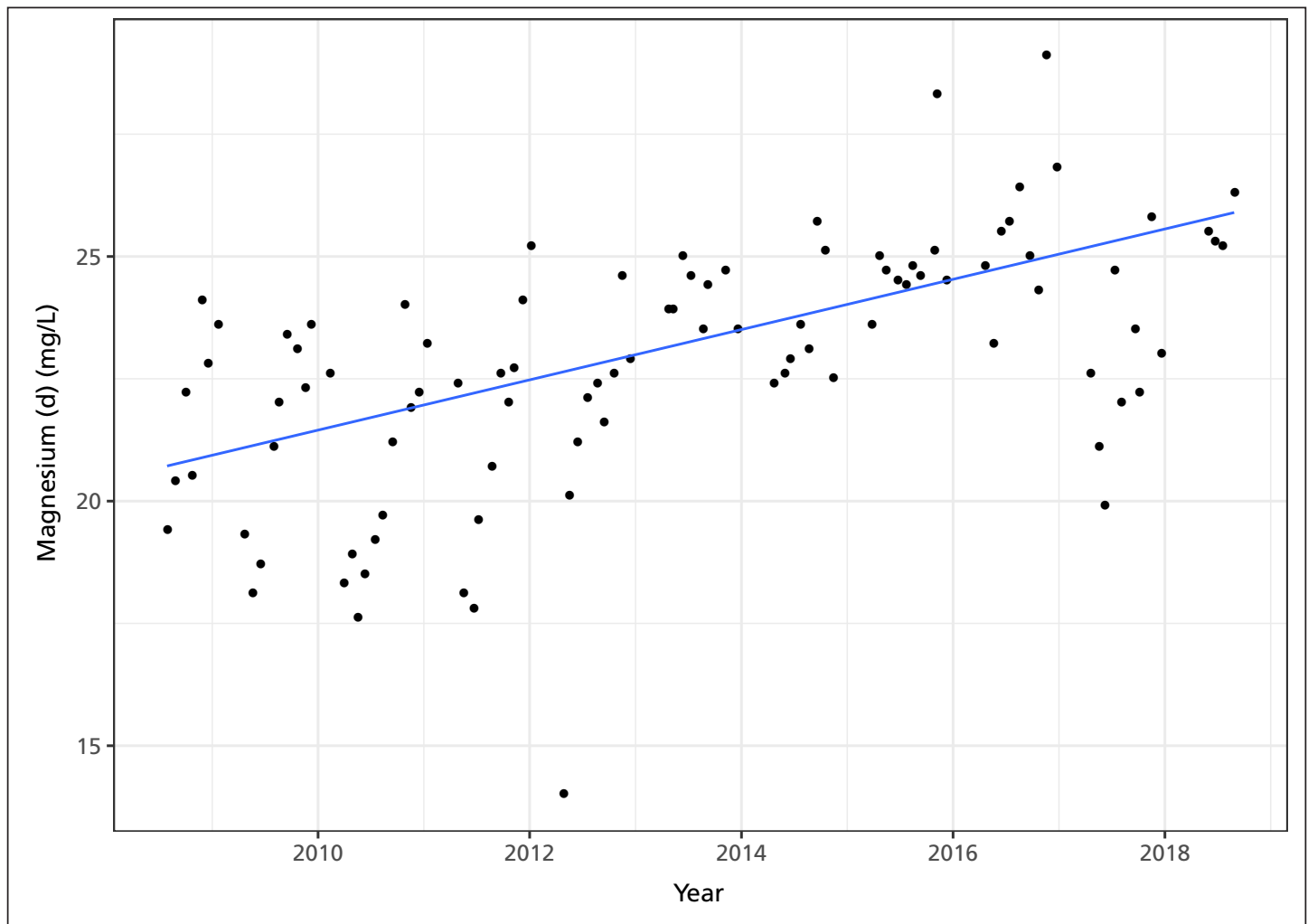

Figure 3-14. Increase in magnesium over time in Hansen Lake, with a quantile regression at the median (slope $=$ $0.5 \mathrm{mg} / \mathrm{L}$ per year). 


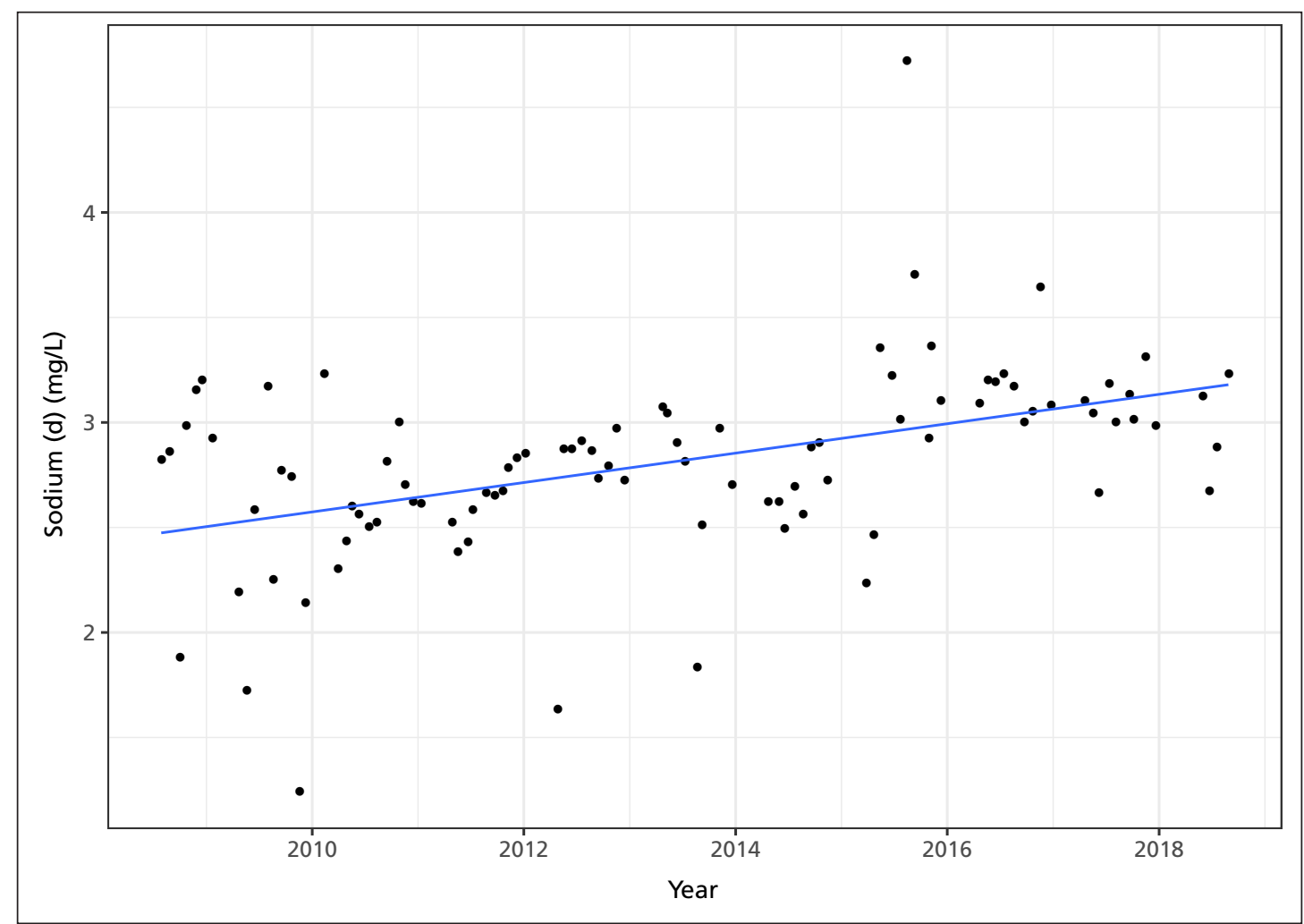

Figure 3-15. Increase in sodium over time in Hansen Lake, with a quantile regression at the median (slope $=0.07$ $\mathrm{mg} / \mathrm{L}$ per year).

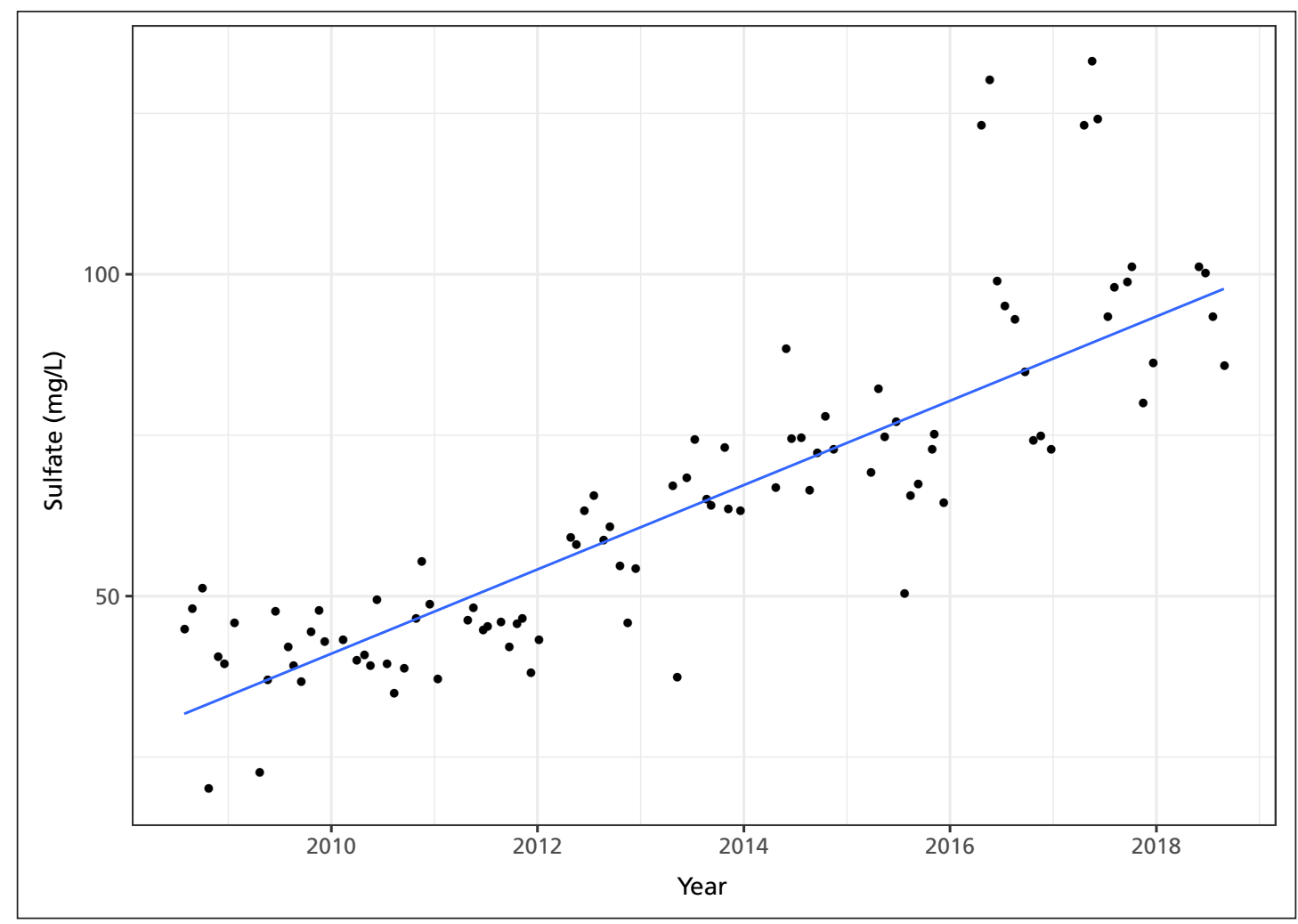

Figure 3-16. Increase in sulfate over time in Hansen Lake, with a quantile regression at the median (slope $=6.5$ $\mathrm{mg} / \mathrm{L}$ per year). 


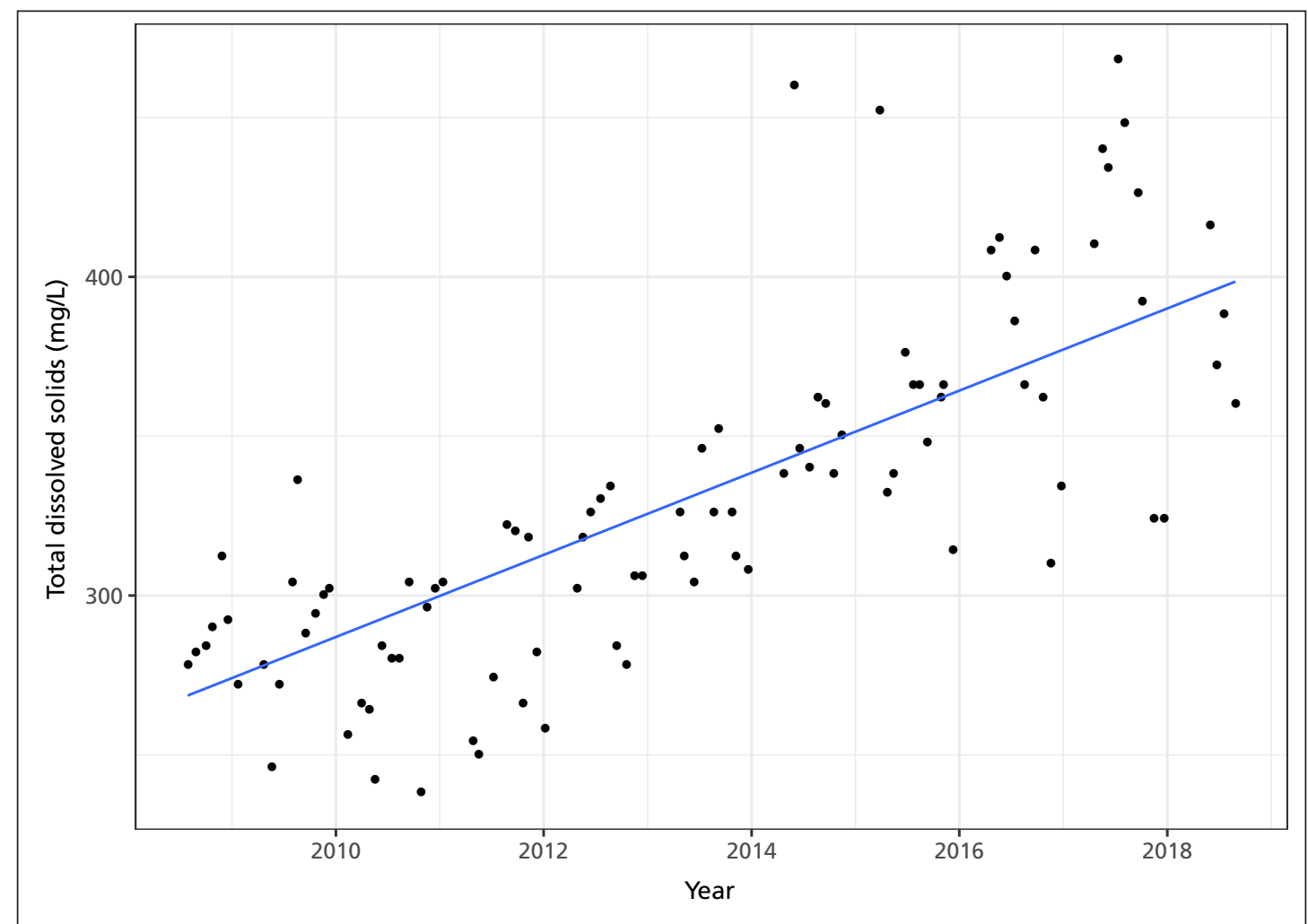

Figure 3-17. Increase in total dissolved solids over time in Hansen Lake, with a quantile regression at the median (slope $=12.9 \mathrm{mg} / \mathrm{L}$ per year).

Table 3-5. Summary statistics for nutrients in Hansen Lake, including the number of samples that were censored; concentrations at the 10th, 50th, and 90th percentiles; and trend results.

\begin{tabular}{lcccccccc}
\hline Parameter & Start & End & Test $^{A}$ & $\begin{array}{c}\text { Samples } \\
\text { (censored) }\end{array}$ & 10th & Median & 90th & Trend \\
\hline Ammonia as N (mg/L) & $7 / 29 / 2008$ & $8 / 28 / 2018$ & NA & $96(94)$ & $<0.05$ & $<0.05$ & $<0.05$ & - \\
\hline $\begin{array}{l}\text { Nitrite + Nitrate as N (d) } \\
\text { (mg/L) }\end{array}$ & $7 / 29 / 2008$ & $8 / 28 / 2018$ & T & $94(0)$ & 0.519 & 0.759 & 1.113 & none \\
Nitrogen (d) (mg/L) & $7 / 29 / 2008$ & $8 / 28 / 2018$ & T & $95(0)$ & 0.606 & 0.892 & 1.264 & none \\
\hline $\begin{array}{l}\text { Phosphorus as P (d) } \\
\text { (mg/L) }\end{array}$ & $11 / 7 / 2011$ & $8 / 28 / 2018$ & C,T & $51(6)$ & $<0.003$ & 0.005 & 0.008 & none \\
$\begin{array}{l}\text { Total phosphorus as P } \\
\text { (mg/L) }\end{array}$ & $11 / 7 / 2011$ & $8 / 28 / 2018$ & C,T & $51(6)$ & $<0.003$ & 0.005 & 0.011 & none \\
\hline
\end{tabular}

${ }^{A} \mathrm{C}=$ censored quantile regression, $\mathrm{NA}=$ no analysis ( $>50 \%$ censored data), $\mathrm{T}=$ time-only quantile regression. 
Table 3-6. Summary statistics for trace elements ( $\mu \mathrm{g} / \mathrm{L})$ in Hansen Lake, including the number of samples that were censored; concentrations at the 10th, 50th, and 90th percentiles; and trend results.

\begin{tabular}{lcccccccc}
\hline Parameter & Start & End & Test & $\begin{array}{c}\text { Samples } \\
\text { (censored) }\end{array}$ & 10th & Median & 90 th & Trend \\
\hline Aluminum (d) & $7 / 29 / 2008$ & $7 / 18 / 2018$ & NA & $37(35)$ & $<10$ & $<10$ & $<10$ & - \\
\hline Arsenic (d) & $7 / 29 / 2008$ & $7 / 18 / 2018$ & NA & $37(37)$ & $<1$ & $<1$ & $<1$ & - \\
\hline Barium (d) & $7 / 29 / 2008$ & $7 / 18 / 2018$ & NA & $37(31)$ & $<100$ & $<100$ & $<100$ & - \\
\hline Boron (d) & $7 / 29 / 2008$ & $7 / 18 / 2018$ & NA & $42(37)$ & $<30$ & $<30$ & $<30$ & - \\
\hline Cadmium (d) & $7 / 29 / 2008$ & $7 / 18 / 2018$ & NA & $37(34)$ & $<0.1$ & $<0.1$ & $<0.1$ & - \\
\hline Chromium (d) & $7 / 29 / 2008$ & $7 / 18 / 2018$ & NA & $37(29)$ & $<2$ & $<2$ & 3.57 & - \\
\hline Copper (d) & $7 / 29 / 2008$ & $7 / 18 / 2018$ & C,T & $36(11)$ & $<1$ & 1.23 & 2.15 & none \\
\hline Iron (d) & $7 / 29 / 2008$ & $7 / 18 / 2018$ & NA & $42(40)$ & $<30$ & $<30$ & $<30$ & - \\
Lead (d) & $7 / 29 / 2008$ & $7 / 18 / 2018$ & NA & $36(27)$ & $<0.1$ & $<0.1$ & 0.14 & - \\
\hline Manganese (d) & $7 / 29 / 2008$ & $7 / 18 / 2018$ & NA & $36(36)$ & $<5$ & $<5$ & $<5$ & - \\
\hline Mercury (d) & $7 / 29 / 2008$ & $7 / 18 / 2018$ & NA & $37(37)$ & $<0.2$ & $<0.2$ & $<0.2$ & - \\
\hline Nickel (d) & $7 / 29 / 2008$ & $7 / 18 / 2018$ & NA & $36(36)$ & $<5$ & $<5$ & $<5$ & - \\
\hline Silver (d) & $7 / 29 / 2008$ & $7 / 18 / 2018$ & NA & $37(37)$ & $<0.5$ & $<0.5$ & $<0.5$ & - \\
\hline Zinc (d) & $7 / 29 / 2008$ & $7 / 18 / 2018$ & NA & $36(29)$ & $<10$ & $<10$ & 11.2 \\
\hline
\end{tabular}

${ }^{A} \mathrm{C}=$ censored quantile regression, $\mathrm{NA}=$ no analysis ( $>50 \%$ censored data), $\mathrm{T}=$ time-only quantile regression.

\subsection{Hidden Lake}

Hidden Lake is located directly adjacent to the main cave tour route, in the Timpanogos Cave section of the cave system (Figure 3-18). The bathymetry of the pool has not been mapped. A rimstone dam visible in the right part of Figure 3-18 is the overflow for Hidden Lake. The top of the dam is approximately 3.8 feet above lake bottom. It is not known to currently overflow but represents a prior overflow into a room known as the Cavern of Sleep during wetter climatic conditions.

Pool levels in Hidden Lake changed substantially from 2010 to 2018 (Figure 3-19). After minor fluctuations from 2010 to 2012, the pool dropped precipitously from 2013 to 2015 before rebounding to higher levels in 2017 and then beginning a new decline. Because of significant nonlinearity in changes over time, we did not test for a trend over time. However, median pool levels were still lower at the end of the period of record than at the beginning. There was no clear correlation between monthly precipitation and monthly gage height, but this analysis was hampered by a lack of reliable monthly precipitation data. There was a modest correlation between April 1 SWE and median gage height for the water year $\left(\mathrm{r}^{2}=0.41\right)$.
Because pool levels changed over time, it is possible that trends over time could be conflated with changing pool levels. We explicitly tested for this possibility by comparing models that included pool levels to models without pool levels. We tested for trends over time using the full dataset, then subsetted the data to those records that had paired pool-level records to determine whether these trends could be attributed primarily to changes in pool levels. Several parameters did have relationships with pool levels: alkalinity and calcium concentrations increased as pool levels increased, and $\mathrm{pH}$, copper, and zinc decreased as pool levels increased.

From July 2008 to September 2018, there were increasing trends over time in $\mathrm{pH}$, water temperature, and selenium (see Table 3-1). There were decreasing trends over time in specific conductance, alkalinity, DIC, calcium, total dissolved solids, and nickel. After adjusting for pool levels, decreasing trends in alkalinity and calcium remained, while zinc concentrations showed a decrease. This suggests that changes in pool levels may drive some, but not all, of the trends in water-quality parameters observed in Hidden Lake. 


\subsubsection{Carbonate chemistry summary}

Saturation indices for calcite and dolomite fluctuated above and below zero from 2008 to mid-2013, indicating fluctuations of precipitating to dissolving conditions in Hidden Lake (Figure 3-20, Table 3-7). In September 2013, the saturation indices stabilized to above zero, indicating recent conditions were favorable for continued speleothem formation. From 2008 to mid2013, dissolved $\mathrm{CO}_{2}$ was 5-20 times higher than the global atmospheric daily mean $\mathrm{CO}_{2}$ (Figure 3-21). After September 2013, $\mathrm{PCO}_{2}$ ranged from 2 to 10 times higher than the atmospheric daily mean $\mathrm{CO}_{2}$, and in a similar range to that of Hansen Cave, which is located off the main cave tour route.

\subsubsection{Core parameters}

There were no trends over time in dissolved oxygen or turbidity (Tables 3-1, 3-8). pH increased with a median annual change of $0.03 \mathrm{pH}$ units (LCL $=0.02, \mathrm{UCL}=0.05$; Figure 3-22). Specific conductance decreased by $12.6 \%$ over the period of record, with a median annual change of $-6.6 \mu \mathrm{S} / \mathrm{cm}$ (LCL $=-8.3, \mathrm{UCL}=-3.6$; Figure 3-23). Water temperature increased by $3.6 \%$ over the period of record, with a median annual change of $0.03^{\circ} \mathrm{C}(\mathrm{LCL}=0.02, \mathrm{UCL}=0.04$; Figure 3-24). After adjusting for pool levels, there was still no trend in dissolved oxygen. $\mathrm{pH}$, specific conductance, turbidity, and water temperature models were not improved by including pool levels.

\subsubsection{Major ions}

There were no trends over time in chloride, magnesium, sodium, or sulfate (Tables 3-1, 3-9). Potassium and total suspended solids had $>50 \%$ censored data and were not analyzed for trends. Several major ions had decreasing trends, including alkalinity $(-15.6 \%$ total change, slope $=-3.2 \mathrm{mg} / \mathrm{L} \mathrm{CaCO}_{3}$ per year, $\mathrm{LCL}=-5.3, \mathrm{UCL}=-1.5$; Figure $3-25)$, DIC $\left(-17.6 \%\right.$ total change, slope $=-7 \mathrm{e}^{-5}, \mathrm{LCL}$ $=-11 \mathrm{e}^{-5}, \mathrm{UCL}=-3 \mathrm{e}^{-5}$; Figure 3-26), calcium $(-18.9 \%$ total change, slope $=-0.9 \mathrm{mg} / \mathrm{L}$ per year, $\mathrm{LCL}=-1.4, \mathrm{UCL}=-0.2$; Figure $3-27)$, and total dissolved solids $(-7.9 \%$ total change, slope $=-2.2 \mathrm{mg} / \mathrm{L}$ per year, $\mathrm{LCL}=$ $-5.4, \mathrm{UCL}=-0.3$; Figure 3-28). After adjusting for pool levels, trends remained for alkalinity (slope $=-3.8$ ) and calcium (slope $=-0.7$ ), and we continued to see no trend in magnesium. Models for chloride, sodium, sulfate, and total dissolved solids were not improved by including pool levels.

\subsubsection{Nutrients}

Ammonia, dissolved phosphate, and total phosphate had $>50 \%$ censored data and were not analyzed for trends over time (Tables 3-1, 3-10). Both nitrite plus nitrate and total dissolved nitrogen remained stable over time. Models for nitrite plus nitrate and total dissolved nitrogen models were not improved by including pool levels.

\subsubsection{Trace elements}

Most trace elements had $>50 \%$ censored data and were not analyzed for trends over time (Tables 3-1, 3-11). Barium, copper, and zinc concentrations remained stable over time. Nickel decreased by $94.6 \%$ over the period of record, with a median annual change of $-0.56 \mu \mathrm{g} / \mathrm{L}$ ( $\mathrm{LCL}=-0.78$, UCL $=-0.34$; Figure $3-29)$. Selenium increased by $13.8 \%$ over the period of record, with a median annual change of $0.05 \mu \mathrm{g} / \mathrm{L}(\mathrm{LCL}=$ 0.02 , UCL $=0.12$; Figure 3-30). After adjusting for pool levels, a decreasing trend occurred in zinc concentrations at $-1.4 \mu \mathrm{g} / \mathrm{L}$ per year $(\mathrm{LCL}=-2.7, \mathrm{UCL}=-0.2)$, and copper concentrations remained stable. Models for barium, nickel, and selenium were not improved by including pool levels. 


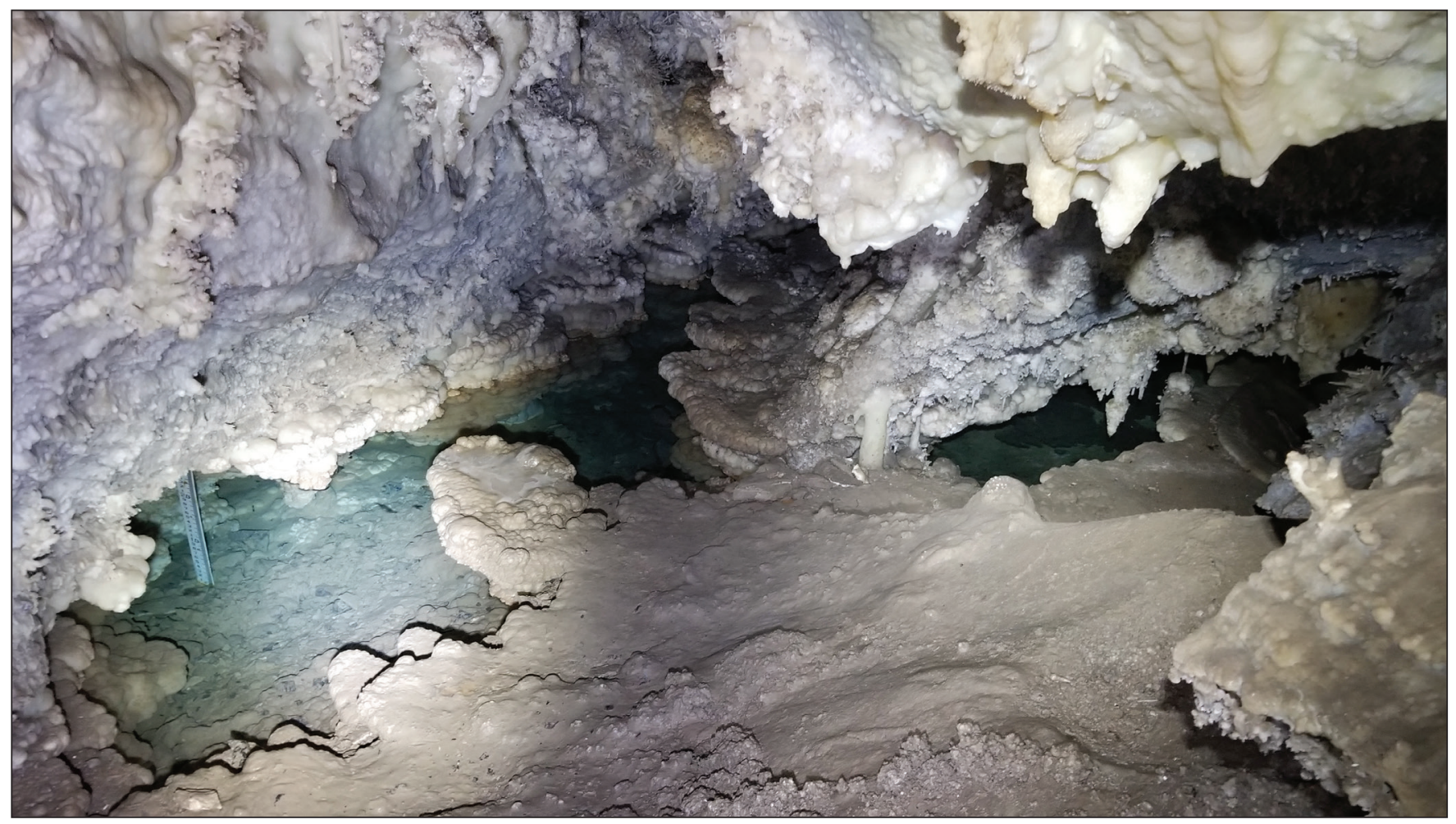

Figure 3-18. Hidden Lake, July 4, 2019.

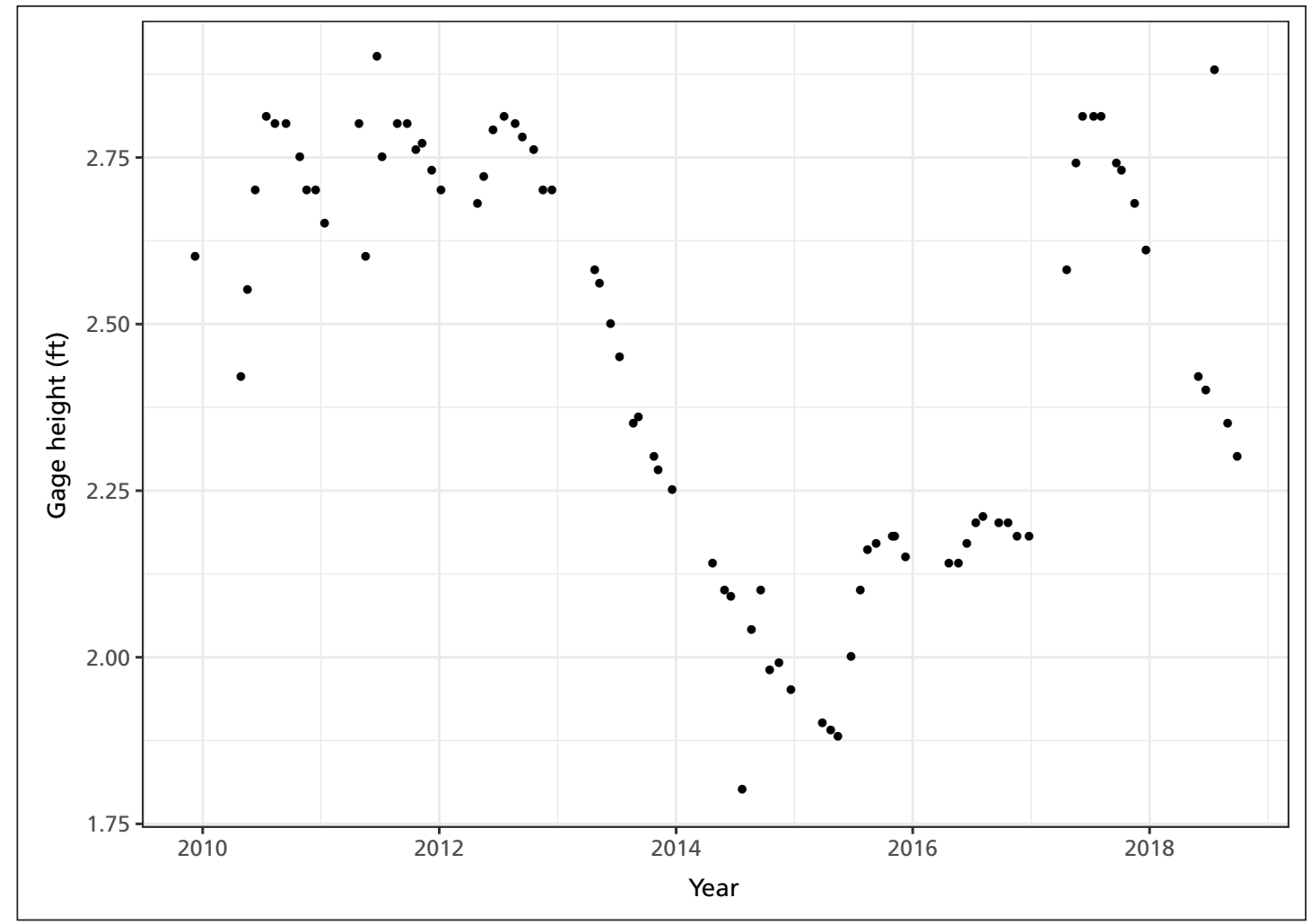

Figure 3-19. Gage height over time in Hidden Lake. 


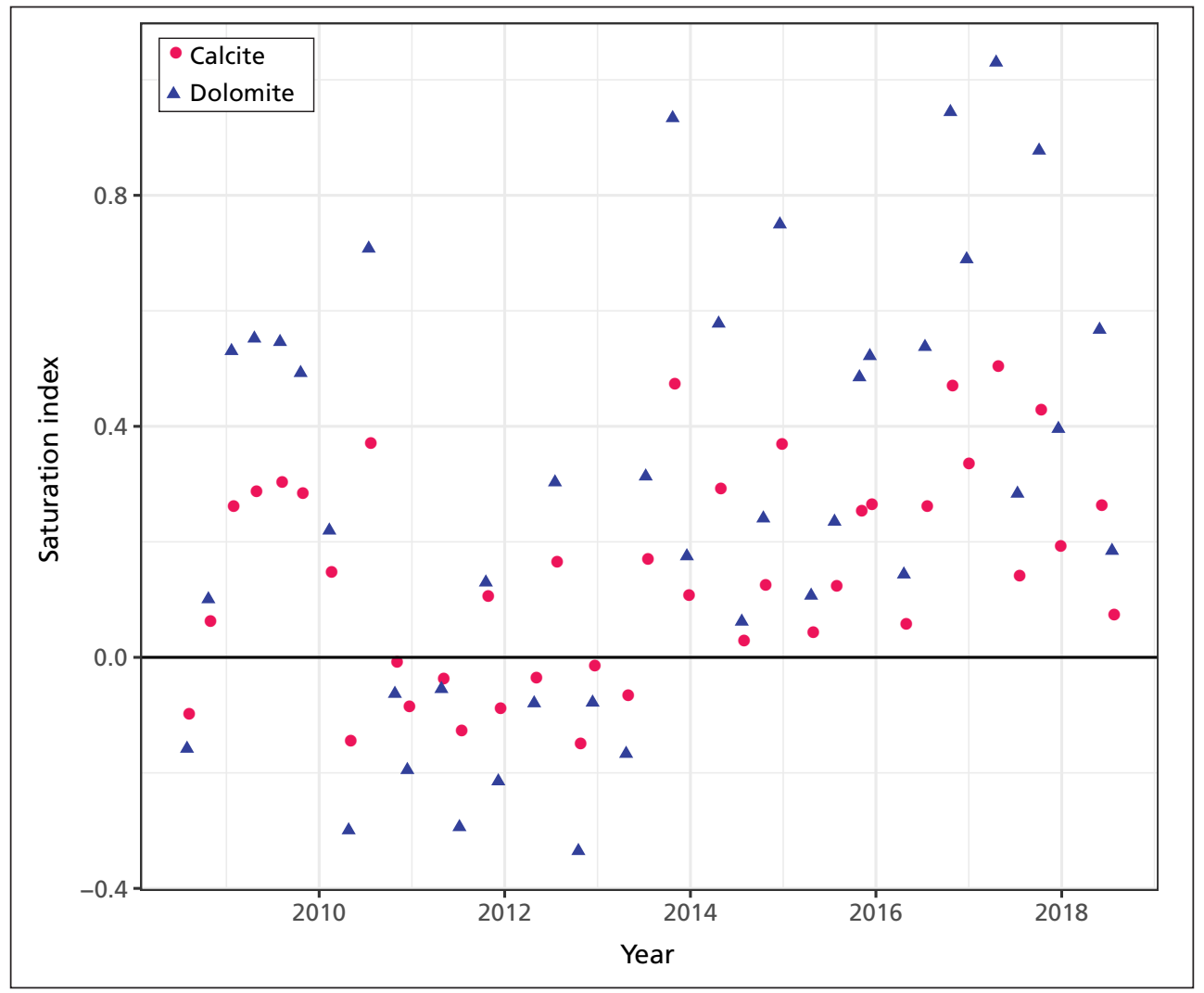

Figure 3-20. Saturation indices (SI) for calcite and dolomite at Hidden Lake over time. The index is logarithmic, and precipitating conditions are noted by positive numbers, while dissolving conditions are noted by negative numbers. Equilibrium is marked by a black line.

Table 3-7. Summary statistics for saturation indices ( $\mathrm{SI})$ and dissolved $\mathrm{CO}_{2}\left(\mathrm{PCO}_{2}\right)$ as a multiple of atmospheric $\mathrm{CO}_{2}$ in Hidden Lake, including values at the 10th, 50th, and 90 th percentiles.

\begin{tabular}{lcccccc}
\hline Parameter & Start & End & Samples & 10th & Median & 90th \\
\hline PCO $_{2}$ multiple & $7 / 30 / 2008$ & $7 / 18 / 2018$ & 41 & 4.2 & 8.4 & 16.4 \\
SI calcite & $7 / 30 / 2008$ & $7 / 18 / 2018$ & 41 & -0.09 & 0.14 & 0.37 \\
SI dolomite & $7 / 30 / 2008$ & $7 / 18 / 2018$ & 41 & -0.19 & 0.24 & 0.75 \\
\hline
\end{tabular}




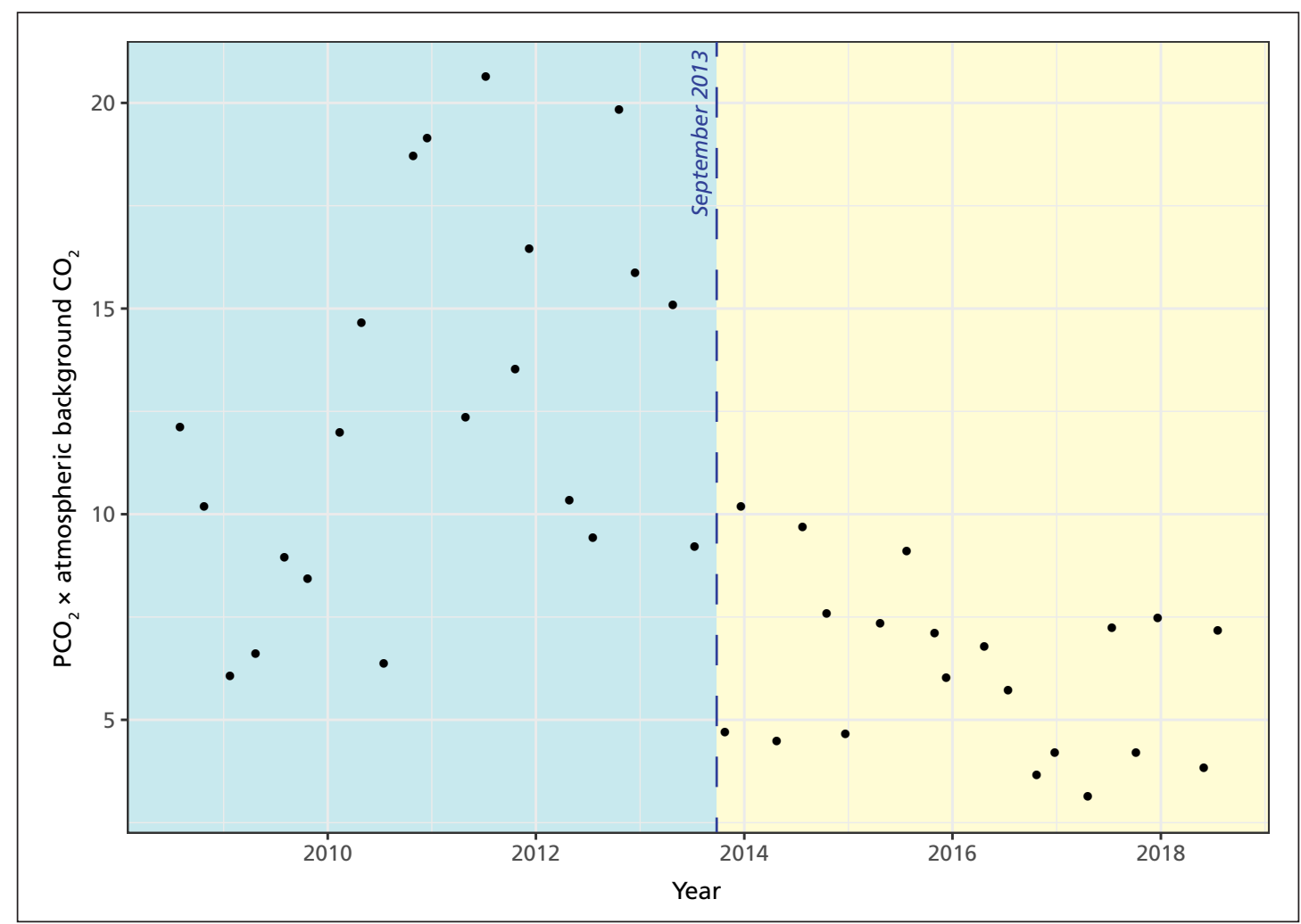

Figure 3-21. Dissolved $\mathrm{CO}_{2}\left(\mathrm{PCO}_{2}\right)$ in Hidden Lake as a multiple of the daily mean global atmospheric $\mathrm{CO}_{2}$ concentration, as recorded at the Mauna Loa observatory.

Table 3-8. Summary statistics for core parameters in Hidden Lake, including the number of samples that were censored; concentrations at the $10^{\text {th }}, 50^{\text {th }}$, and $90^{\text {th }}$ percentiles; and trend results. ${ }^{\mathrm{A}}$

\begin{tabular}{lcccccccc}
\hline Parameter & Start & End & Test & $\begin{array}{c}\text { Samples } \\
\text { (censored) }\end{array}$ & 10th & Median & 90th & Trend \\
\hline $\begin{array}{l}\text { Dissolved oxygen } \\
\text { (mg/L) }\end{array}$ & $9 / 30 / 2008$ & $9 / 27 / 2018$ & $\mathrm{~T}$ & $84(0)$ & 8.06 & 8.75 & 9.26 & none \\
\hline Gage height (ft) & $12 / 7 / 2009$ & $9 / 27 / 2018$ & - & $81(0)$ & 2.04 & 2.55 & 2.8 & - \\
\hline $\mathrm{pH}$ & $7 / 30 / 2008$ & $9 / 27 / 2018$ & $\mathrm{~T}$ & $96(0)$ & 7.52 & 7.78 & 8.01 & up \\
$\begin{array}{l}\text { Specific conductance } \\
(\mu \mathrm{S} / \mathrm{cm})\end{array}$ & $9 / 30 / 2008$ & $9 / 27 / 2018$ & $\mathrm{~T}$ & $65(0)$ & 498.2 & 524.9 & 562.9 & down \\
Turbidity (NTU) & $7 / 30 / 2008$ & $7 / 18 / 2018$ & $\mathrm{C}, \mathrm{T}$ & $41(7)$ & $<0.1$ & 0.52 & 2.04 & none \\
\hline Water temperature $\left({ }^{\circ} \mathrm{C}\right)$ & $9 / 30 / 2008$ & $9 / 27 / 2018$ & $\mathrm{~S}$ & $91(0)$ & 8.03 & 8.18 & 8.33 & up \\
\hline
\end{tabular}

${ }^{\mathrm{A}} \mathrm{C}=$ censored quantile regression, $\mathrm{NA}=$ no analysis ( $>50 \%$ censored data), $\mathrm{S}=$ time plus seasonality quantile regression, $\mathrm{T}$ = time-only quantile regression. 


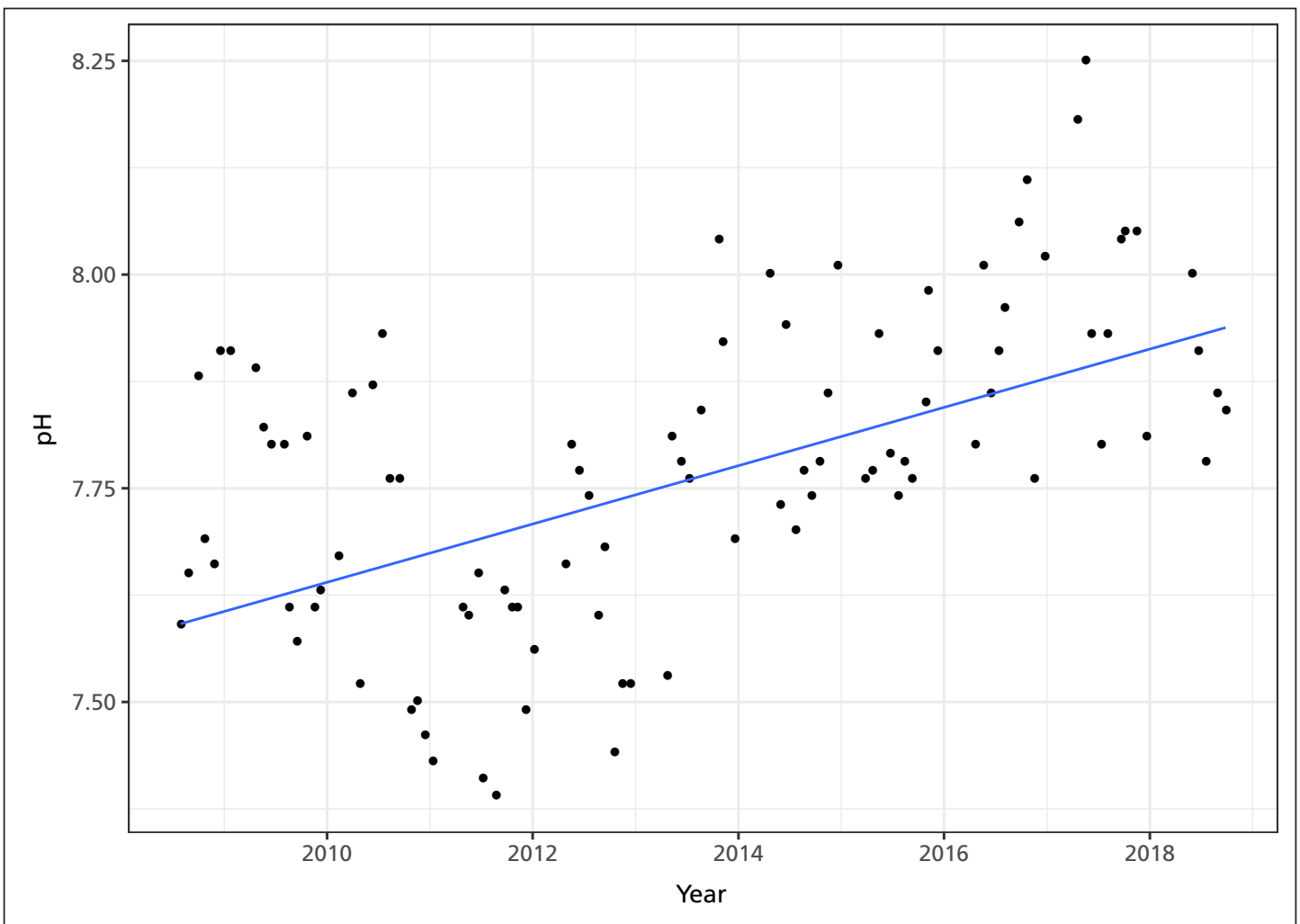

Figure 3-22. Increase in $\mathrm{pH}$ over time at Hidden Lake, with a quantile regression at the median (slope $=0.03 \mathrm{pH}$ units per year).

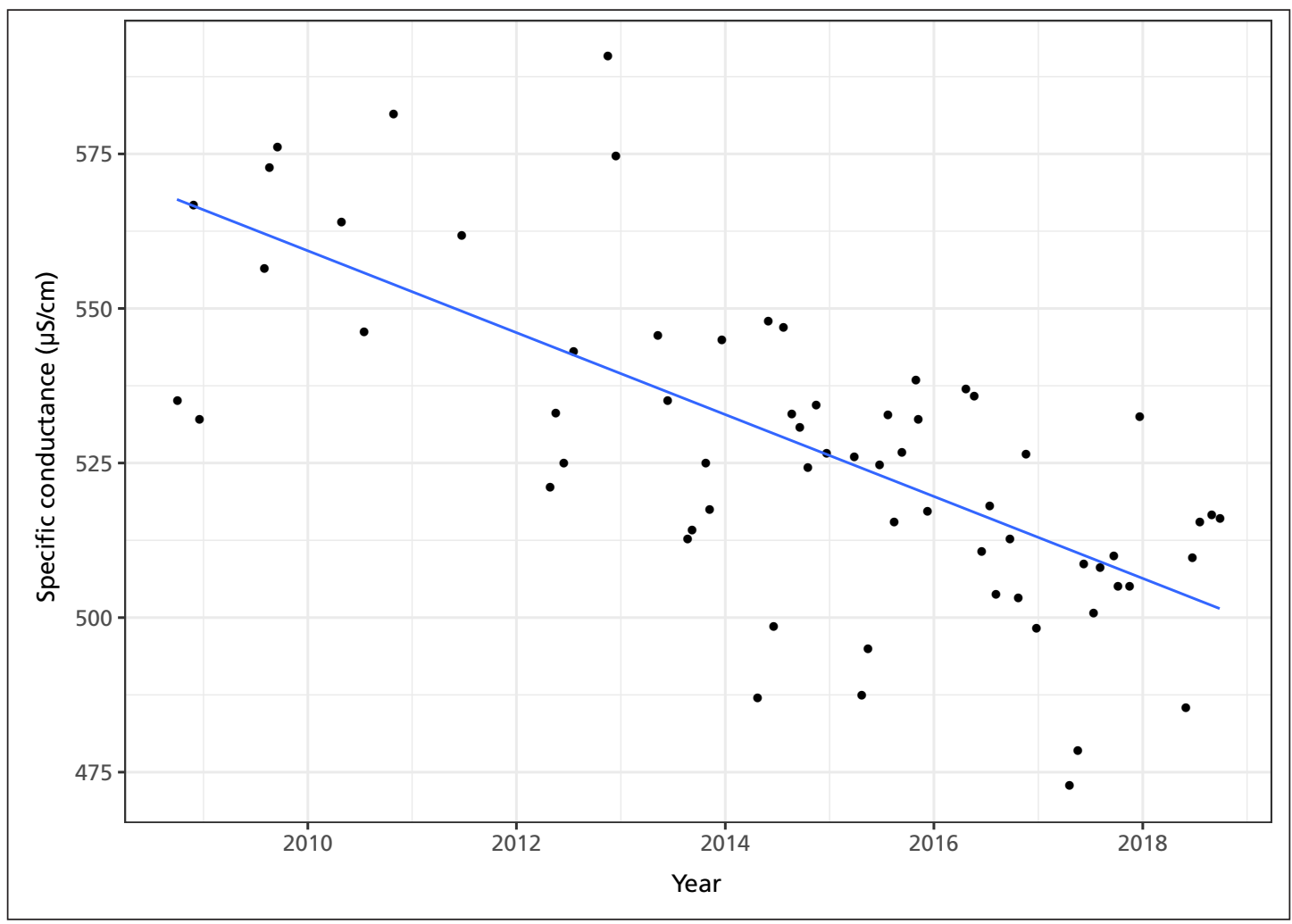

Figure 3-23. Decrease in specific conductance over time at Hidden Lake, with a quantile regression at the median (slope $=-6.6 \mu \mathrm{S} / \mathrm{cm}$ per year). 


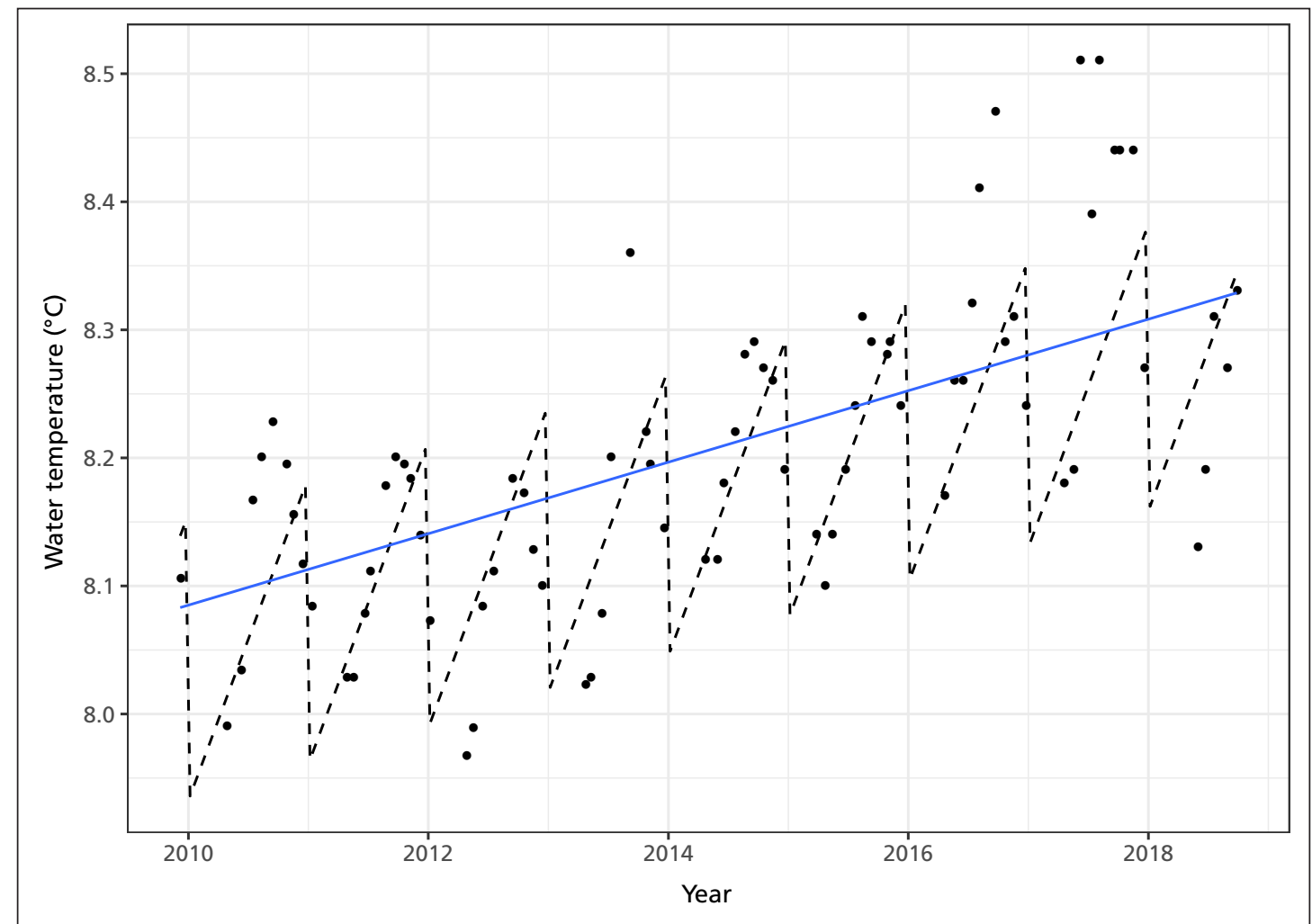

Figure 3-24. Increase in water temperature over time at Hidden Lake, with seasonality (dashed line) and a quantile regression at the median (slope $=0.03^{\circ} \mathrm{C}$ per year).

Table 3-9. Summary statistics for major ions in Hidden Lake, including the number of samples that were censored; concentrations at the 10th, 50th, and 90th percentiles; and trend results.

\begin{tabular}{lcccccccc}
\hline Parameter & Start & End & Test $^{A}$ & $\begin{array}{c}\text { Samples } \\
\text { (censored) }\end{array}$ & 10th & Median & 90th & Trend \\
\hline Alkalinity (mg/L CaCO $)$ & $7 / 30 / 2008$ & $7 / 18 / 2018$ & $\mathrm{~S}$ & $41(0)$ & 186 & 205 & 225 & down \\
\hline $\begin{array}{l}\text { Dissolved inorganic } \\
\text { carbon (mol/L) }\end{array}$ & $7 / 30 / 2008$ & $7 / 18 / 2018$ & $\mathrm{~T}$ & $41(0)$ & 0.0035 & 0.0040 & 0.0044 & down \\
\hline Calcium (d) (mg/L) & $7 / 30 / 2008$ & $7 / 18 / 2018$ & $\mathrm{~S}$ & $41(0)$ & 42.0 & 47.6 & 55.7 & down \\
\hline $\begin{array}{l}\text { Chloride (mg/L) } \\
\text { Magnesium (d) (mg/L) }\end{array}$ & $7 / 30 / 2008$ & $7 / 18 / 2018$ & $\mathrm{~T}$ & $41(0)$ & 4.54 & 4.85 & 5.60 & none \\
\hline Potassium (d) (mg/L) & $7 / 30 / 2008$ & $7 / 18 / 2018$ & $\mathrm{~S}$ & $41(0)$ & 34.9 & 38.0 & 40.5 & none \\
\hline Sodium (d) (mg/L) & $7 / 30 / 2008$ & $7 / 18 / 2018$ & $\mathrm{~T}$ & $41(0)$ & 4.20 & 4.52 & 5.04 & none \\
\hline Sulfate (mg/L) & $7 / 30 / 2008$ & $7 / 18 / 2018$ & $\mathrm{~T}$ & $40(0)$ & 61.1 & 64.0 & 66.6 & none \\
\hline $\begin{array}{l}\text { Total dissolved solids } \\
\text { (mg/L) }\end{array}$ & $7 / 30 / 2008$ & $7 / 18 / 2018$ & $\mathrm{~T}$ & $41(0)$ & 254 & 280 & 310 & down \\
\hline $\begin{array}{l}\text { Total suspended solids } \\
\text { (mg/L) }\end{array}$ & $7 / 30 / 2008$ & $7 / 18 / 2018$ & $\mathrm{NA}$ & $41(32)$ & $<4$ & $<4$ & 5.0 & - \\
\hline
\end{tabular}

${ }^{A} \mathrm{NA}=$ no analysis (>50\% censored data), $\mathrm{S}=$ time plus seasonality quantile regression, $\mathrm{T}=$ time-only quantile regression. 


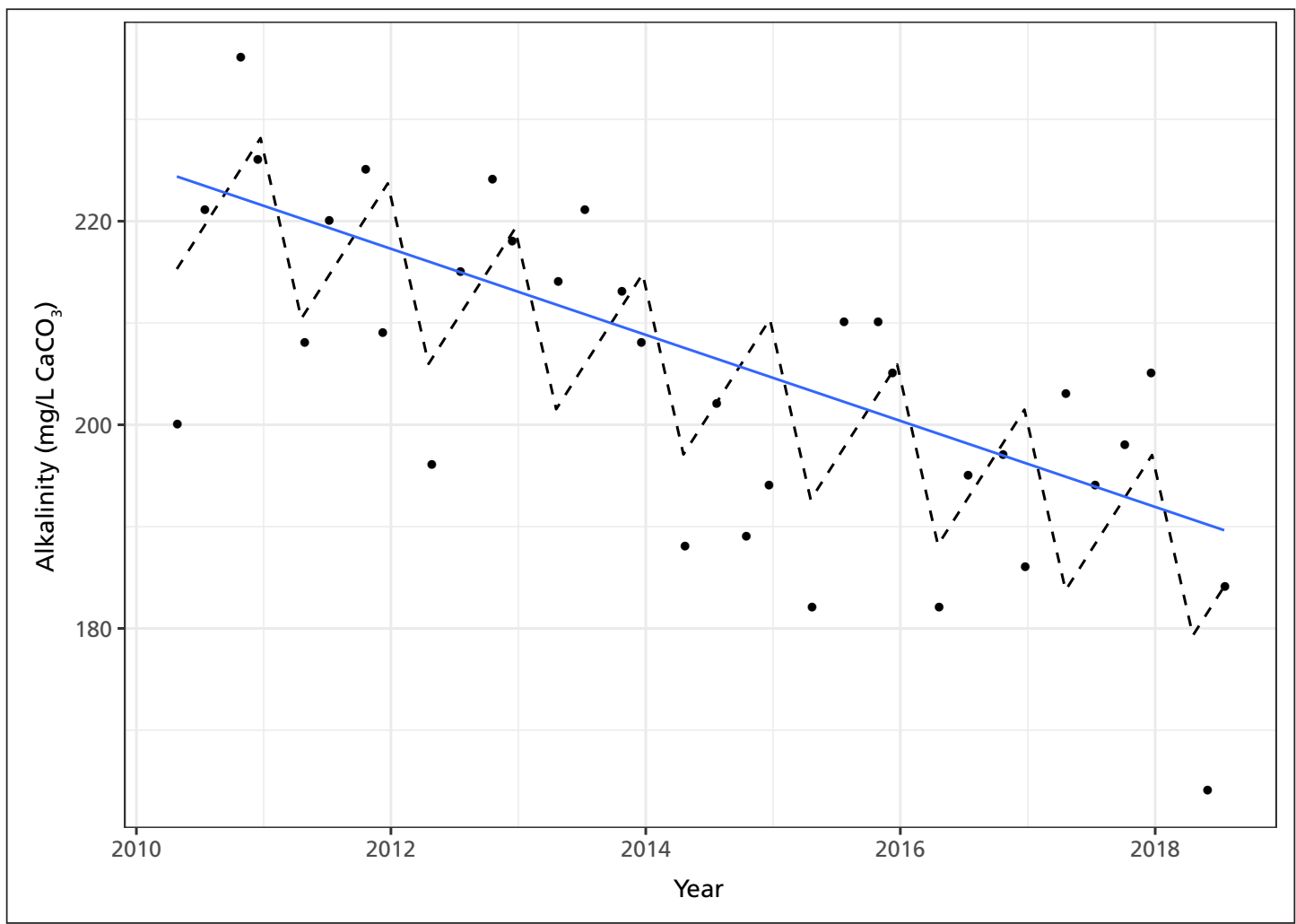

Figure 3-25. Decrease in alkalinity over time at Hidden Lake, with seasonality (dashed line) and a quantile regression at the median (slope $=-3.2 \mathrm{mg} / \mathrm{L} \mathrm{CaCO}_{3}$ per year).

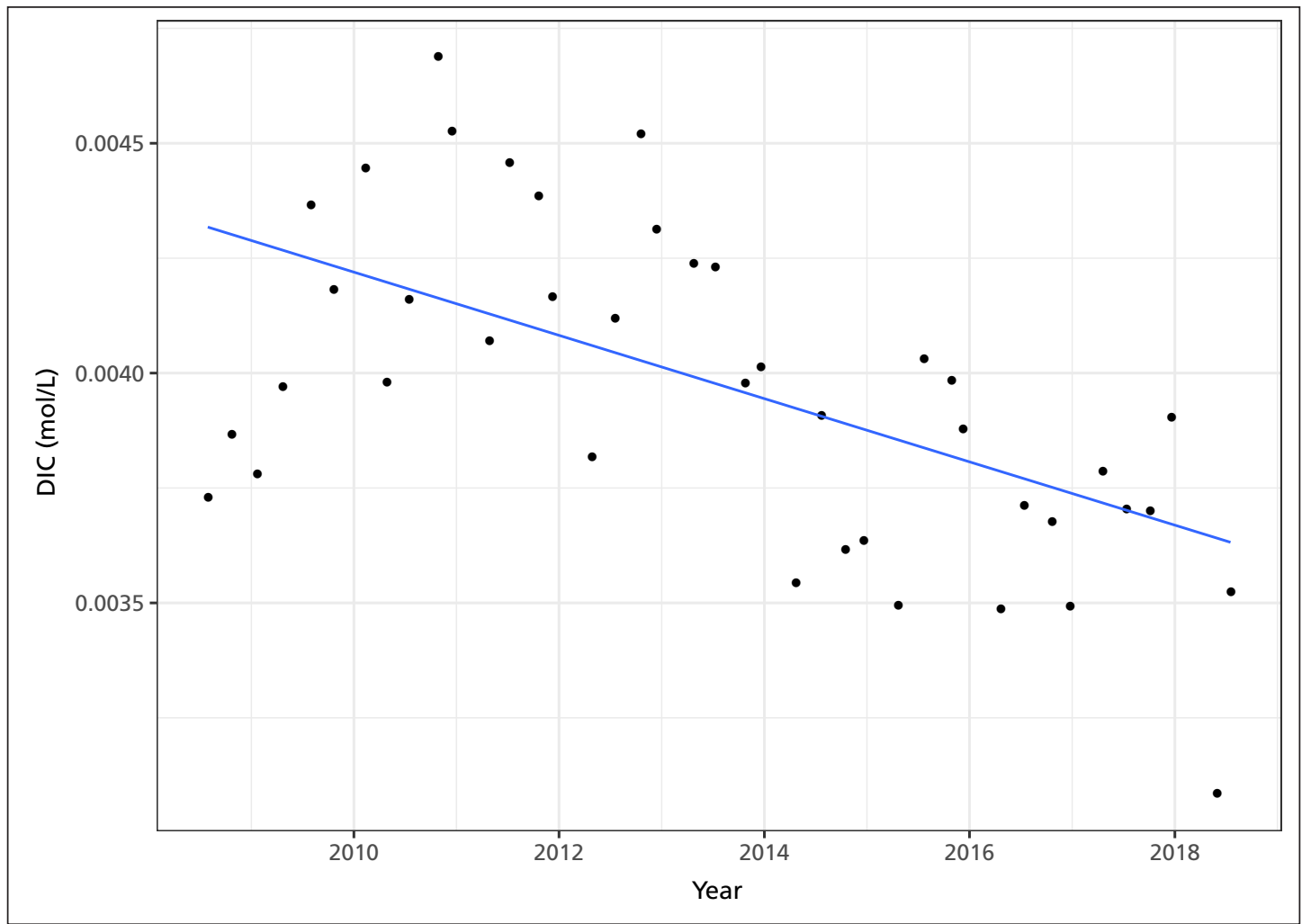

Figure 3-26. Decrease in dissolved inorganic carbon (DIC) over time at Hidden Lake, with a quantile regression at the median (slope $=-0.00007 \mathrm{~mol} / \mathrm{L}$ per year). 


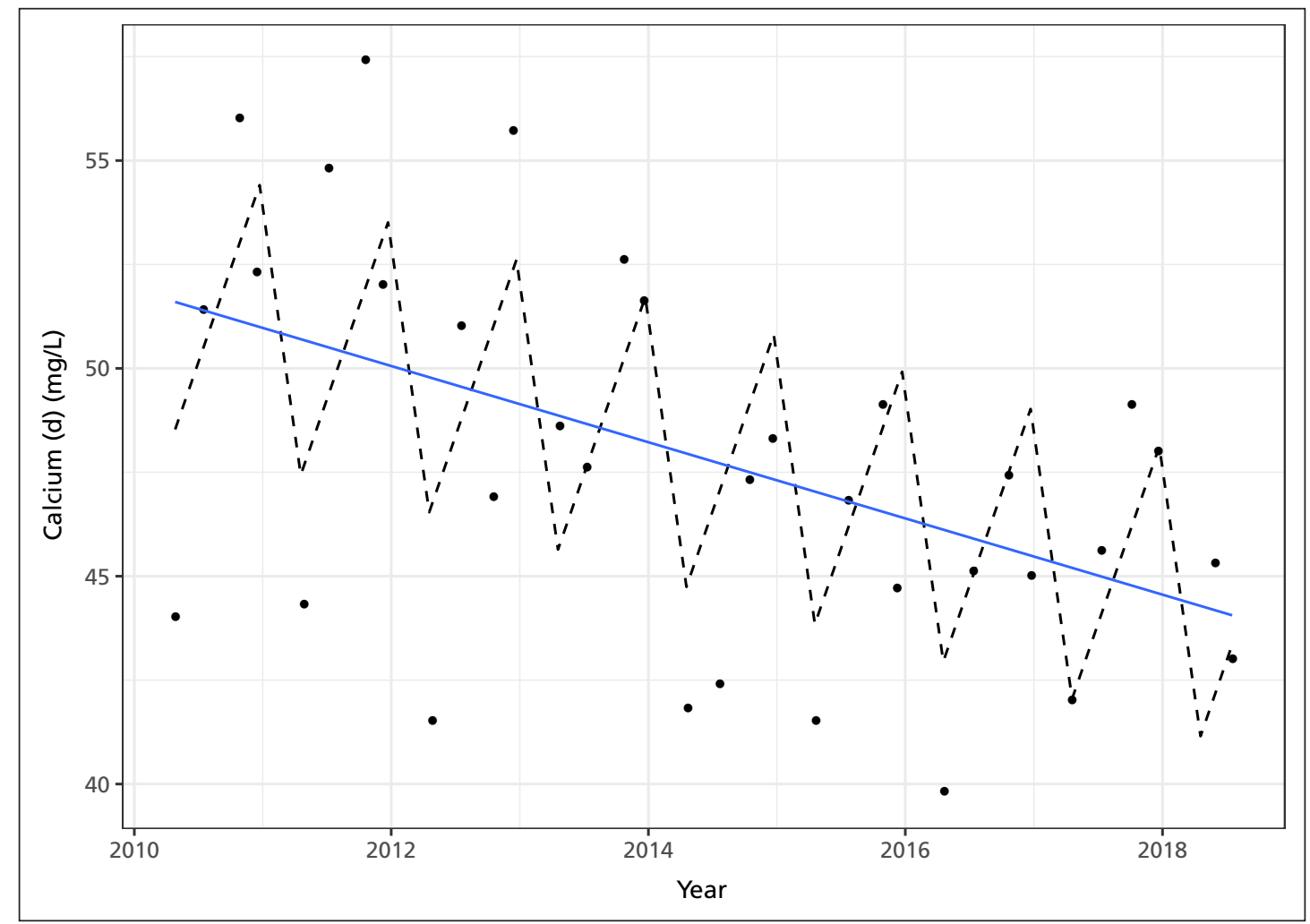

Figure 3-27. Decrease in calcium over time at Hidden Lake, with seasonality (dashed line) and a quantile regression at the median (slope $=-0.9 \mathrm{mg} / \mathrm{L}$ per year).

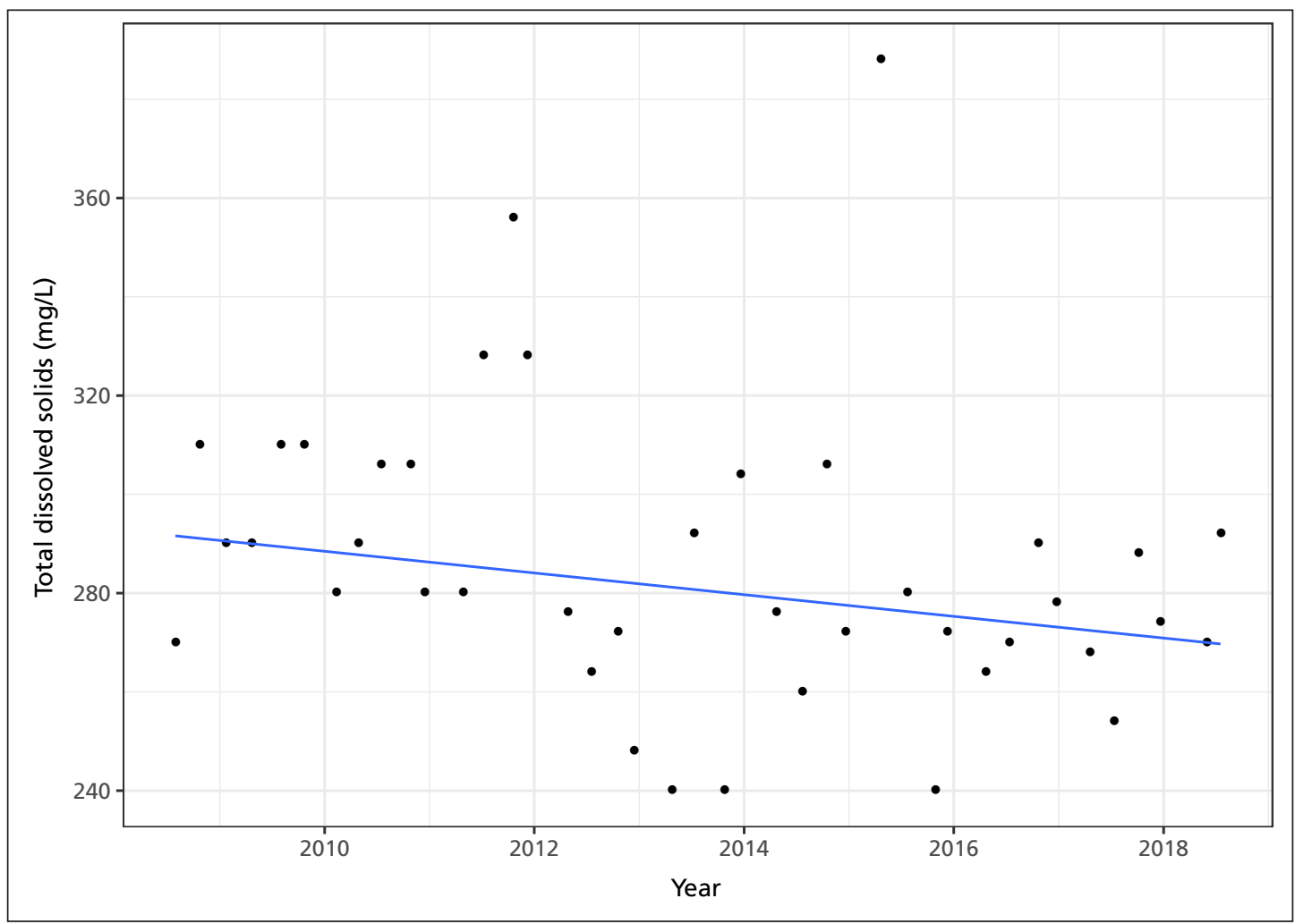

Figure 3-28. Decrease in total dissolved solids over time at Hidden Lake, with a quantile regression at the median (slope $=-2.2 \mathrm{mg} / \mathrm{L}$ per year). 
Table 3-10. Summary statistics for nutrients $(\mathrm{mg} / \mathrm{L})$ in Hidden Lake, including the number of samples that were censored; concentrations at the 10th, 50th, and 90th percentiles; and trend results.

\begin{tabular}{lcccccccc}
\hline Parameter & Start & End & Test $^{\mathrm{A}}$ & $\begin{array}{c}\text { Samples } \\
\text { (censored) }\end{array}$ & 10th & Median & 90th & Trend \\
\hline Ammonia as N (d) & $7 / 30 / 2008$ & $7 / 18 / 2018$ & NA & $40(29)$ & $<0.05$ & $<0.05$ & 0.1061 & - \\
\hline Nitrite + Nitrate as N & $7 / 30 / 2008$ & $7 / 18 / 2018$ & T & $41(0)$ & 1.45 & 1.60 & 1.77 & none \\
Nitrogen (d) & $7 / 30 / 2008$ & $7 / 18 / 2018$ & T & $41(0)$ & 1.47 & 1.70 & 2.50 & none \\
\hline Phosphate (d) & $7 / 30 / 2008$ & $5 / 30 / 2018$ & NA & $38(36)$ & $<0.1$ & $<0.1$ & $<0.1$ & - \\
\hline Phosphate & $7 / 30 / 2008$ & $7 / 18 / 2018$ & NA & $39(35)$ & $<0.05$ & $<0.05$ & 0.05 & - \\
\hline
\end{tabular}

${ }^{\mathrm{A} N A}=$ no analysis ( $>50 \%$ censored data), $\mathrm{T}=$ time-only quantile regression.

Table 3-11. Summary statistics for trace elements $(\mu \mathrm{g} / \mathrm{L})$ in Hidden Lake, including the number of samples that were censored; concentrations at the 10th, 50th, and 90th percentiles; and trend results.

\begin{tabular}{|c|c|c|c|c|c|c|c|c|}
\hline Parameter & Start & End & Test $^{A}$ & $\begin{array}{c}\text { Samples } \\
\text { (censored) }\end{array}$ & 10th & Median & 90th & Trend \\
\hline Aluminum (d) & $7 / 30 / 2008$ & $7 / 18 / 2018$ & NA & 40 (39) & $<100$ & $<100$ & $<100$ & - \\
\hline Arsenic (d) & $7 / 30 / 2008$ & $7 / 18 / 2018$ & NA & $40(23)$ & $<2$ & $<2$ & $<2$ & - \\
\hline Barium (d) & $7 / 30 / 2008$ & $7 / 18 / 2018$ & $\mathrm{~T}$ & $40(0)$ & 32.5 & 35.5 & 38.1 & none \\
\hline Boron (d) & $7 / 30 / 2008$ & $7 / 18 / 2018$ & NA & $40(40)$ & $<500$ & $<500$ & $<500$ & - \\
\hline Cadmium (d) & $7 / 30 / 2008$ & $7 / 18 / 2018$ & NA & $40(40)$ & $<0.5$ & $<0.5$ & $<0.5$ & - \\
\hline Chromium (d) & $7 / 30 / 2008$ & $7 / 18 / 2018$ & NA & $40(40)$ & $<10$ & $<10$ & $<10$ & - \\
\hline Copper (d) & $7 / 30 / 2008$ & $7 / 18 / 2018$ & $\mathrm{~T}$ & $40(0)$ & 2.80 & 4.00 & 5.69 & none \\
\hline Iron (d) & $7 / 30 / 2008$ & $7 / 18 / 2018$ & NA & $40(36)$ & $<100$ & $<100$ & $<100$ & - \\
\hline Lead $(d)$ & $7 / 30 / 2008$ & $7 / 18 / 2018$ & NA & $40(37)$ & $<2$ & $<2$ & $<2$ & - \\
\hline Manganese (d) & $7 / 30 / 2008$ & $7 / 18 / 2018$ & NA & $40(36)$ & $<2$ & $<2$ & $<2$ & - \\
\hline Mercury (d) & $7 / 30 / 2008$ & $7 / 18 / 2018$ & NA & 39 (39) & $<0.2$ & $<0.2$ & $<0.2$ & - \\
\hline Nickel (d) & $7 / 30 / 2008$ & $7 / 18 / 2018$ & $\mathrm{~T}$ & $40(0)$ & 4.28 & 5.92 & 9.75 & down \\
\hline Selenium (d) & $7 / 30 / 2008$ & $7 / 18 / 2018$ & $\mathrm{~T}$ & $40(0)$ & 3.13 & 3.62 & 4.11 & up \\
\hline Silver (d) & $7 / 30 / 2008$ & $7 / 18 / 2018$ & NA & $40(40)$ & $<2$ & $<2$ & $<2$ & - \\
\hline Zinc (d) & $7 / 30 / 2008$ & $7 / 18 / 2018$ & $\mathrm{~T}$ & $41(0)$ & 15.3 & 25.8 & 33.2 & none \\
\hline
\end{tabular}

${ }^{\mathrm{A} N A}=$ no analysis ( $>50 \%$ censored data), $\mathrm{T}=$ time-only quantile regression. 


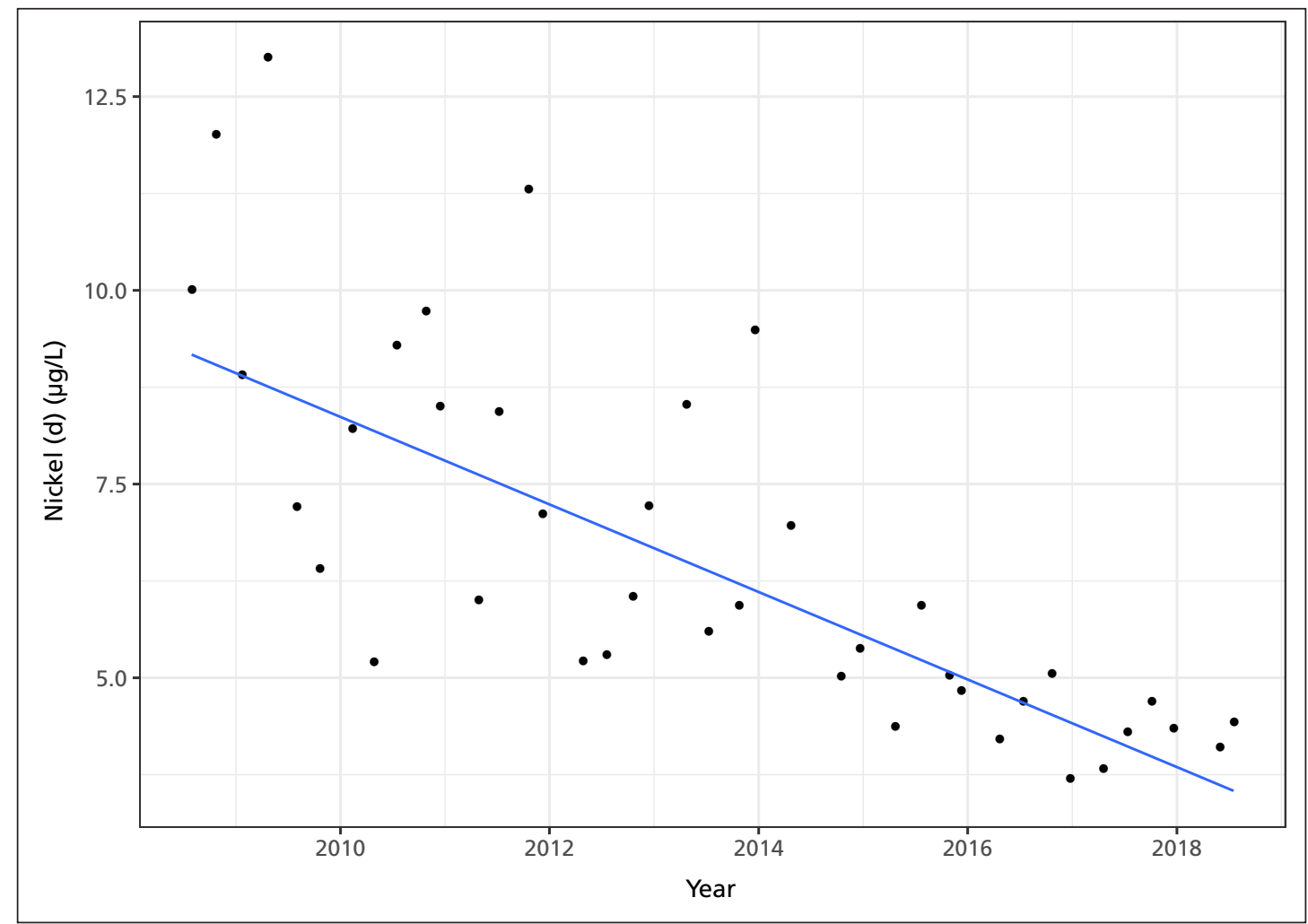

Figure 3-29. Decrease in nickel over time at Hidden Lake, with a quantile regression at the median (slope $=-0.56$ $\mu \mathrm{g} / \mathrm{L}$ per year).

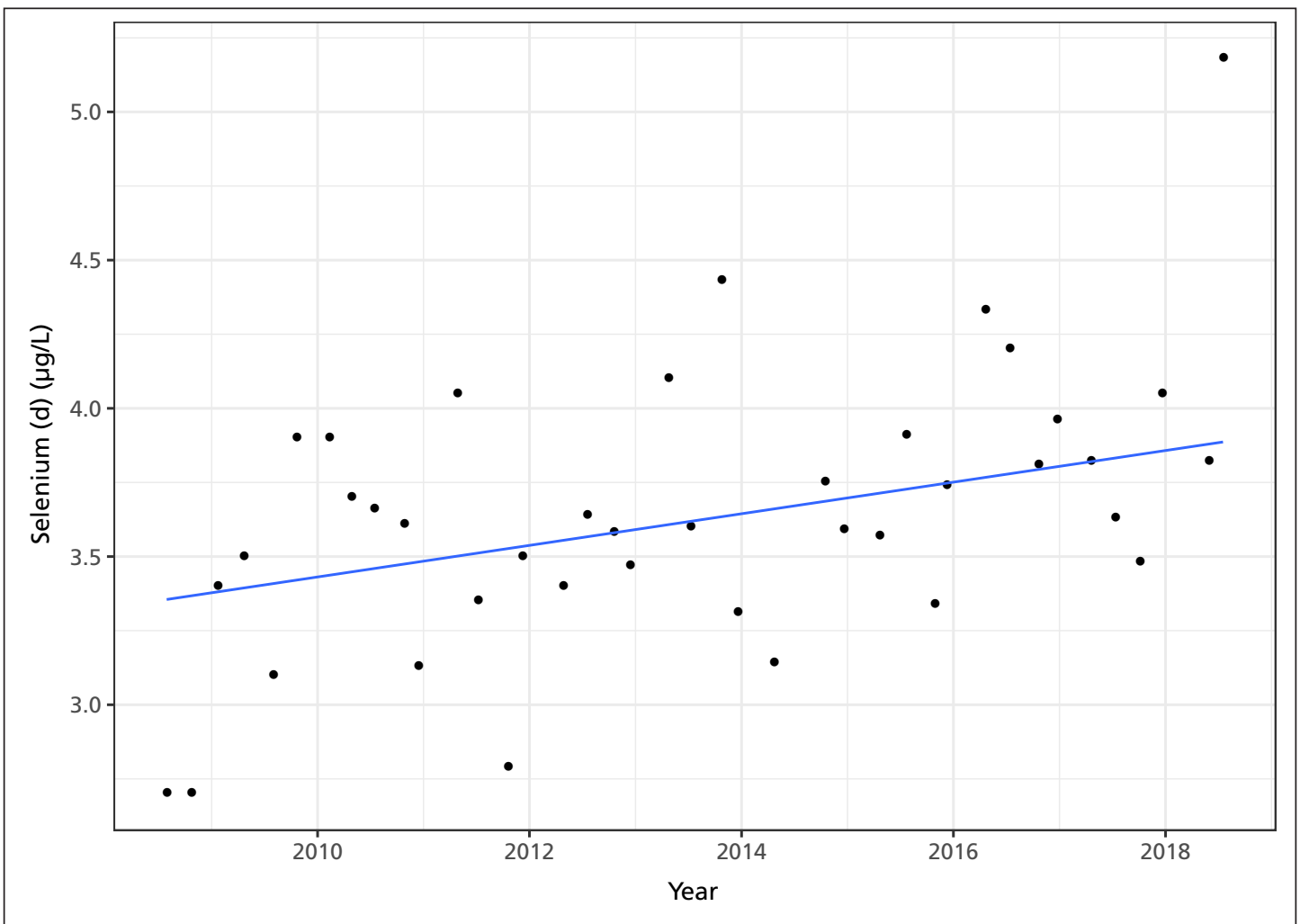

Figure 3-30. Increase in selenium over time at Hidden Lake, with a quantile regression at the median (slope $=0.05$ $\mu \mathrm{g} / \mathrm{L}$ per year). 


\section{Discussion}

\subsection{Patterns in pool levels}

As noted in a previous study, pool levels in Hansen Lake fluctuated seasonally, while seasonal fluctuations at Hidden Lake were muted or absent (Tranel et al. 1992). Anecdotally, park staff have noted that Hansen Lake rises sharply due to snowmelt, then subsides over time. In wet years, Hidden Lake rises less-and more slowly_than Hansen Lake, and continues to rise even after Hansen Lake begins to lower. Hansen Lake also receives immediate recharge throughout the year during heavy rain events, when runoff can enter the cave directly through fractures in the overlying bedrock. Hidden Lake is not fed by rapid fracture systems and is presumably recharged via the Timpanogos Fault, a fault that is about 300 meters high but only millimeters to centimeters in width. It is possible that flow from a large portion of the recharge area for Hidden Lake was influenced by cave-trail development in the 1920s.

Park staff have anecdotally noted a shift from snowmelt to rainfall-derived recharge. The seasonality of precipitation and the effects of snowfall as compared to rainfall may be important contributors to trends in quantity and quality of cave water that should be investigated further. It is also important to note that pool levels can have a muted, nonlinear relationship to recharge because a rise in pool level depends on the shape of the pool. Hansen Lake has a deeper section and then transitions to a gradual, sloping room, where changes in gage height are slower. Hidden Lake is contained in a basin with a more cylindrical profile, leading to a more stable relationship between pool level and inflow.

Interestingly, Hansen Lake's levels remained relatively stable over time despite highly variable snowpacks. Hidden Lake's pool levels had a modest statistical link to regional snowpack, as represented by April 1 SWE. Snowpack in water years 2008 and 2009 was above average, and was historically high in the Wasatch Mountains in WY2011, with cool temperatures leading to a long and slow melt (Cordova and Angeroth 2012) conditions that favor groundwater recharge. Monthly gage-height readings at Hidden Lake began in December 2009, so pool levels may have been higher than average near the beginning of the period of record. Below-average snowpack in water years 2012-2016 corresponded to a precipitous decline in pool levels at Hidden Lake from 2012 to 2015 . However, the pool level began to rebound mid-way through 2015, when snowpack was still low, suggesting pool levels are affected by more than just recharge.

In addition to gaining water from recharge, cave pools can also lose water to evaporation and outflow. For both Hansen Lake and Hidden Lake, no overflow has been observed, and any current outflow is presumed to be via seepage through a clay-sediment aquitard down through the underlying fault. Outflow is presumed to be fairly slow, constant, and stable over our period of record. The removal of water for water-quality sampling became more concerning to park staff as Hidden Lake's pool level declined in the early 2010s. A review of water-quality parameters allowed the park to reduce the analytical suite for Hidden Lake in 2015, reducing the amount of water removed during each sampling visit from about six liters to about four liters. This reduction may have contributed to the stabilization and subsequent improvement in Hidden Lake's pool level.

During the sampling period, the park also made several management changes that reduced evaporative potential within the cave. In 2013, with the implementation of a cave management plan, tour sizes were reduced and a 15-minute buffer between tours was implemented. Cave lighting was also switched from halogen to LED. Both changes may have helped stabilize the cave climate. In 2015, four new cold-storage type tunnel doors (one on each end of the two tunnels) were installed to help restore natural airflow in the cave system. The new doors provide a more effective separation of the cave climates, leading to a reduction of drying, chimney-effect wind between the caves. Since the door installations, park staff have visually noticed the caves remaining 
wetter for a longer period of time throughout the year, with persistent wet sections of trail and condensation build-up on doors. Hidden Lake is located in a notably breezy spot and historically had higher evaporation than Hansen Lake (Tranel et al. 1992). The reduction in air leakage from the new doors has likely reduced evaporation from the pool. Park staff noted a rise in Hansen Lake from 1992 to 2000, after the first tunnel doors between caves were installed. Reduced evaporation may have contributed to the rebound in Hidden Lake's pool level, which also began in June 2015.

\subsection{Patterns in water chemistry and quality}

The two cave pools at Timpanogos Cave had only one trend in common: increasing water temperature over time. Cavewater temperatures are affected by a variety of factors, but systems without a geothermal component tend to be near the annual mean surface temperature and in equilibrium with cave air temperature (Cuthbert et al. 2014). Cave pools at Timpanogos Cave NM are regularly exposed to influxes of surface air due to the opening and closing of cave doors during tour operations. As noted above, attempts to reduce atmospheric mixing within the cave system have improved stability of the cave climate, but cavewater temperatures continue to steadily increase. When compared to a 10 -year rolling mean of air-surface temperature, cavewater temperatures showed a similar increase over time (Figure 4-1). Hansen Lake's mean water temperature was lower than the mean air-surface temperature, likely indicating the cooling effect of rapid recharge. Hidden Lake is relatively close to the 10-year rolling mean. The increase in cavewater temperatures is likely linked to increasing air-surface temperatures, and is expected to continue as temperatures rise globally.

The pools also had several conflicting trends. While nearly all major ions, total dissolved solids, and specific conductance increased in Hansen Lake, specific conductance, calcium, and total dissolved solids decreased in Hidden Lake. These conflicting trends may be related to the different groundwater flow paths and residence times between the two pools. Changes in visitation management may also have affected cavewater chemistry in Hidden Lake.

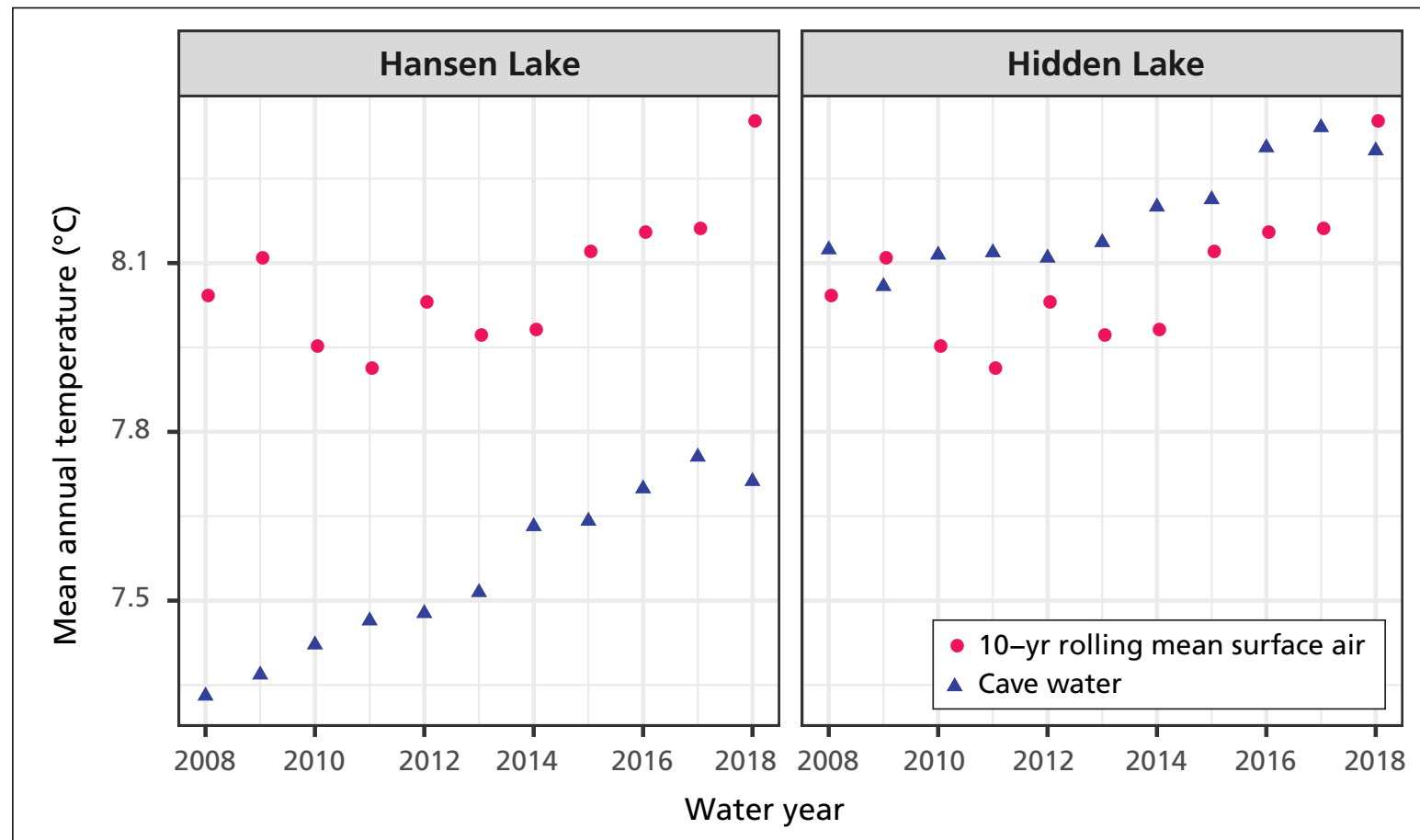

Figure 4-1. Annual mean water temperatures in two cave pools compared to the 10-year mean annual surface temperature calculated from Daymet data. 


\subsubsection{Potential drivers of change in Hansen Lake}

Due to rapid recharge, Hansen Lake may have more direct connections to surface effects in the cave watershed than Hidden Lake. There is limited ground disturbance in the presumed watershed, but regionally there are high levels of air pollution. Increases in major ions in surface water and soil, like those seen in Hansen Lake, can correspond to wind-blown dust, and dust deposition is of increasing concern across the West and on the Wasatch Front (Brahney et al. 2013; Skiles et al. 2018). Dust deposition can also increase major ions and trace elements in snow (Carling et al. 2012; Sorooshian et al. 2013), and has been shown to alter the biogeochemistry of alpine lakes (Ballantyne et al. 2011). The nearest atmospheric deposition monitoring station (NADP station UT01) is located at Logan, Utah, approximately 160 kilometers north of Timpanogos Cave NM. The station recorded increases in sulfate, nitrogen, magnesium, calcium, sodium, potassium, and chloride deposition from 2008 to 2018 (NADP 2019). Hansen Lake also had increases in many of these constituents, including sulfate, magnesium, calcium, sodium, and chloride. The role of atmospheric deposition, particularly from dust, in changing water chemistry in Hansen Lake could be investigated further.

Changes in the timing and type of precipitation could also alter the chemistry of recharge into the caves. Statewide, the proportion of precipitation falling as snow has decreased (Frankson et al. 2017), and down-scaled climate models indicate Wasatch Front snowpack will become increasingly vulnerable as temperatures rise (Scalzitti et al. 2016). Streamwater chemistry changes with fluctuations in snow and rain (Heath and Baron 2014; Foks et al. 2018), and the role of differing precipitation types in geochemistry cycling is an active topic of research. The seasonality of precipitation could also interact with seasonal patterns in atmospheric deposition (Carling et al. 2012; Sorooshian et al. 2013), leading to complex patterns in recharge chemistry.

\subsubsection{Potential drivers of change in Hidden Lake}

Because Hidden Lake is not affected by rapid recharge, evaporation would be the most straightforward explanation for trends in water chemistry and quality at this site. Evaporation concentrates solutes in less water, so concentrations should increase as pool levels go down. However, alkalinity and calcium concentrations were lower in Hidden Lake when pool-water levels were lower. Decreases in these parameters over time, as well as decreases in specific conductance and total dissolved solids, suggest that changes in water chemistry in Hidden Lake are not due to evaporative concentration of solutes.

In September 2013, some relatively abrupt changes occurred in Hidden Lake: saturation indices for calcite $\left(\mathrm{SI}_{\text {cal }}\right)$ and dolomite $\left(\mathrm{SI}_{\mathrm{dol}}\right)$ increased, while dissolved $\mathrm{CO}_{2}$ decreased. Dissolved $\mathrm{CO}_{2}$ can strongly affect cavewater chemistry, in part because it determines how much calcite can be dissolved in water. For example, a decrease in dissolved $\mathrm{CO}_{2}$ directly causes an increase in $\mathrm{pH}$. These $\mathrm{CO}_{2}$ and $\mathrm{pH}$ changes, in turn, lead to a host of cascading effects on water chemistry, causing both $\mathrm{SI}_{\text {cal }}$ and $\mathrm{SI}_{\text {dol }}$. to increase. In Hidden Lake, this scenario created a continuous environment favoring carbonate mineral precipitation, which would in turn be consistent with observed decreases in calcium, alkalinity, and total dissolved solids. It is likely that the change in dissolved $\mathrm{CO}_{2}$ drove many of the trends in water chemistry seen in Hidden Lake.

The decrease in dissolved $\mathrm{CO}_{2}$ corresponded to the implementation of a new cave management plan in May 2013. Tour sizes were reduced from 20 people to 16 , and the tour's starting interval was increased from 10 minutes to 15 minutes. These changes reduced the number of people in the cave at any one time and the total number of people visiting the cave each day. Prior to implementation, dissolved $\mathrm{CO}_{2}$ in Hidden Lake ranged from 5 to 20 times higher than atmospheric background $\mathrm{CO}_{2}$ concentra- 


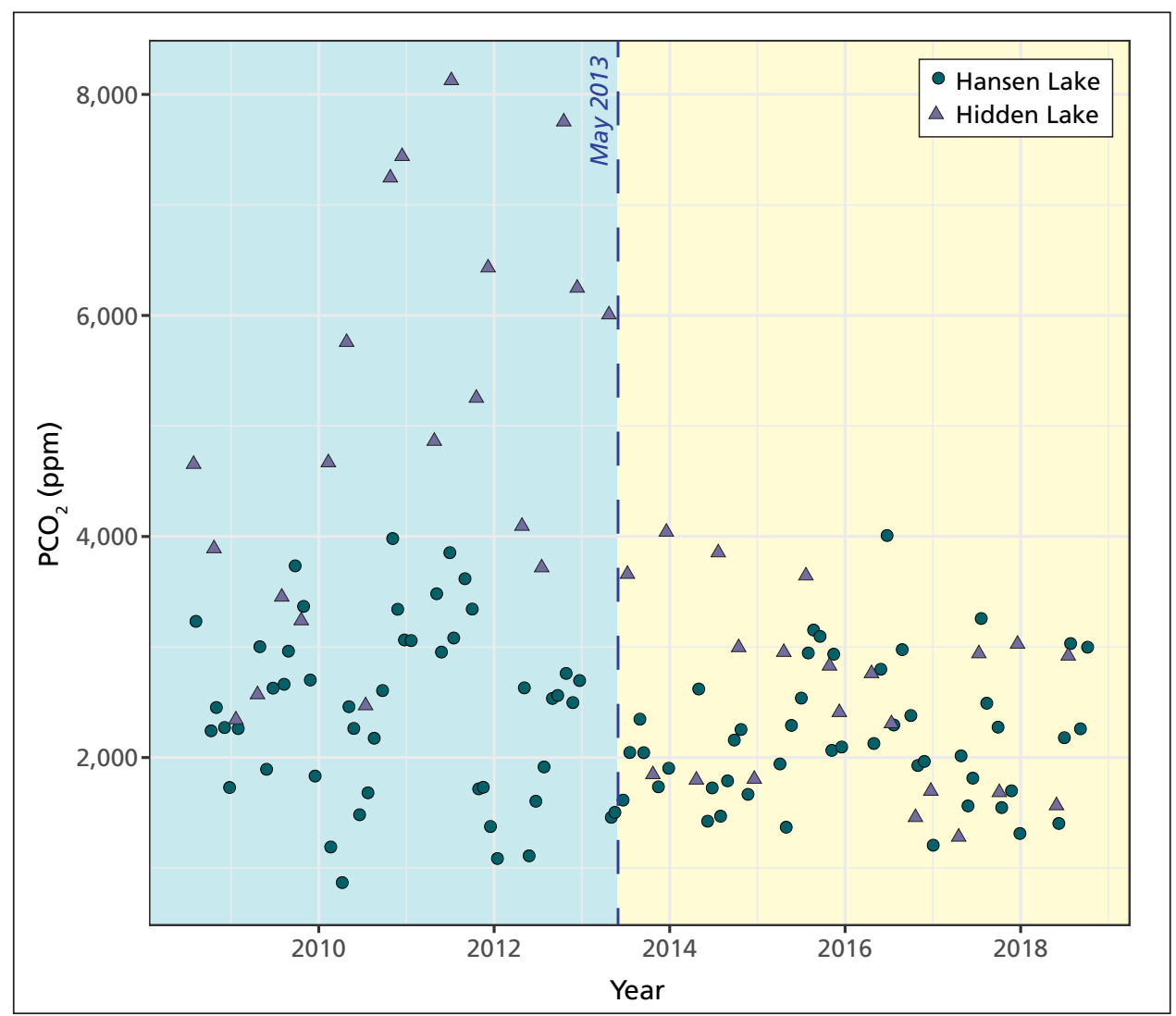

Figure 4-2. Dissolved $\mathrm{CO}_{2}$ (ppm) in Hansen and Hidden lakes over time.

tions. After implementation of the new plan, dissolved $\mathrm{CO}_{2}$ in Hidden Lake dropped to the same range as recorded in Hansen Lake, which is off the main cave tour route and is considered more representative of natural cave conditions (Figure 4-2). A concurrent change to LED lighting and the installation of a timer reduced artificial lighting conditions at Hidden Lake, which may have also reduced algal growth in the pool. (However, park staff have not noted significant algal growth before or after the cave management plan.)

It seems likely that a reduction in the number of people in the cave (and thus, a reduction in exhaled $\mathrm{CO}_{2}$ ) reduced the amount of $\mathrm{CO}_{2}$ in the cave air, causing dissolved $\mathrm{CO}_{2}$ to drop as cave waters equilibrated with the lower air concentrations of $\mathrm{CO}_{2}$. This, in turn, altered the saturation indices for Hidden Lake and led to persistent conditions favoring calcite and dolomite precipitation and speleothem formation-an important management goal in an active cave system.
Due to the COVID-19 pandemic, the caves were closed to visitation in 2020. The park now has a unique opportunity to investigate how cave $\mathrm{CO}_{2}$ levels fluctuate in the absence of visitors, and how that may affect cavewater chemistry. Park staff have increased the frequency of sampling at Hidden Lake to take advantage of this unforeseen experiment.

\subsection{Conclusions and management recommendations}

Ten years of water-quality data have revealed numerous changes in water chemistry and pool levels at two cave pools in Timpanogos Cave National Monument. As of 2018, both pools consistently had conditions that favored the precipitation of calcite and dolomite, which could lead to the continued formation of speleothems. Hansen Lake has consistently had precipitating conditions over time, while at Hidden Lake, conditions improved in 2013, after a new cave management plan was implemented. A decrease in 
the number of visitors allowed into the cave each day appears to have led to a decrease in $\mathrm{CO}_{2}$ concentrations that, in turn, promoted a shift to precipitating conditions. If true, cave management practices have the potential to affect water chemistry in a way that promotes active cave processes by reducing the buildup of visitor-based $\mathrm{CO}_{2}$ within the cave.

For Hansen Lake, trends in water chemistry mimicked trends noted in surface-water chemistry that can be caused by air pollution, and particularly by dust deposition. Up-canyon transport of pollutants and dust from the Wasatch Front urban area and beyond may contribute to changes in the cave watershed. In July 2019, park staff installed an air-quality monitoring station that will help managers understand local contaminant flows of atmospheric $\mathrm{PM}_{2.5}$. Additional research could help managers better understand how surface conditions affect the chemistry of recharge into Hansen Lake.

Another factor likely to play an important role in future cave recharge is climate change, particularly changes in the amount and timing of precipitation in the cave watershed. In May 2020, instrumentation at the Timpanogos Cave CO-OP weather station was updated with new sensors and an internet connection for real-time reporting. The data are now reported as MesoWest Lone Peak-Timpanogos Cave. These improvements should help minimize future gaps in weather data to better track the influence of climate change on the cave system.

Additional investigation of several key issues would improve understanding of the cave system and how it is affected by its surroundings. Questions include:

1. What are the surface watersheds for each cave, and how do different flow patterns affect Hansen and Hidden lakes?

2. Does atmospheric deposition affect the chemistry of cavewater recharge?

3. Are there differential effects of snowfall and rainfall in cavewater recharge and in the water chemistry of that recharge?

4. Is there an interaction between precipitation and air pollution, and does it affect cavewater chemistry?

5. How do changes in visitation patterns affect cavewater quality?

Long-term cavewater monitoring is not well represented in the body of scientific literature on caves. The ten-year record at Timpanogos Cave NM shows the value of such monitoring by revealing unanticipated trends in cavewater quality. These trends hint at important changes in the cave watershed and cave system, suggesting that cavewater quality is an important indicator of the health of cave resources at the park. 



\section{Literature Cited}

Ballantyne, A. P., J. Brahney, D. Fernandez, C. Lawrence, J. Saros, and J. C. Neff. 2011. Biogeochemical response of alpine lakes to a recent increase in dust deposition in the Southwestern US. Biogeosciences 8:2689.

Brahney, J., A. P. Ballantyne, C. Sievers, and J. C. Neff. 2013. Increasing Ca2+ deposition in the western US: The role of mineral aerosols. Aeolian Research 10:77-87.

Burnham, K. P., and D. R. Anderson. 2002. Model selection and multimodel inference: a practical information theoretic approach, Second edition. Springer, New York, New York, USA.

Busenberg, E., and N. Plummer. 1982. The kinetics of dissolution of dolomite in $\mathrm{CO}_{2}-\mathrm{H}_{2} \mathrm{O}$ systems at 1.5 to $65^{\circ} \mathrm{C}$ and 0 to $1 \mathrm{~atm} \mathrm{PCO}_{2}$. American Journal of Science 282(1):45-78.

Cade, B. S. 2017. Quantile regression applications in ecology and the environmental sciences. Pages 429-454 in R. Koenker and others, eds., Handbooks of modern statistical methods: Handbook of quantile regression. New York: CRC Press.

Cade, B. S., and B. R. Noon. 2003. A gentle introduction to quantile regression for ecologists. Frontiers in Ecology and the Environment 1(8):412-420.

Carling, G. T., D. P. Fernandez, and W. P. Johnson. 2012. Dust-mediated loading of trace and major elements to Wasatch mountain snowpack. Science of the Total Environment 432:65-77.

Cordova, J. T., and C. E. Angeroth. 2012. Runoff conditions in Utah for water year 2011: U.S. Geological Survey Fact Sheet 2012-3041.

Cuthbert, M. O., G. C. Rau, M. S. Anderson, H. Roshan, H. Rutlidge, C. E. Marjo, M. Markowska, C. N. Jex, P. W. Graham, G. Mariethoz, R. I. Acworth, and A. Baker. 2014. Evaporative cooling of speleothem drip water. Scientific Reports 4:5162.
Dreybrodt, W., L. Eisenlohr, B. Madry, and S. Ringer. 1997. Precipitation kinetics of calcite in the system $\mathrm{CaCO}_{3}-\mathrm{H}_{2} \mathrm{O}-\mathrm{CO}_{2}$ : The conversion to $\mathrm{CO}_{2}$ by the slow process $\mathrm{H}^{+}+\mathrm{HCO}_{3}{ }^{-} \Leftrightarrow \mathrm{CO}_{2}+\mathrm{H}_{2} \mathrm{O}$ as a rate limiting step. Geochimica et Cosmochimica Acta 61(18):3897-3904.

Florea, L. J., C. R. Dugan, and C. McKinney. 2013. Preliminary summary of water resource investigations during 2012 at Timpanogos Cave National Monument, Utah. Pages 39-45 in Proceedings of the $20^{\text {th }}$ National Cave and Karst Management Symposium, October 3-7, 2011, Midway, Utah. http://nckms.org/wpcontent/uploads/2018/05/2011NCKMS Proceedings_sm.pdf.

Foks, S. S., E. G. Stets, K. Singha, and D. W. Clow. 2018. Influence of climate on alpine stream chemistry and water sources. Hydrological Processes 2018:1-16.

Frankson, R., K. Kunkel, L. Stevens, and D. Easterling. 2017. Utah state climate summary. NOAA Technical Report NESDIS 149-UT.

Hackbarth, C., and R. Weissinger. 2013. Water quality in the Northern Colorado Plateau Network: Water years 2010-2012. Natural Resource Technical Report NPS/NCPN/NRTR-2013/831. National Park Service, Fort Collins, Colorado.

Hackbarth, C., and R. Weissinger. 2016. Water quality in the Northern Colorado Plateau Network: Water years 20132015. Natural Resource Report NPS/ NCPN/NRR - 2016/1332. National Park Service, Fort Collins, Colorado.

Hackbarth, C., and R. Weissinger. 2020. Water quality in the Northern Colorado Plateau Network: Water years 20162018. Natural Resource Report NPS/ NCPN/NRR - 2020/2150. National Park Service, Fort Collins, Colorado.

Harned, H. S., and B. B. Owen. 1958. The physical chemistry of electrolytic solutions. New York: Reinhold Publishing Corporation. 
Heath, J., and J. S. Baron. 2014. Climate, not atmospheric deposition, drives the biogeochemical mass-balance of a mountain watershed. Aquatic Geochemistry 20:167-181.

Herman, J. S., and M. M. Lorah. 1988. Calcite precipitation rates in the field: Measurement and prediction for a travertine-depositing stream. Geochimica et Cosmochimica Acta 52(10):2347-2355.

Herron, D. A. 1997. Origin and geologic history of the Timpanogos Cave system, Timpanogos Cave National Monument, Utah County, Utah. MS thesis. Brigham Young University, Provo, Utah.

Keeling, C. D., S. C. Piper, R. B. Bacastow, M. Wahlen, T. P. Whorf, M. Heimann, and H. A. Meijer. 2001. Exchanges of atmospheric $\mathrm{CO}_{2}$ and ${ }^{13} \mathrm{CO}_{2}$ with the terrestrial biosphere and oceans from 1978 to 2000. I. Global aspects, SIO Reference Series, No. 01-06, Scripps Institution of Oceanography.

Koenker, R. 2018. quantreg: Quantile regression. R package version 5.36. https:// CRAN.R-project.org/package $=$ quantreg.

Koenker, R., and G. Bassett. 1978. Regression quantiles. Econometrica 46:33-50.

Langmuir, D. 1971. The geochemistry of some carbonate ground waters in central Pennsylvania. Geochimica et Cosmochimica Acta 35(10):1023-1045.

Mallia, D. V., J. C. Lin, S. Urbanski, J. Ehleringer, and T. Nehrkorn, 2015. Impacts of upwind wildfire emissions on $\mathrm{CO}, \mathrm{CO}_{2}$, and $\mathrm{PM}_{2.5}$ concentrations in Salt Lake City, Utah. Journal of Geophysical Research: Atmospheres 120(1):147-166.

National Atmospheric Deposition Program (NADP). 2019. http://nadp.slh. wisc.edu/data/ntn/plots/ntntrends. html?siteID=UT01, accessed October 9 .

Nehrkorn, T., J. Henderson, M. Leidner, M. Mountain, J. Eluszkiewicz, K. McKain, and S. Wofsy. 2013. WRF simulations of the urban circulation in the Salt Lake City area for $\mathrm{CO}_{2}$ modeling. Journal of Applied Meteorology and Climatology 52(2):323-340.
Palmer, A. N. 2007. Cave geology. Dayton, Ohio: Cave Books.

Portnoy, S. 2003. Censored quantile regression. Journal of the American Statistical Association 98:1001-1012.

R Core Team. 2018. R: A language and environment for statistical computing. R Foundation for Statistical Computing, Vienna, Austria. http://www.R-project. org/.

Rogers, W. H. 1992. sg11: Quantile regression standard errors. Stata Technical Bulletin 9:16-19.

Scalzitti, J., C. Strong, and A. Kochanski. 2016. Climate change impact on the roles of temperature and precipitation in western U.S. snowpack variability. Geophysical Research Letters 43:5361-5369.

Schertz, T. L, R. B. Alexander, and D. J. Ohe. 1991. The computer program ESTimateTREND (ESTREND), a system for the detection of trends in water quality data. U.S. Geological Survey Water Resources Investigations 91-4040.

Scripps Institute of Oceanography (SIO). 2020. The Keeling curve. Available at https://scripps.ucsd.edu/programs/keelingcurve/. Accessed June 20, 2020.

Skiles, S. M., D. V. Mallia, A. G. Hallar, J. C. Lin, A. Lambert, R. Petersen, and S. Clark. 2018. Implications of a shrinking Great Salt Lake for dust on snow deposition in the Wasatch Mountains, UT, as informed by a source to sink case study from the 13-14 April 2017 dust event. Environmental Research Letters 13:124031.

Sorooshian, S., T. Shingler, A. Harpold, C. W. Feagles, T. Meixner, and P. D. Brooks. 2013. Aerosol and precipitation chemistry in the southwestern United States: Spatiotemporal trends and interrelationships. Atmospheric Chemistry and Physics 13:7361-7379.

Stumm, W., and J. J. Morgan. 1970. Aquatic chemistry; an introduction emphasizing chemical equilibria in natural waters. New York: Wiley-Interscience. 
Thoma, D., H. Thomas, D. Sharrow, K. Wynn, J. Brown, and M. Beer. 2017. Water quality vital signs monitoring protocol for park units in the Northern Colorado Plateau Network: Version 1.03. Natural Resource Report NPS/ NCPN/NRR-2017/1499. National Park Service, Fort Collins, Colorado.

Thornberry-Ehrlich, T. 2006. Timpanogos Cave National Monument geologic resource evaluation report. Natural Resource Report NPS/NRPC/GRD/ NRR-2006/013. National Park Service, Denver, Colorado.

Thornton, P. E., M. M. Thornton, B. W. Mayer, Y. Wei, R. Devarakonda, R. S. Vose, and R. B. Cook. 2018. Daymet: Daily surface weather data on a 1-km grid for North America, version 3. Oak Ridge National Laboratory Distributed Active Archive Center, Oak Ridge, Tennessee. https://doi.org/10.3334/ ORNLDAAC/1328.

Tranel, M. J., A. L. Mayo, and T. J. Jensen. 1992. Preliminary investigation of the hydrogeology and hydrogeochemistry at Timpanogos Cave National Monument, Utah, and its implications for cave management. Pages 164-178 in Proceedings from the 1991 National Cave Management Symposium. American Cave Conservation Association, Horse Cave, Kentucky.
Van Grinsven, M., D. Thoma, M. Malick, and M. Moran. 2010. Water quality in the Northern Colorado Plateau Network, 2006-2009. Natural Resource Technical Report NPS/NCPN/NRTR2010/358. National Park Service, Fort Collins, Colorado.

Weissinger, R. 2016. Evaluation of qualitycontrol data and quality assurance for routine water quality monitoring: Bryce Canyon, Capitol Reef, and Zion national parks, water years 2006-2013. Natural Resource Report. NPS/NCPN/NRR2016/1154. National Park Service. Fort Collins, Colorado

Weissinger, R., B. Blackwell, K. Keteles, W. Battaglin, and P. Bradley. 2018. Bioactive contaminants of emerging concern in national park waters of the northern Colorado Plateau, USA. Science of the Total Environment 636:910-918.

White, W. B., and J. J. Van Gundy. 1974. Reconnaissance geology of Timpanogos Cave, Wasatch County, Utah. The National Speleological Society Bulletin 36:5-17.

White, W. B. 1988. Geomorphology and hydrology of karst terrains. New York: Oxford University Press. 



\section{Appendix A: Analytical Methods and Reporting Limits}

Table A-1. Analytical methods and reporting limits for water-quality parameters analyzed at the Utah Public Health Laboratory for Hansen Lake.

\begin{tabular}{|c|c|c|c|c|c|c|}
\hline Parameter & Category & $\begin{array}{l}\text { Analytical } \\
\text { method }\end{array}$ & Start date & End date & $\begin{array}{l}\text { Highest } \\
\text { reporting } \\
\text { limit }^{\mathrm{A}}\end{array}$ & Samples \\
\hline Alkalinity $(\mathrm{mg} / \mathrm{L} \mathrm{CaCO})$ & Major ions & 2320 & $7 / 29 / 2008$ & $9 / 27 / 2018$ & NR & 96 \\
\hline Calcium (d) (mg/L) & Major ions & $200.7(W)$ & $7 / 29 / 2008$ & $9 / 21 / 2016$ & NR & 80 \\
\hline Calcium (d) (mg/L) & Major ions & $200.8(W)$ & $10 / 20 / 2016$ & $9 / 27 / 2018$ & NR & 17 \\
\hline Chloride (mg/L) & Major ions & 325.2 & $8 / 23 / 2011$ & 9/27/2018 & NR & 64 \\
\hline Magnesium (d) (mg/L) & Major ions & $200.7(W)$ & $7 / 29 / 2008$ & $9 / 21 / 2016$ & NR & 79 \\
\hline Magnesium (d) (mg/L) & Major ions & $200.8(W)$ & $10 / 20 / 2016$ & $9 / 27 / 2018$ & NR & 17 \\
\hline Potassium (d) (mg/L) & Major ions & $200.7(W)$ & $7 / 29 / 2008$ & $9 / 21 / 2016$ & 1 & 79 \\
\hline Potassium (d) (mg/L) & Major ions & $200.8(\mathrm{~W})$ & $10 / 20 / 2016$ & $9 / 27 / 2018$ & 1 & 17 \\
\hline Sodium (d) (mg/L) & Major ions & $200.7(W)$ & $7 / 29 / 2008$ & $9 / 21 / 2016$ & NR & 79 \\
\hline Sodium (d) (mg/L) & Major ions & $200.8(W)$ & $10 / 20 / 2016$ & $9 / 27 / 2018$ & NR & 17 \\
\hline Sulfate (mg/L) & Major ions & 375.2 & $7 / 29 / 2008$ & $9 / 27 / 2018$ & 20 & 97 \\
\hline Total dissolved solids (mg/L) & Major ions & $2540-C$ & $7 / 29 / 2008$ & $6 / 14 / 2016$ & NR & 76 \\
\hline Total dissolved solids (mg/L) & Major ions & 160.1 & $7 / 12 / 2016$ & $9 / 27 / 2018$ & NR & 20 \\
\hline Ammonia as $\mathrm{N}(\mathrm{mg} / \mathrm{L})$ & Nutrients & 350.1 & $7 / 29 / 2008$ & 9/27/2018 & 0.05 & 97 \\
\hline Nitrite + Nitrate as N (d) (mg/L) & Nutrients & 353.2 & $7 / 29 / 2008$ & $9 / 27 / 2018$ & NR & 95 \\
\hline Nitrogen $(\mathrm{d})(\mathrm{mg} / \mathrm{L})$ & Nutrients & $4500-\mathrm{N}-\mathrm{C}$ & $7 / 29 / 2008$ & $9 / 27 / 2018$ & NR & 94 \\
\hline Phosphorus as $\mathrm{P}(\mathrm{d})(\mathrm{mg} / \mathrm{L})$ & Nutrients & 365.1 & $11 / 7 / 2011$ & $9 / 27 / 2018$ & 0.003 & 52 \\
\hline Total Phosphorus as P (mg/L) & Nutrients & 365.1 & $11 / 7 / 2011$ & 9/27/2018 & 0.003 & 51 \\
\hline Aluminum $(d)(\mu g / L)$ & Trace elements & $200.8(W)$ & $7 / 29 / 2008$ & $7 / 18 / 2018$ & 10 & 37 \\
\hline Arsenic (d) ( $\mu \mathrm{g} / \mathrm{L})$ & Trace elements & $200.8(W)$ & $7 / 29 / 2008$ & $7 / 18 / 2018$ & 1 & 37 \\
\hline Barium $(d)(\mu g / L)$ & Trace elements & $200.8(W)$ & $7 / 29 / 2008$ & $7 / 18 / 2018$ & 100 & 37 \\
\hline Boron $(d)(\mu g / L)$ & Trace elements & $200.7(W)$ & $7 / 29 / 2008$ & $9 / 21 / 2016$ & 30 & 33 \\
\hline Boron $(d)(\mu g / L)$ & Trace elements & $200.8(W)$ & $10 / 20 / 2016$ & $7 / 18 / 2018$ & 30 & 9 \\
\hline Cadmium (d) ( $\mu \mathrm{g} / \mathrm{L})$ & Trace elements & $200.8(\mathrm{~W})$ & $7 / 29 / 2008$ & $7 / 18 / 2018$ & 0.1 & 37 \\
\hline Chromium (d) ( $\mu \mathrm{g} / \mathrm{L})$ & Trace elements & $200.8(W)$ & $7 / 29 / 2008$ & $7 / 18 / 2018$ & 2 & 37 \\
\hline Copper $(d)(\mu g / L)$ & Trace elements & $200.8(W)$ & $7 / 29 / 2008$ & $7 / 18 / 2018$ & 1 & 36 \\
\hline Iron $(d)(\mu g / L)$ & Trace elements & $200.7(W)$ & $7 / 29 / 2008$ & $9 / 21 / 2016$ & 20 & 32 \\
\hline Iron $(d)(\mu g / L)$ & Trace elements & $200.8(W)$ & $10 / 20 / 2016$ & $7 / 18 / 2018$ & 30 & 10 \\
\hline Lead $(d)(\mu g / L)$ & Trace elements & $200.8(W)$ & $7 / 29 / 2008$ & $7 / 18 / 2018$ & 0.1 & 36 \\
\hline Manganese (d) ( $\mu \mathrm{g} / \mathrm{L})$ & Trace elements & $200.8(W)$ & $7 / 29 / 2008$ & $7 / 18 / 2018$ & 5 & 36 \\
\hline Mercury (d) ( $\mu \mathrm{g} / \mathrm{L})$ & Trace elements & 245.1 & $7 / 29 / 2008$ & $7 / 18 / 2018$ & 0.2 & 37 \\
\hline Nickel (d) $(\mu \mathrm{g} / \mathrm{L})$ & Trace elements & $200.8(W)$ & $7 / 29 / 2008$ & $7 / 18 / 2018$ & 5 & 36 \\
\hline Silver $(d)(\mu g / L)$ & Trace elements & $200.8(W)$ & $7 / 29 / 2008$ & $7 / 18 / 2018$ & 0.5 & 37 \\
\hline Zinc (d) ( $\mu \mathrm{g} / \mathrm{L})$ & Trace elements & $200.8(W)$ & $7 / 29 / 2008$ & $7 / 18 / 2018$ & 10 & 36 \\
\hline
\end{tabular}

${ }^{\mathrm{A} N R}=$ Not Reported (all results detected and quantified). 
Table A-2. Analytical methods and reporting limits for water-quality parameters analyzed at the American West Analytical Laboratory for Hidden Lake.

\begin{tabular}{|c|c|c|c|c|c|c|}
\hline Parameter & Category & $\begin{array}{l}\text { Analytical } \\
\text { method }\end{array}$ & Start date & End date & $\begin{array}{l}\text { Highest } \\
\text { reporting } \\
\text { limit }\end{array}$ & Samples \\
\hline Alkalinity $\left(\mathrm{mg} / \mathrm{L} \mathrm{CaCO}_{3}\right)$ & Major ions & 2320 & $7 / 30 / 2008$ & $7 / 18 / 2018$ & 20 & 41 \\
\hline Calcium (d) (mg/L) & Major ions & $200.7(\mathrm{~W})$ & $7 / 30 / 2008$ & $7 / 18 / 2018$ & 10 & 41 \\
\hline Chloride (mg/L) & Major ions & $300(A)$ & $7 / 30 / 2008$ & $7 / 18 / 2018$ & 1 & 41 \\
\hline Magnesium (d) (mg/L) & Major ions & $200.7(\mathrm{~W})$ & $7 / 30 / 2008$ & $7 / 18 / 2018$ & 10 & 41 \\
\hline Potassium (d) (mg/L) & Major ions & $200.7(W)$ & $7 / 30 / 2008$ & $7 / 18 / 2018$ & 1 & 41 \\
\hline Sodium (d) (mg/L) & Major ions & $200.7(W)$ & $7 / 30 / 2008$ & $7 / 18 / 2018$ & 1 & 41 \\
\hline Sulfate (mg/L) & Major ions & $300(A)$ & $7 / 30 / 2008$ & $7 / 18 / 2018$ & 15 & 40 \\
\hline Total dissolved solids (mg/L) & Major ions & $2540-C$ & $7 / 30 / 2008$ & $7 / 18 / 2018$ & 20 & 41 \\
\hline Total suspended solids (mg/L) & Major ions & 2540-D & $7 / 30 / 2008$ & $7 / 18 / 2018$ & 4 & 41 \\
\hline Ammonia as $\mathrm{N}(\mathrm{d})$ (mg/L) & Nutrients & 350.1 & $7 / 30 / 2008$ & $7 / 18 / 2018$ & 0.05 & 40 \\
\hline Nitrite + Nitrate as $\mathrm{N}(\mathrm{mg} / \mathrm{L})$ & Nutrients & 353.2 & $7 / 30 / 2008$ & $7 / 18 / 2018$ & 0.1 & 41 \\
\hline Nitrogen (d) (mg/L) & Nutrients & AWAL_TOTAL_N & $7 / 30 / 2008$ & $7 / 18 / 2018$ & 1 & 41 \\
\hline Phosphate (d) (mg/L) & Nutrients & 4500-P-F & $7 / 30 / 2008$ & $5 / 30 / 2018$ & 0.1 & 38 \\
\hline Phosphate (mg/L) & Nutrients & 4500-P-F & $7 / 30 / 2008$ & $7 / 18 / 2018$ & 0.05 & 39 \\
\hline Aluminum $(d)(\mu g / L)$ & Trace elements & $200.7(W)$ & $7 / 30 / 2008$ & $7 / 18 / 2018$ & 100 & 40 \\
\hline Arsenic (d) ( $\mu \mathrm{g} / \mathrm{L})$ & Trace elements & $200.8(\mathrm{~W})$ & $7 / 30 / 2008$ & $7 / 18 / 2018$ & 2 & 40 \\
\hline Barium $(d)(\mu g / L)$ & Trace elements & $200.8(W)$ & $7 / 30 / 2008$ & $7 / 18 / 2018$ & 2 & 40 \\
\hline Boron (d) $(\mu \mathrm{g} / \mathrm{L})$ & Trace elements & $200.7(W)$ & $7 / 30 / 2008$ & $7 / 18 / 2018$ & 500 & 40 \\
\hline Cadmium (d) ( $\mu \mathrm{g} / \mathrm{L})$ & Trace elements & $200.8(W)$ & $7 / 30 / 2008$ & $7 / 18 / 2018$ & 0.5 & 40 \\
\hline Chromium (d) ( $\mu \mathrm{g} / \mathrm{L})$ & Trace elements & $200.7(W)$ & $7 / 30 / 2008$ & $7 / 18 / 2018$ & 10 & 40 \\
\hline Copper $(d)(\mu g / L)$ & Trace elements & $200.8(W)$ & $7 / 30 / 2008$ & $7 / 18 / 2018$ & 2 & 40 \\
\hline Iron $(d)(\mu \mathrm{g} / \mathrm{L})$ & Trace elements & $200.7(W)$ & $7 / 30 / 2008$ & $7 / 18 / 2018$ & 100 & 40 \\
\hline Lead $(d)(\mu g / L)$ & Trace elements & $200.8(W)$ & $7 / 30 / 2008$ & $7 / 18 / 2018$ & 2 & 40 \\
\hline Manganese $(d)(\mu g / L)$ & Trace elements & $200.8(W)$ & $7 / 30 / 2008$ & $7 / 18 / 2018$ & 2 & 40 \\
\hline Mercury $(d)(\mu \mathrm{g} / \mathrm{L})$ & Trace elements & 245.1 & $7 / 30 / 2008$ & $7 / 18 / 2018$ & 0.2 & 39 \\
\hline Nickel (d) ( $\mu \mathrm{g} / \mathrm{L})$ & Trace elements & $200.8(W)$ & $7 / 30 / 2008$ & $7 / 18 / 2018$ & 2 & 40 \\
\hline Selenium $(d)(\mu g / L)$ & Trace elements & $200.8(W)$ & $7 / 30 / 2008$ & $7 / 18 / 2018$ & 2 & 40 \\
\hline Silver $(d)(\mu g / L)$ & Trace elements & $200.8(W)$ & $7 / 30 / 2008$ & $7 / 18 / 2018$ & 2 & 40 \\
\hline $\operatorname{Zinc}(d)(\mu g / L)$ & Trace elements & $200.8(W)$ & $7 / 30 / 2008$ & $7 / 18 / 2018$ & 5 & 36 \\
\hline Zinc $(d)(\mu g / L)$ & Trace elements & $200.7(W)$ & $4 / 22 / 2014$ & $4 / 21 / 2015$ & 10 & 5 \\
\hline
\end{tabular}




\section{Appendix B. Timeseries Graphs of All Parameters}
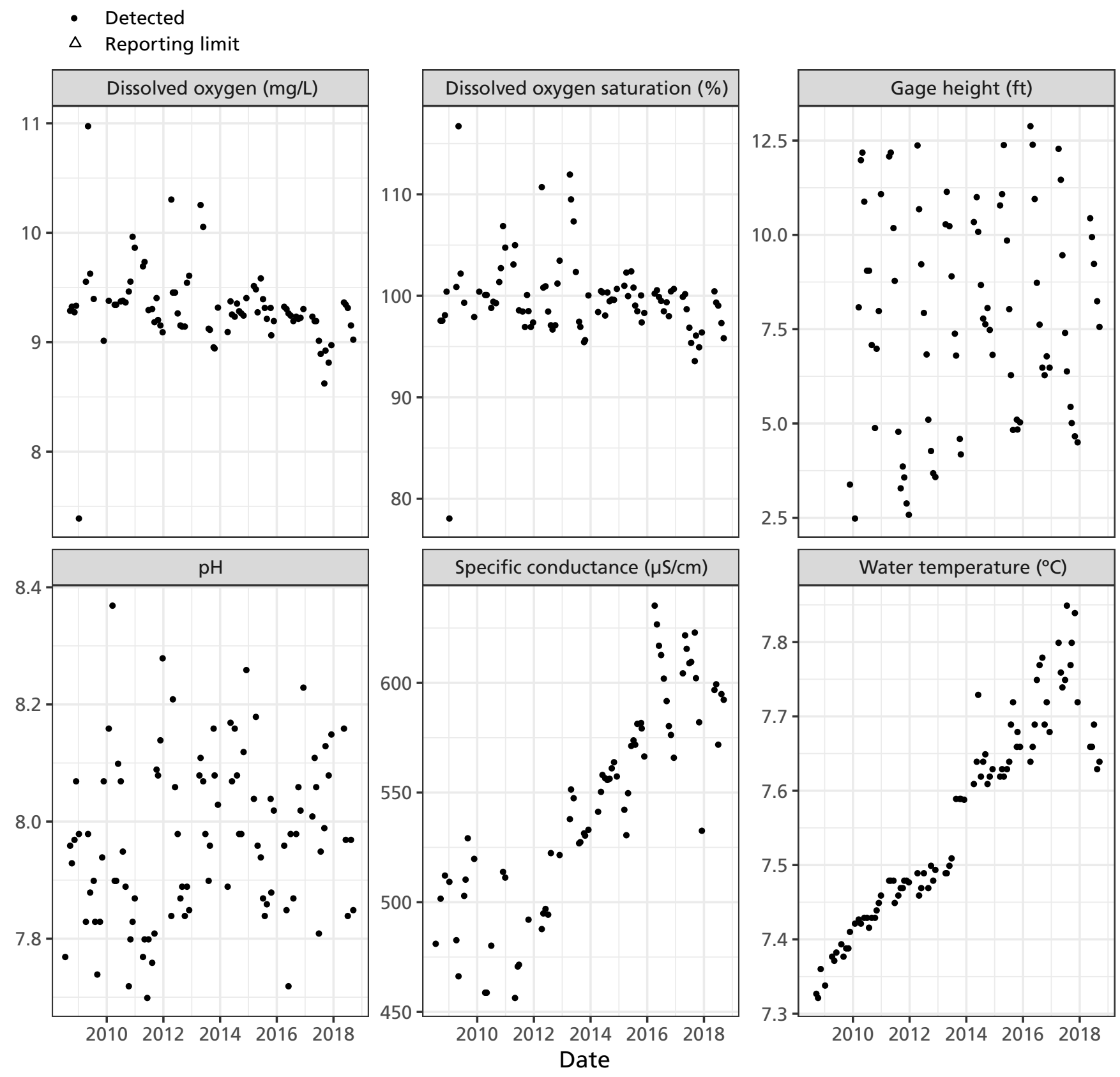

Figure B-1. Timeseries graphs of parameters for Hansen Lake. 
- $\quad$ Detected

$\Delta$ Reporting limit
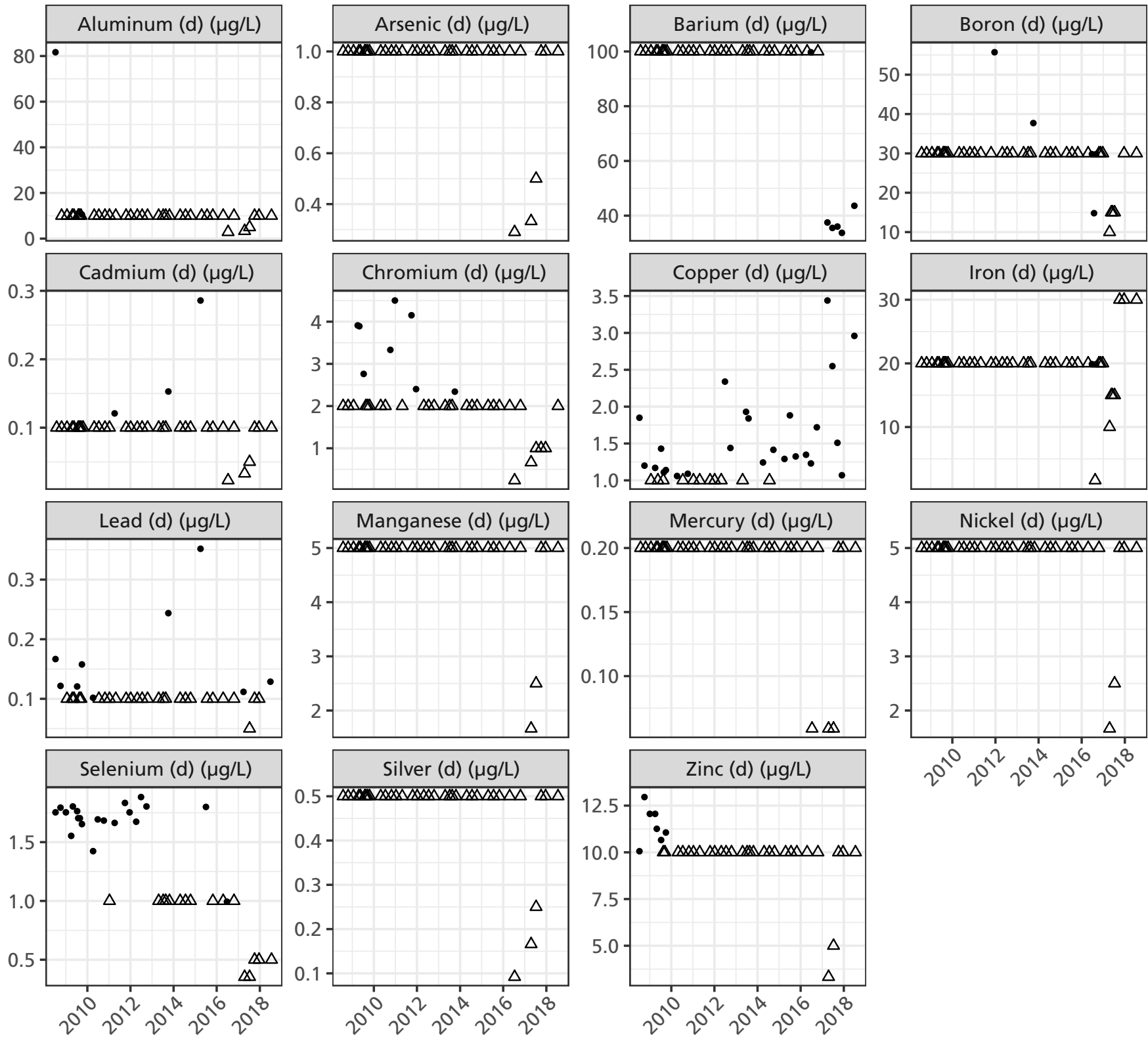

Date

Figure B-2. Timeseries graphs of parameters for Hansen Lake. 
- Detected

$\Delta$ Reporting limit
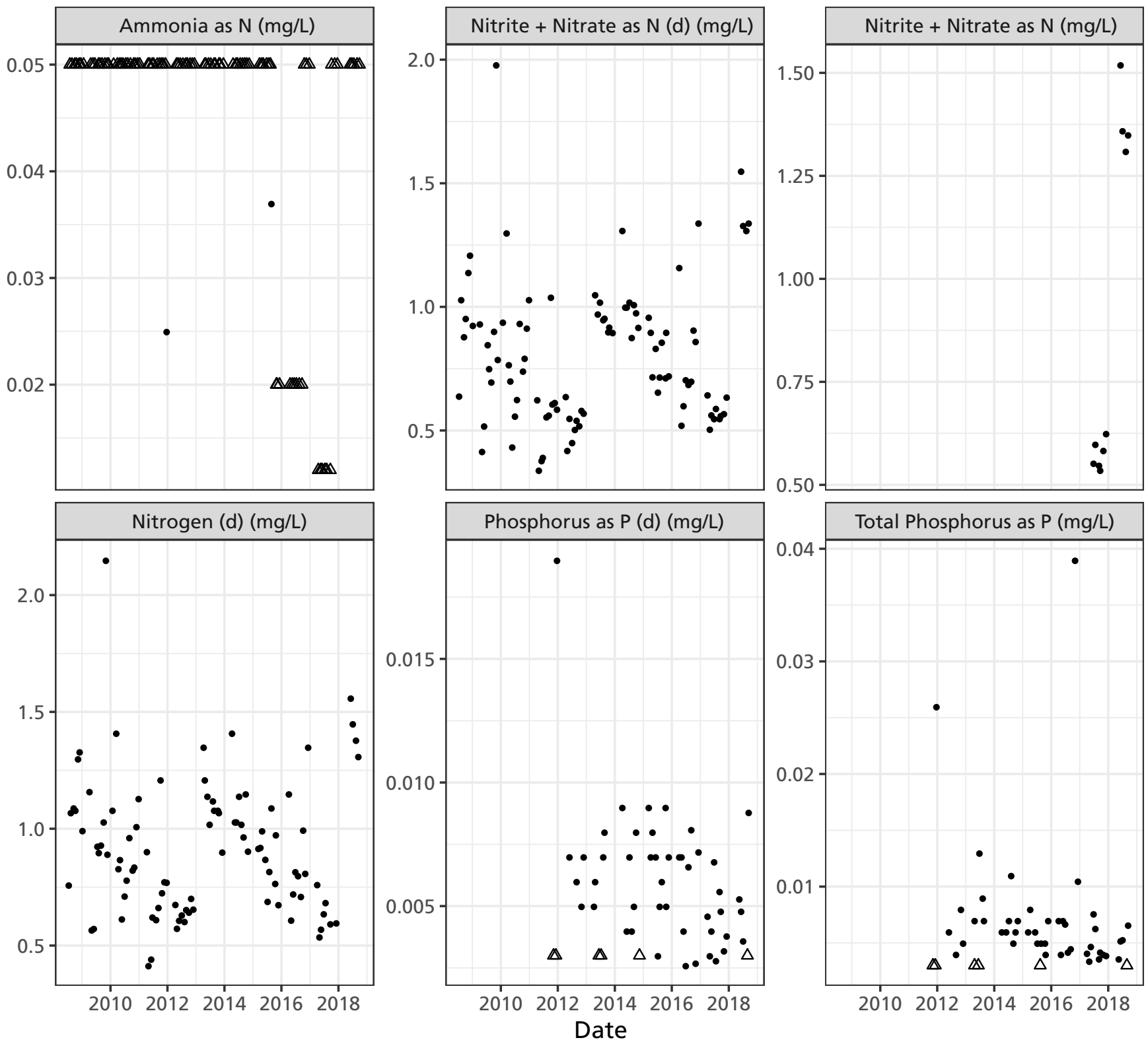

Figure B-3. Timeseries graphs of parameters for Hansen Lake. 
- Detected

$\Delta$ Reporting limit
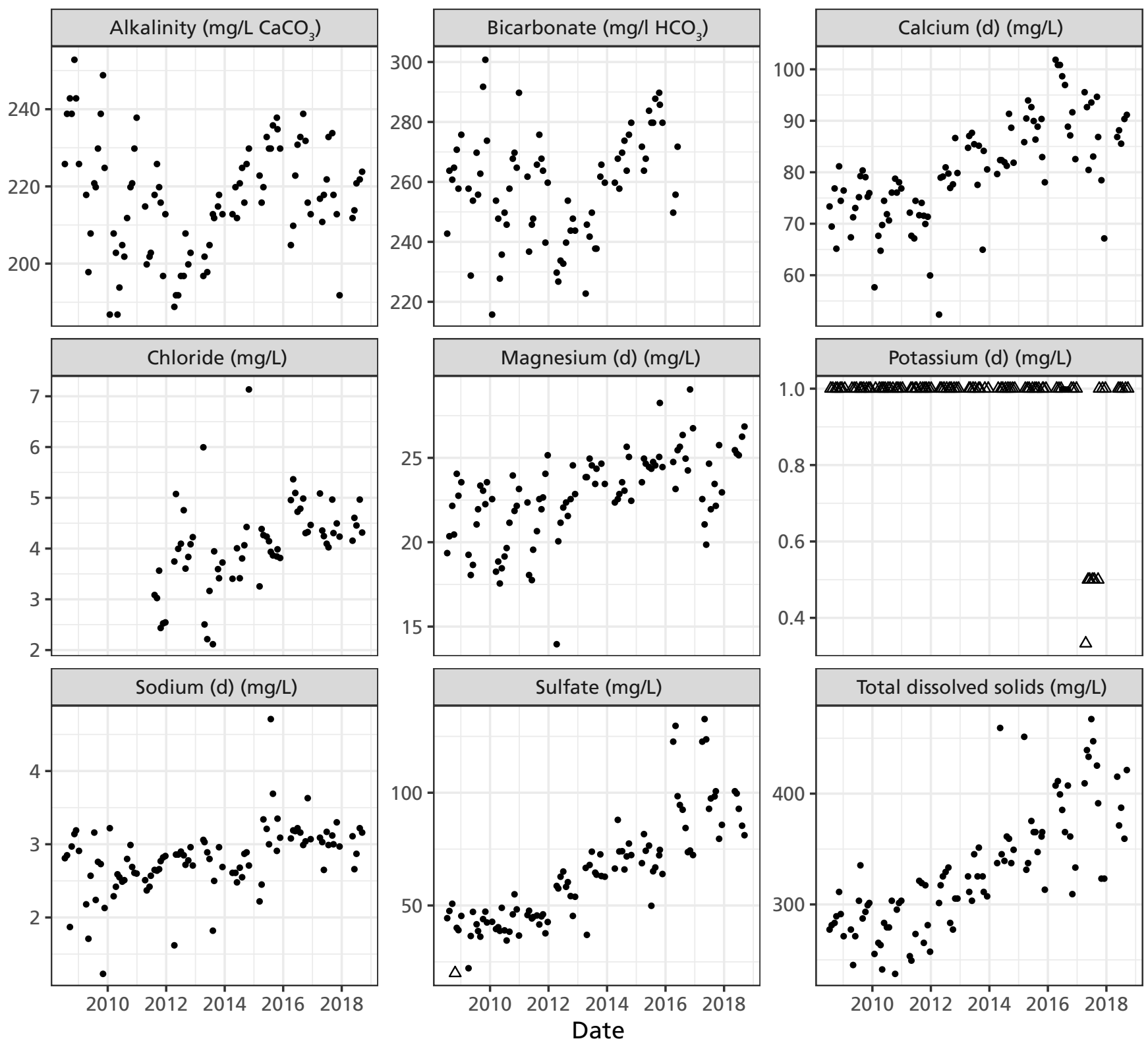

Figure B-4. Timeseries graphs of parameters for Hansen Lake. 
- Detected

$\Delta$ Reporting limit
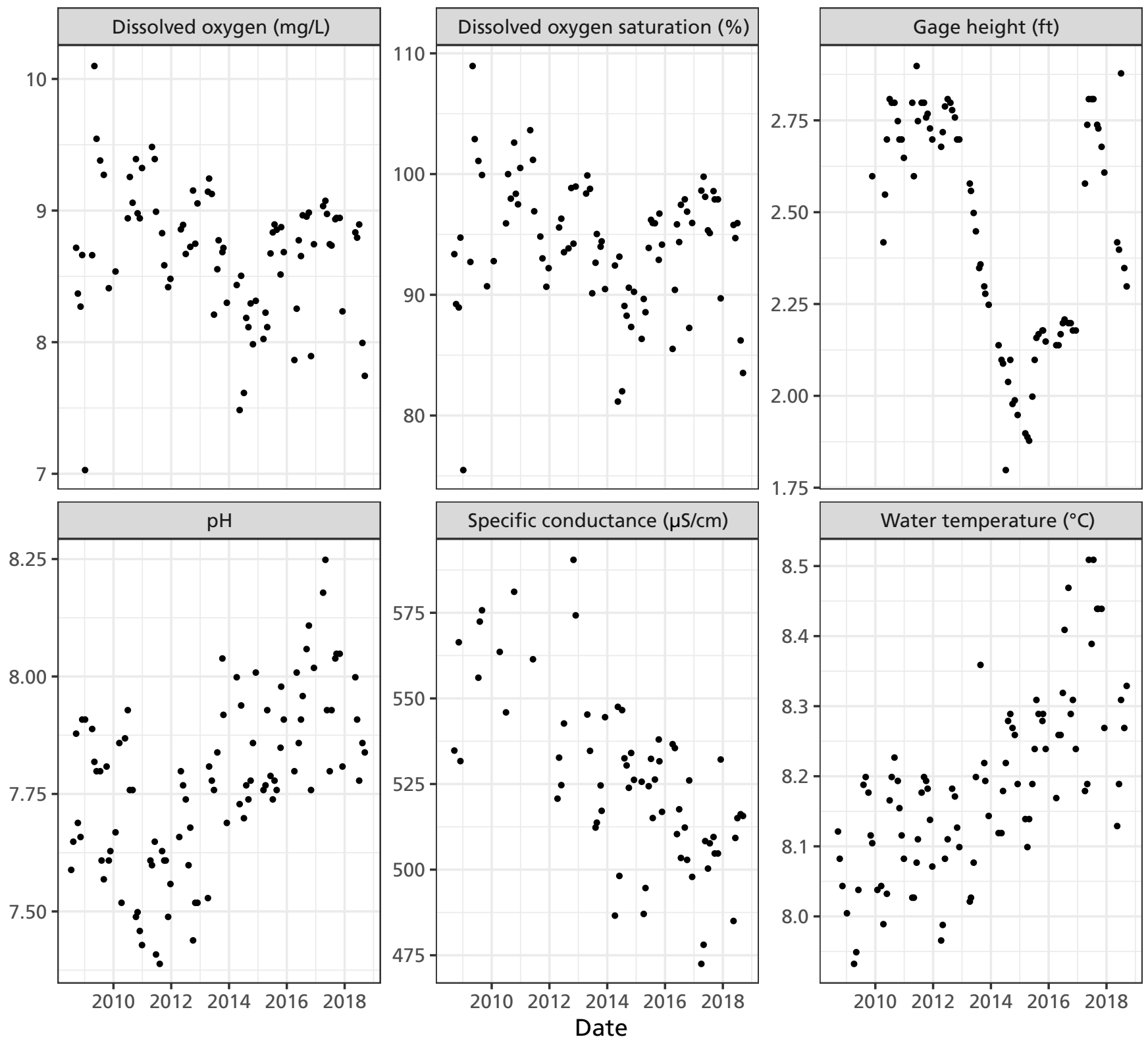

Figure B-5. Timeseries graphs of parameters for Hidden Lake. 


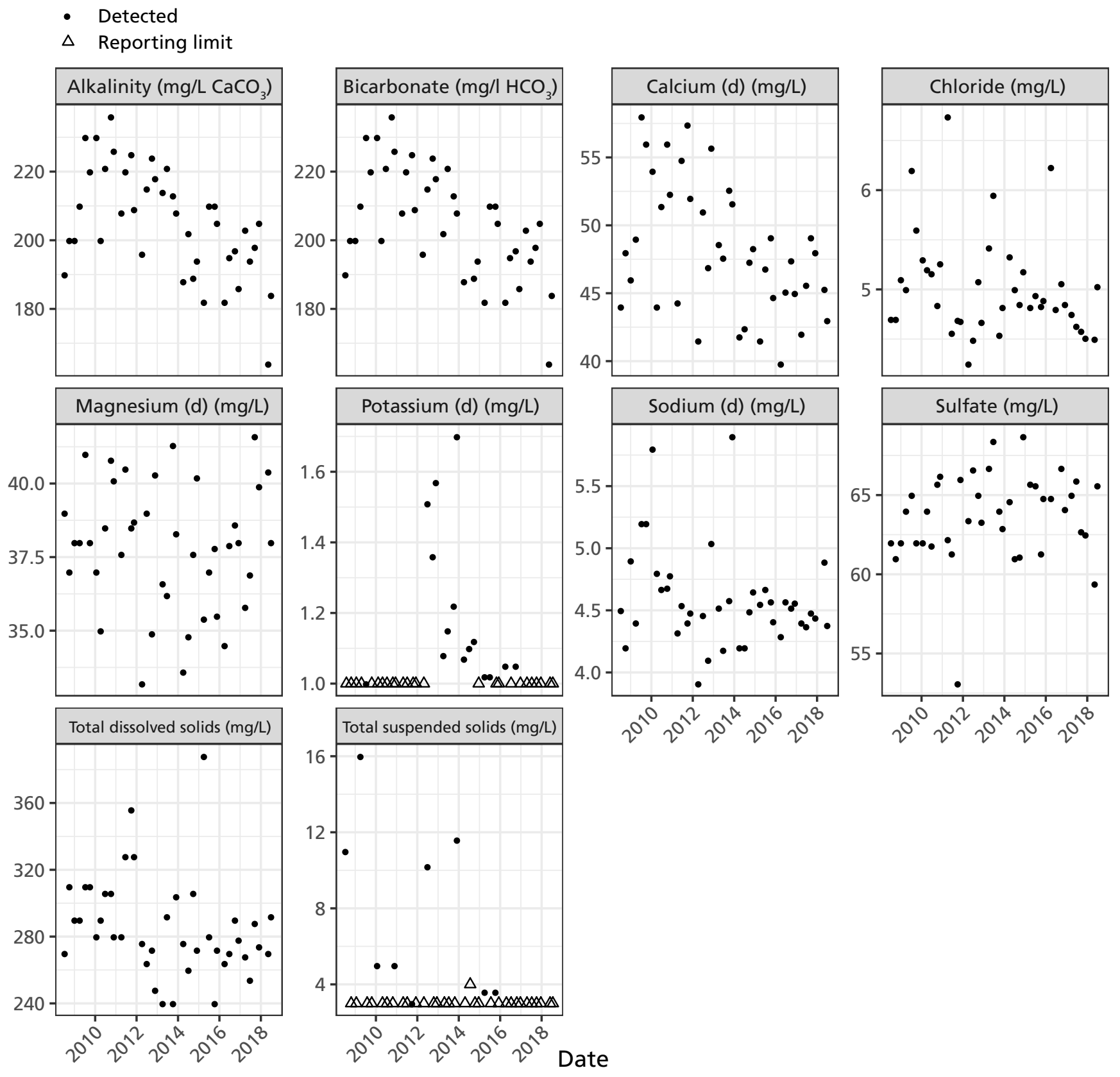

Figure B-6. Timeseries graphs of parameters for Hidden Lake. 
- $\quad$ Detected

$\Delta$ Reporting limit
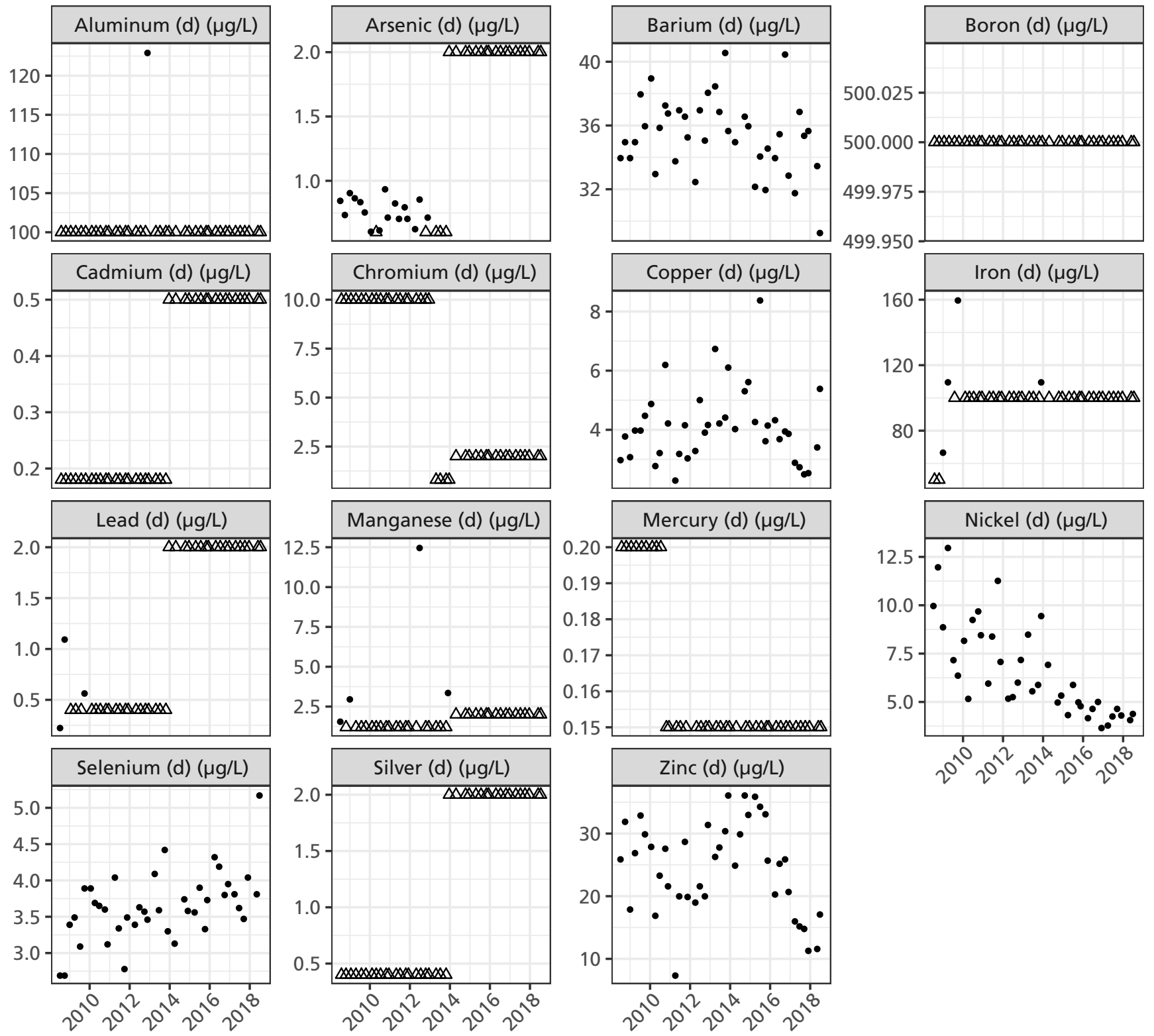

Date

Figure B-7. Timeseries graphs of parameters for Hidden Lake. 
- Detected

$\Delta$ Reporting limit
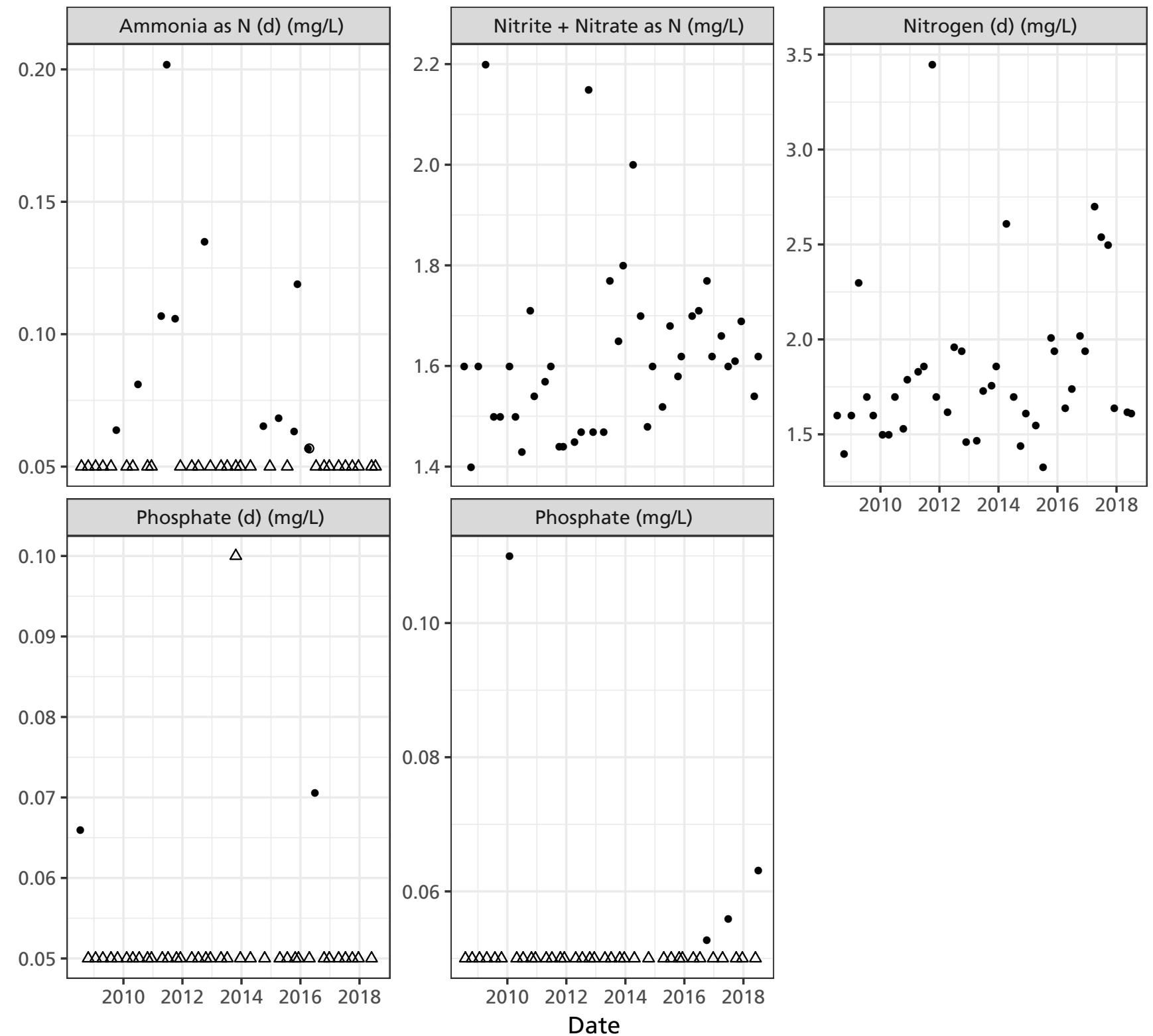

Figure B-8. Timeseries graphs of parameters for Hidden Lake. 
The Department of the Interior protects and manages the nation's natural resources and cultural heritage; provides scientific and other information about those resources; and honors its special responsibilities to American Indians, Alaska Natives, and affiliated Island Communities.

NPS 153/173792, October 2020 
National Park Service

U.S. Department of the Interior

Natural Resource Stewardship and Science

1201 Oak Ridge Drive, Suite 150

Fort Collins, Colorado 80525

www.nature.nps.gov 